Department of Anaesthesia and Intensive Care Medicine

U niversity of Helsinki, Finland

\title{
Awareness with recall during general anesthesia
}

\section{Seppo Ranta}

\author{
Academic Dissertation
}

To be publicly discussed by permission of the Medical Faculty of the University of $\mathrm{Helsinki}$, in Auditorium 2, Biomedicum Helsinki, Haartmaninkatu 8, on September 21,2002, at 12 o'clock noon

Helsinki 2002 


\section{Supervised by:}

D ocent $M$ arkku $H$ ynynen, M D

$D$ epartment of Anaesthesia and Intensive $C$ are $M$ edicine, H elsinki U niversity C entral H ospital, Jorvi H ospital, Espoo, Finland

\section{Reviewed by:}

Professor $\mathrm{H}$ arry Scheinin, M D

Turku PET Centre, Turku University H ospital

Turku, Finland

D ocent Arvi Yli-H ankala, M D

D epartment of Anaesthesia, Tampere University H ospital

Tampere, Finland

\section{Official opponent:}

Professor Rolf Sandin, M D

The Karolinska Institute, Stockholm,

and $\mathrm{D}$ epartment for Anesthesia and Intensive $\mathrm{C}$ are,

Länssjukhuset, Kalmar, Sweden

ISBN 952-91-4981-6 (nid.)

ISBN 952-10-0642-0 (PDF)

$\mathrm{H}$ akapaino $0 \mathrm{y}$

H elsinki 2002

http://ethesis.helsinki.fi/ 



\section{Contents}

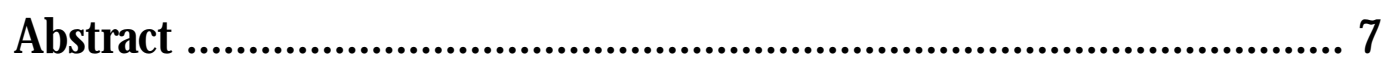

List of original publications ..................................................... 9

Abbreviations......................................................................... 10

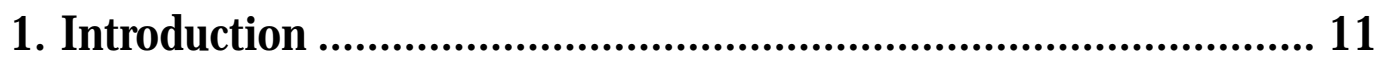

2. Review of the literature ....................................................... 12

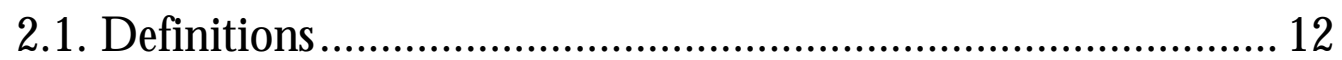

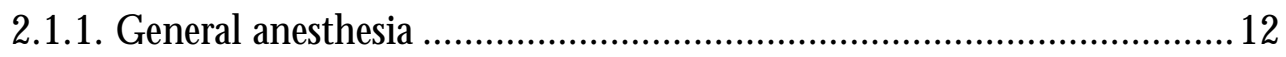

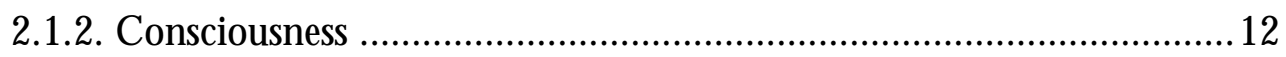

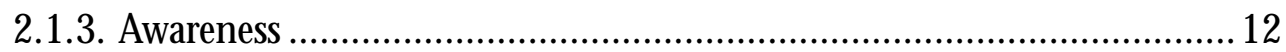

2.1.4. M emory and Recall ................................................................... 13

2.1.5. Awareness with recall during general anesthesia ................................ 13

2.2. The nature of the experience of awareness during general anesthe-

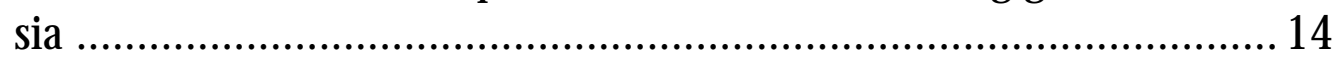

2.3. M ethods of detecting awareness during general anesthesia ........ 14

2.4. Incidence of awareness and recall during general anesthesia ...... 15

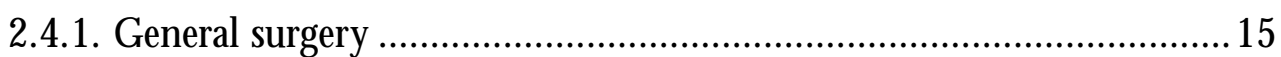

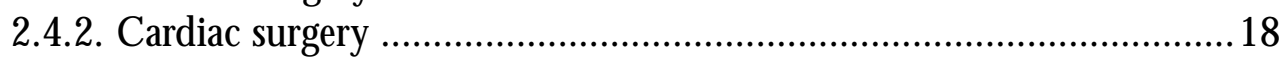

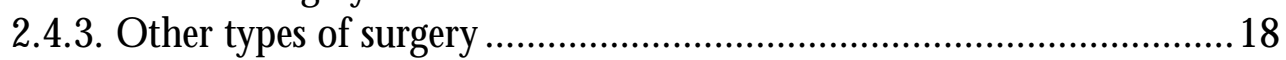

2.5. Reasons for awareness with recall during general anesthesia ..... 22

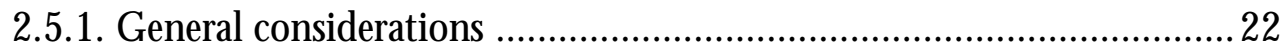

2.5.2. Anesthetics ...................................................................................... 23

2.5.2.1. The concepts of minimum alveolar concentration and effective concentration .23 


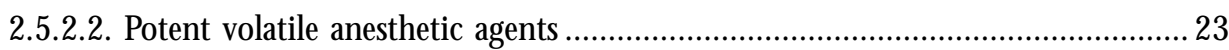

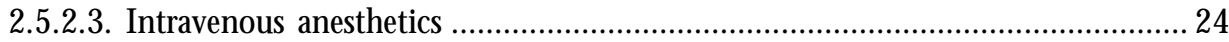

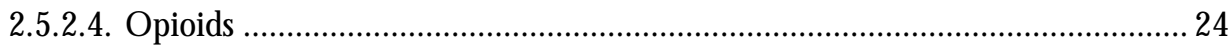

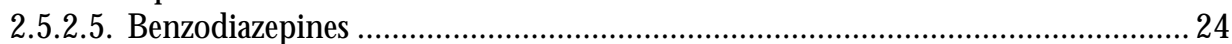

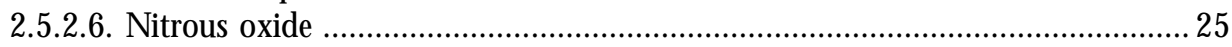

2.5.2.7. Neuromuscular blocking agents ............................................................... 25

2.6. Prevention of awareness with recall ........................................ 25

2.6.1. G eneral recommendations .....................................................25

2.6.2. M ethods of monitoring consciousness during general anesthesia ........26

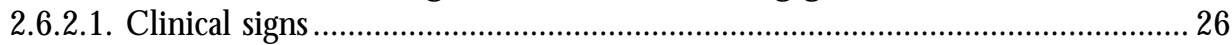

2.6.2.2. The isolated forearm technique............................................................... 26

2.6.2.3. Electroencephalography .............................................................................. 27

2.7. After-effects of awareness with recall during general anesthesia . 28

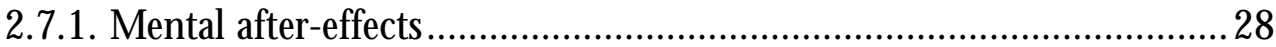

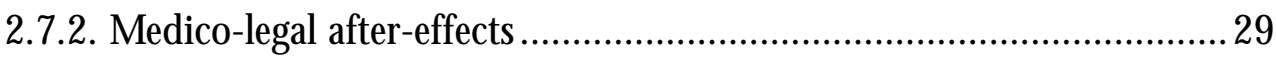

3. Aims of the study ............................................................. 30

4. Patients and methods........................................................... 31

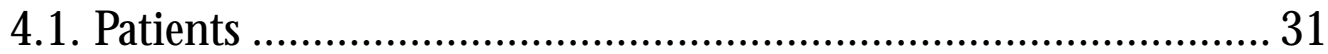

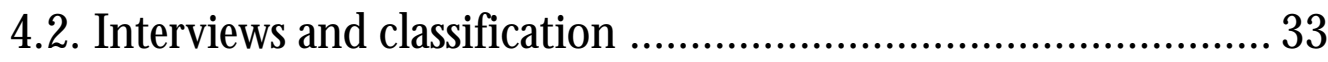

4.3. M edications ............................................................................... 33

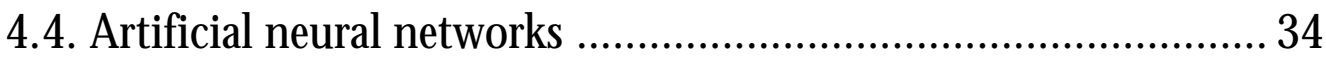

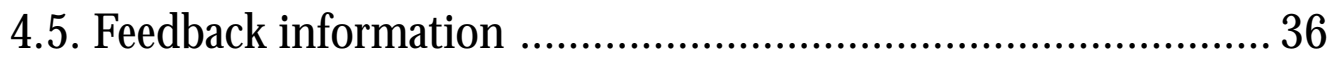

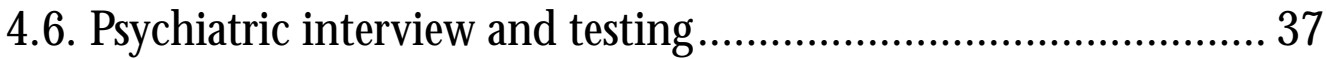

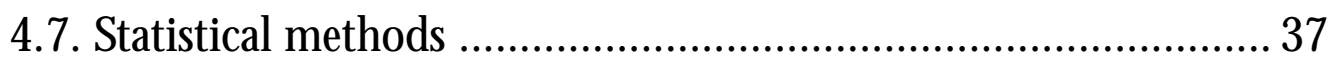

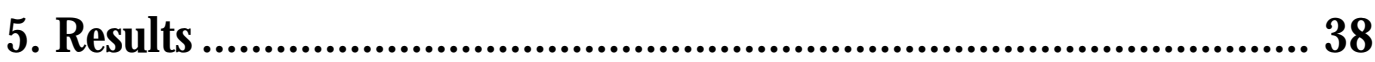

5.1. The nature of the experience of awareness during general anesthe

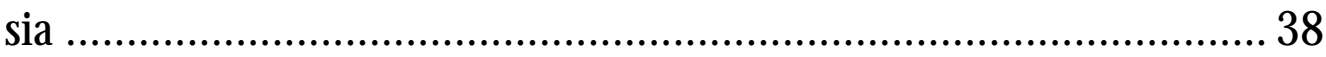

5.2. Incidence of awareness with recall during general surgery ......... 38

5.3. Incidence of awareness with recall during open heart surgery.... 38 5.4. Differences in anesthetic drug dosing between patients with and without awareness

5.5. Conventional statistical methods and artificial neural networks in detecting awareness from monitored physiologic variables 
5.6. The possibility of reducing the incidence of awareness by giving feedback information to the anesthesiologists ................................... 40

5.7. Psychiatric consequences of awareness during anesthesia........... 41

5.8. M edico-legal consequences of awareness with recall in Finland . 42

6. Discussion

6.1. Patients' experiences during the episode of intra-anesthetic aware-

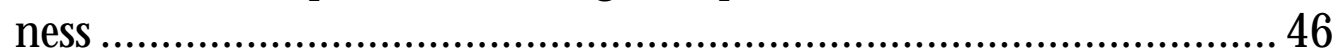

6.2. M ethods used in the present studies...................................... 46

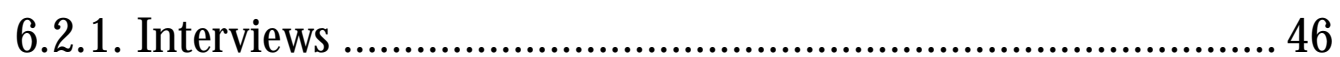

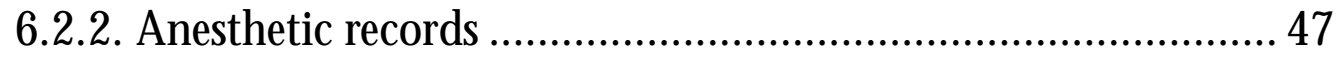

6.3. Incidence of awareness with recall during general surgery ........ 47

6.4. Incidence of awareness with recall during cardiac surgery ......... 48

6.5. D ifferences in anesthetic drug dosing between patients with and without awareness

6.6. Conventional statistical methods and artificial neural networks in detecting awareness from monitored physiologic parameters.

6.7. The possibility of reducing the incidence of awareness by giving feedback information to the anesthesiologists ..................................50

6.8. Psychiatric consequences of awareness during anesthesia.......... 51

6.9. M edico-legal consequences of awareness with recall in Finland . 52

7. Conclusions.

8. Practical considerations

9. Future implications.......................................................... 57

Acknowledgements ......................................................... 58

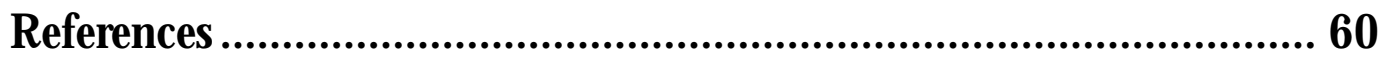

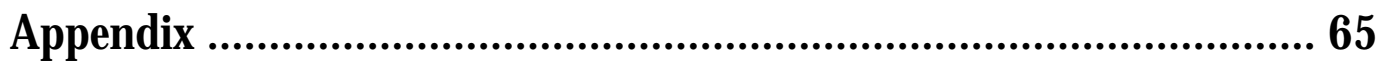




\section{Abstract}

Awareness with recall is a rare but serious complication of general anesthesia with potentially very disabling psychiatric consequences. Prerequisites for the phenomenon of awareness and recall are (1) consciousness with the ability to receiveand process sensory information, (2) storage of the processed information in memory, and (3) recollection of the stored information at some later time.

The present study examines incidence of awareness with recall during general anesthe sia, the effects of anesthetic agents on it, methods of detecting and preventing it, and its psychiatric and medico-legal after-effects. A total of 3,868 cases (1,485 male and 2,383 female) were included in this study. Structured interviews were conducted after general anesthesia for cardiac or general surgery to find patients who had experienced awareness during anesthesia and were able later to recall their experience. Additional cases were identified from insurance claims based on awareness with recall filed with the Patient Insurance Association in Finland. Psychiatric interview and testing were used to evaluate after-effects of awareness and recall. Feedback information was given to cardiac anesthesiologists in order to study the possibility of reducing incidence of awareness with recall by educational means. Artificial neural networks were used to evaluate the likelihood of detecting intraoperative awareness on the basis of conventional monitoring information.
In the present studies, the incidence of undisputed intraoperative awareness was 0.2 $0.4 \%$ of all general anesthetics given for general surgery procedures, while the incidence was about $0.3 \%$ during cardiac anesthesia. Both incidences are 6 to 7 fold higher if cases of possible awareness and recall are included. Lower doses of primary anesthetic agents were given to patients with awareness and recall when compared to controls (isoflurane 0.42 $\mathrm{Fi} \%$ vs. $0.65 \mathrm{Fi} \%$ [ $\mathrm{p}<0.005$ ] and propofol 73 $\mu \mathrm{g} / \mathrm{kg} / \mathrm{min}$ vs. $228 \mu \mathrm{g} / \mathrm{kg} / \mathrm{min}$ [ $\mathrm{p}<0.05$ ], during general surgery respectively; midazolam $0.8 \mu \mathrm{g} / \mathrm{kg} / \mathrm{min}$ vs. $1.1 \mu \mathrm{g} / \mathrm{kg} / \mathrm{min}[\mathrm{p}<0.05$ ] during cardiac surgery respectively). Standard physiologic monitoring used during general anesthesia did not reliably detect inadequate depth of anesthesia, even when analyzed with computer-based artificial intelligence. Information given to anesthesiologists about intraoperative awareness lead to a decreasing trend in its incidence with simultaneous increase in the use of anesthetics and decrease in the use of muscle relaxants.

The psychiatric studies reveal ed anxiety in one patient after awareness and recall. In addition, a case of pre-existing depression was exacerbated after an episode of awareness and recall. Awareness during general anesthesia has triggered a small number of Patient Insurance claims in Finland (about $1 \%$ of anesthesiarelated claims). Seventy percent of the patients who filed insurance claims received compen- 
sations for pain; the average amount of compensation was EU R 1,000.

Awareness with recall is a rare complication of general anesthesia and its incidence is on the decline. Insufficient dosing of general anesthetics contributes significantly to the present incidence and it is likely that informing anesthesiologists about this complication would decrease it further Awareness cannot be detected by standard monitoring; better monitoring tools need to be developed. The incidence of psychiatric after-effects of intraoperative awareness is not known. In Finland, a small number of Patient Insurance claims has been the only medico-legal after-effect of this complication. 


\section{List of original publications}

1. Ranta S., Laurila R., Saario J., Ali-M elkkiläT., H ynynen M .: Awareness with recall during general anesthesia - Incidence and risk factors. Anesth Analg 86: 1084-1089, 1998.

2. Ranta S., Jussila J., H ynynen M .: Recall of awareness during cardiac anaesthesia: influence of feedback information to the anaesthesiologist. Acta Anaesthesiol Scand 40:554-560, 1996.

3. Ranta S., H erranen $P$, H ynynen M .: Patients' conscious recollections from cardiac anesthesia. J Cardiothorac Vasc Anesth 16:426-430, 2002.

4. Ranta S., H ynynen M ., Räsänen J: Application of artificial neural networks as an indicator of awareness with recall during general anaesthesia. J Clin M onit Comput 17:53-60, 2002.

5. Ranta S., Ranta V., Aromaa U.: The claims of compensation for awareness with recall during general anaesthesia in Finland. Acta Anaesthesiol Scand 41:356-359, 1997. 


\section{Abbreviations}

$\begin{array}{ll}\text { AA } & \text { Anesthetic agent } \\ \text { AEP } & \text { Auditory evoked potential } \\ \text { AER } & \text { Auditory evoked response } \\ \text { AN OVA } & \text { Analysis of variance } \\ \text { ASA } & \text { American Society of Anesthesiologists } \\ \text { BIS } & \text { Bispectral index } \\ \text { BP } & \text { Blood pressure } \\ \text { CABG } & \text { Coronary artery bypass grafting } \\ \text { CI } & \text { Confidence interval } \\ \text { CO } & \text { Carbon dioxide } \\ \text { D\&C } & \text { Dilatation and curettage } \\ \text { DSM -III } & \text { Diagnostic and Statistical M anual of M ental Disorders, 3rd edition } \\ \text { DSM -IV } & \text { Diagnostic and Statistical M anual of M ental D isorders, 4th edition } \\ \text { EBT } & \text { Endobronchial tube } \\ \text { EC } & \text { Effective concentration in } 50 \text { percent of the subjects } \\ \text { ECG } & \text { Electrocardiogram } \\ \text { EEG } & \text { Electroencephalogram } \\ \text { ET } & \text { End-tidal } \\ \text { ETAGC } & \text { End-tidal anesthetic gas concentration } \\ \text { ET T } & \text { Endotracheal tube } \\ \text { EUR } & \text { Euro } \\ \text { Fi } & \text { Inspiratory fraction } \\ \text { FIM } & \text { Finnish M ark } \\ \text { GBP } & \text { Pound sterling } \\ \text { i.V. } & \text { Intravenous } \\ \text { ICU } & \text { Intensive care unit } \\ \text { IFT } & \text { Isolated forearm technique } \\ \text { M AC } & \text { M inimum alveolar concentration } \\ \text { M LAEP } & \text { Mid-latency auditory evoked potential } \\ \text { M VR } & \text { Mitral valve replacement } \\ \text { N .A. } & \text { Not assessed } \\ \text { N } 2 & \text { Nitrous oxide } \\ \text { N M B } & \text { Neuro-muscular blocker } \\ \text { nS. } & \text { non-significant } \\ \text { PACU } & \text { Post-anesthesia care unit } \\ \text { PIA } & \text { Patient Insurance Association } \\ \text { P } & \text { Prediction probability } \\ \text { PTSD } & \text { Post-traumatic stress disorder } \\ \text { SaO } & \text { Arterial blood oxygen saturation } \\ \text { SE } & \text { Standard error } \\ \text { TX } & \text { Transplantation } \\ \text { USD } & \text { United States D ollar } \\ & \end{array}$




\section{Introduction}

Conscious awareness with recall as a complication of general anesthesia has existed for as long as general anesthesia itself. In 1846, William M orton gave the first anesthetic to Gilbert Abbott in a demonstration at the $M$ assachusetts $G$ eneral Hospital in Boston. Gilbert Abbott told later that he was aware during the anesthetic but felt no pain. 0 nly a small number of further reports of awareness during anesthesia were published in the nineteenth and in the early twentieth century (Ghoneim, 2001). In the early days of anesthesia, the practice of using a single general anesthetic agent in relatively high concentrations to produce all components of general anesthesia - unconsciousness, relief from pain, absence of reflexes, and muscle relaxation apparently protected the patients from traumatic awareness. M oreover, neuromuscular blocking agents (N M B) were not available, and patients were, therefore, able to signal awareness by movement. W hen N M Bs were introduced into anesthetic practice to improve operative conditions and to reduce the toxicity of general anesthetic agents, traumatic awareness became possible.

The first case report of traumatic conscious awareness with later recall during general anesthesia was described in 1950 (W interbottom, 1950). Perhaps describing the attitude of somemembers of themedical profession towards this complication, the surgeon who operated on the patient reported by W interbottom, later published a letter where hewrotethat "theanaesthetic as a whole could only be described as excellent" (Wells, 1950). Studies of the incidence of awareness with recall began in the 1960s. Generally, the possible traumatic psychologic sequelae of this complication were not acknowledged in the medical literature until the 1970s. H owever, despite several decades of attention to this problem, patient groups and, especially, individual patients at risk have not been clearly identified, the definition of this complication is not entirely clear, its prevention has not been studied in detail, and the nature and incidence of possible after-effects of awareness during general anesthesia are not known. Furthermore, this complication is one of the most frequent fears of our patients. In a preoperative interview study, $54 \%$ of patients were anxious about not being asleep during the operation (M cCleane, and Cooper, 1990).

This thesisfocuses solely on awareness with explicit recall during general anesthesia. The possibility of subconscious learning and memory during general anesthesia, or its possible sequelae are not discussed. 


\section{Review of the literature}

\subsection{Definitions}

\subsubsection{General anesthesia}

General anesthesia is a state characterized by unconsciousness, anal gesia, muscle relaxation, and depression of reflexes (W illenkin, 1990) or, the administration of chemical agents to produce reversible unconsciousness and depression of reflex response to afferent stimuli (C ritchley, 1978). H owever, there are also definitions of anesthesia where loss of consciousness, an all-or-none phenomenon, defines the beginning and ending of the anesthetic state (Prys-Roberts, 1987). Thus, analgesia, muscle relaxation, and suppression of autonomic activity, are not components of anesthesia, but rather, should be considered as desirable supplements to the state of anesthesia (Prys-Roberts, 1987). 0 ther authors, however, consider that the state of general anesthesia includes different, smoothly changing states of consciousness (Jones, and Konieczko, 1986). As the present thesis focuses on awareness during general anesthesia with explicit recall occurring afterwards, the term 'unconsciousness' becomes the most important component of general anesthesia. It should be clear that by preventing consciousness during general anesthesia there should be no recall of it.

\subsubsection{Consciousness}

The term 'consciousness' is explained as "the state of being conscious; awareness of one's own existence, sensations, thoughts, surroundings, etc." (Anonymous, 1989). Consciousness involves four functions: stimulus uptake (perception), stimulus processing (mnemonic representation), stimulus evaluation (emotion), and stimulus response (volition). These processes are integrated by complex neuronal systems to achieve regional linking within one modality, temporal, and semantic binding of information. (Pöppel, and Schwender, 1993).

\subsubsection{Awareness}

The term 'awareness' is explained as "having knowledge, conscious, cognizant" (Anonymous, 1989). The term represents the state of mind at a certain moment of time irrespective of whether that state is later recalled or not (G honeim, and M ewaldt, 1990). However, Jones and Konieczko have claimed, that there would be different stages of "conscious awareness" and that also "unconscious awareness" would be possible(Jones, and Konieczko, 1986).

In medical terminology, the term "awareness" has sometimes been regarded as meaning only consciousness during general anesthesia (C ritchley, 1978). This usage is different from both the general meaning of the term and its meaning in the context of psychologi- 
cal research. Therefore, the 'medical ization' of the term "awareness" is best avoided.

In this thesis, the terms "awareness" and "consciousness" are used interchangeably, as suggested by Ghoneim and Block (G honeim, and Block, 1997). As general anesthesia is defined as a state of unconsciousness, it would logically follow that a patient under general anesthesia cannot be aware, and the converse. The term "awareness during general anesthesia" is, however, almost universally accepted by both medical and legal circles, and itsmeaning is well understood. Therefore, this term is used in thisthesis, and in other papers, as there is no simple substitute (Payne, 1994).

\subsubsection{Memory and Recall}

$M$ emory is essential for the recall of intraoperative perception. As a cognitive function, memory has been divided to a variety of subsystems (Andrade, and Baddeley, 1993). These includea working memory comprising a 'phonological loop' for linguistic memory and 'visuospatial sketchpad' for visual and spatial information processing, and a 'central executive' which organizes the process. The processed ideas are then transferred from working memory to long term memory for storage, and possible retrieval. Forgetting is possible in both the working memory and long term memory. Responding to ideas retrieved from long term memory requires that these ideas are processed again in the working memory. (Baddeley, 1990; Andrade, and Baddeley, 1993; Bailey, and Jones, 1997)

The anatomical representation of the working memory in the human brain is the prefrontal cortex. The long term memory is scattered in the medial temporal lobe, the hippocampus, and the posterior neocortex (Bailey, and Jones, 1997).

The retrieval from memory can be either a conscious or subconscious process. The former, explicit memory retrieval, includes the spatio-temporal context in which the recalled event occurred, and thelatter, implicit memory retrieval, is revealed by a change in task performance (Kihlstrom, and Schacter, 1990). Explicit memory is also called declarative and implicit memory non-declarative (Bailey, and Jones, 1997). D eclarative memory is further divided into episodic, or autobiographical memory, and semantic, or factual memory (Bailey, and Jones, 1997). Explicit memory requires effortful recall (Bailey, and Jones, 1997). Examples of explicit memory are re membering meeting a person, or recalling having seen an accident. Examples of implicit memory are subconscious processes like walking, or riding a bicycle. It is likely that the learning mechanismsinvolved in implicit and explicit memory are different (Griffiths, and Jones, 1990).

$M$ emory is tested with direct and indirect tests; the former are used to test explicit recall, the latter test implicit recall. In direct memory tests the subject is asked whether he or she remembers the stimulus such as hearing a word. Of primary importance is not, which words the subject knows but, rather, the specific process of hearing a word in a certain situation. Indirect tests assess the change in theperformance of the subject. For example, prior exposure to a certain word increases the likelihood of that word being chosen from a list of words. (Ghoneim, and Block, 1992; Andrade, and Baddeley, 1993)

\subsubsection{Awareness with recall during general anesthesia}

The experience of awareness with recall during general anesthesia requires general anesthesia and awareness being present in the patient simultaneously. Furthermore, it is required that the patient later recalls this incident.

It is claimed that anesthetic agents prevent the occurrence of awareness with recall by three mechanisms: 1. by interfering with the development of neuronal adequacy for signal pro- 
cessing, 2 . by interfering with the establishment of the time marker for the sensory experience thus distorting the experience, and 3. by interfering with recall of the conscious experience (Jessop, and Jones, 1991).

We rely on memory for evidence of what has been perceived during general anesthesia. This evidence, when negative, will always be somewhat equivocal (Kihlstrom, and Schacter, 1990). Accordingly, it is not unequivocally possible to discriminate between patients who have or have not been 'aware' or 'conscious' during general anesthesia. T he term 'wakefulness' has been used to describe patients who are able to react meaningfully to stimuli during general anesthesia but are not able to recall either the stimuli or their reactions postoperatively (Tunstall, 1977). Thereis evidence that a large number of such patients exist (Tunstall, 1977, 1979; Russell, 1985, 1986, 1993; Russell, and Wang, 1997). There also is some evidence that wakefulness without explicit recall might be detrimental for the patient (Wang, 2001) but this has not been definitely proven (Ghoneim, and Block, 1997).

In the present thesis, only awareness with explicit recall is studied. This means that, in a post-operative interview, the patient can recall having had perceptions of some kind during the time-context of general anesthesia. This is called 'awareness with recall' or, for brevity, 'awareness' in this study.

\subsection{The nature of the experience of awareness during general anesthesia}

The primary characteristics of awareness vary between published reports. In a study of 26 patients with intraoperative awareness based on voluntary referral by anesthesiologists M oerman et al. (1993) found that the most common form of recall was hearing sounds, reported by $89 \%$ of the patients. Paralysis was the second most common feeling, recalled by $85 \%$ of the study population, while pain was reported by $39 \%$ of those included in the study

Cobcroft, and Forsdick (1993) recruited patients by advertising in popular magazines, and found pain to be the most common recollection reported by $39 \%$ of those responding to the survey. Recollection of sounds was reported by $31 \%$ of this study population.

Schwender et al., (1998) recruited patients both with advertisements in newspapers and on the internet, and by referral from colleagues. They confirmed auditory perceptions to be the most common sensory modality during intraoperative awareness (100\% of patients). The next most common were tactile perceptions (64\%), and paralysis (60\%); $24 \%$ of the patients felt pain. In a closed claims analysis, auditory perception was recalled by $30 \%$ of the study population, tactile perceptions by $25 \%$, pain by $21 \%$, and paralysis by $20 \%$ of the patients (D omino et al., 1999).

\subsection{Methods of detecting awareness during general anesthesia}

O bviously, detection of learning and explicit memory during general anesthesia, requires interviewing the patient postoperatively (Kihlstrom, and Schacter, 1990; Ghoneim, and Block, 1992). In principal, either a postoperative interview for intraoperative events, or recall or recognition of stimuli presented during anesthesia can be used (Ghoneim, and Block, 1992). Both types require conscious recollection of specific learning episodes (Wolters, and Phaf, 1990).

The postoperative interview should be structured (G honeim, and Block, 1992), otherwise a lower incidence of awareness and re call is likely to be found (Jelicic, and Bonke, 1989). A structured interview presents a standard set of questions to all interviewed subjects. Brice et al. (1970) have designed five 
Table 1. Questions asked during the interviews.

1. What is the last thing you remember
before going to sleep for the operation?
2. What is the first thing you remember
after waking after the operation?
3. Do you remember anything in between?
4. Did you have any dreams?
5. What was the most unpleasant thing
you remember from your operation and
anesthesia?

simple questions for detecting explicit awareness in a postoperative interview (Table 1).

Some authors, however, have used simpler sets of questions (Lyons, and M acdonald, 1991; Sandin, and N ordström, 1993), and a postoperative interview under hypnosis has been used by others (G oldmann et al., 1987). The value of hypnosis as a tool for studying awareness, learning, or memory during general anesthesia has, however, been questioned (Ghoneim, and Block, 1992).

Typical positive responses indicating aware ness are factual memories of discussions, noises, tactile sensations, or episodes of pain or distress that can be traced back to the intraoperative period. Feeling of muscle paralysis has also been considered typical of intraoperative awareness (Bailey, and Jones, 1997). $D$ reams that are either associated with anesthesia or are altered states of awareness characterized by vivid thoughts and images are considered to be due to inadequate depth of anesthesia (G honeim, and Block, 1992).

The timing of the interview has raised much discussion. There is evidence that assessment of learning during anesthesia is more successful later rather than sooner after exposure to inhalational agents (Bennett, 1986). H owever, there are case reports of patients who remembered an experience of awareness in an early interview but not any more in a later interview (Brice et al., 1970; $\mathrm{H}$ arris et al.,
1971; Dutton et al., 1995). In a well-conducted study, therewas no correlation between general memory performance of intraoperative events and the time-interval between surgery and memory test (Lubke et al., 1999). Recently, it has been shown by Sandin and co-workers that morethan one interview over a time period of at least two weeks increases the number of detected cases of awareness (Sandin et al., 2000).

It was noted very early that, in the interviews, it is difficult to know what, if anything, is actually being remembered (Parkhouse, 1960). Some authors have called for better scrutiny of the reported cases by psychiatric interview and hypnosis (Aldrete, and Wright, 1985). The reporting of the recollections of the study patients varies between studies.

There are many ways of studying the implicit memory by indirect testing. These are reviewed, e.g., by Ghoneim, and Block (1992); Bailey, and Jones (1997); and Ghoneim, and Block (1997).

\subsection{Incidence of awareness and recall during general anesthesia}

\subsubsection{General surgery}

A large number of studies on the incidence of intraoperative awareness and recall have been published since W interbottom's original report of this intraoperative complication in 1950 (W interbottom, 1950). The published studies using postoperative structured interview method are summarized in Table 2

Pedersen, and Johansen (1989) found and incidence of $0.1 \%$ for intraoperative aware nessin astudy of 7,306 anesthetics conducted without structured interviews. M yles et al. (2000) used interviews, although not necessarily structured ones, in another large study, and identified 12 patientswith awareness from a group of 10,811 interviewed patients, giving an incidence of awareness of $0.11 \%$.

In general, the incidence has been on the 
Table 2. Incidence of awareness and recall during anesthesia for general surgery. A structured interview method was used in these studies, and patients had undergone general surgical procedures. Gynecological, but not obstetrical, procedures are considered general surgical procedures in this context. Studies on outpatient anesthesia are included.

\begin{tabular}{|c|c|c|c|c|}
\hline Reference & $\begin{array}{l}\text { Number of } \\
\text { patients }\end{array}$ & $\begin{array}{l}\text { N umber of } \\
\text { interviews, (time } \\
\text { of the interviews } \\
\text { [h] after } \\
\text { anesthesial) }\end{array}$ & $\begin{array}{l}\text { Incidence of } \\
\text { explicit awareness } \\
(\%)^{2)}\end{array}$ & Anesthetics used ${ }^{31}$ \\
\hline $\begin{array}{l}\text { H utchinson } \\
\text { (1960) }\end{array}$ & 656 & $\begin{array}{l}1 \text { (1st post- } \\
\text { operative day) }\end{array}$ & $\begin{array}{l}1.2(1.4), \\
\text { pain: } 63\end{array}$ & $\begin{array}{l}\text { P: }{ }^{5)} \\
\text { I: thp } \\
\text { M: hal|(4)5) N } 20 \\
\text { R: }{ }^{5)}\end{array}$ \\
\hline $\begin{array}{l}\text { Terrell et al. } \\
\text { (1969) }\end{array}$ & 37 & $\begin{array}{l}1 \text { ( } 24-168) \text {, } \\
\text { including } \\
\text { hypnosis }\end{array}$ & 0 & $\begin{array}{l}\text { P: } \mathrm{bar}^{4(5)}, \mathrm{mor}, \mathrm{sco}^{4)} \\
\text { I: } \mathrm{bar}^{4(5)} \\
\text { M: } \mathrm{ee}^{4)}, \mathrm{hal}^{(4)}, \mathrm{mxf^{4) }}, \mathrm{N} 2 \mathrm{O}^{4)} \\
\text { R: } \mathrm{suc}^{4)}, \mathrm{dtc}^{4)}\end{array}$ \\
\hline $\begin{array}{l}\text { Brice et al. } \\
\text { (1970) }\end{array}$ & 60 & $\begin{array}{l}3(i, 24-48, \\
168-192)\end{array}$ & $\begin{array}{l}\text { 1.7, } \\
\text { pain: } 100\end{array}$ & $\begin{array}{l}\text { I: thp } \\
\text { M: N } 20 \\
\mathbf{R : ~ d t c}\end{array}$ \\
\hline $\begin{array}{l}\text { H arris et al. } \\
\text { (1971) }\end{array}$ & 120 & $2(\mathrm{i}, 24-48)$ & $\begin{array}{l}0.8,(1.7), \\
\text { pain: } 0\end{array}$ & $\begin{array}{l}\text { P: } \text { mor }^{4)} \\
\text { I: thp } \\
\text { M: N } 20, \text { hal }^{4)} \\
\text { R: dtc }\end{array}$ \\
\hline $\begin{array}{l}\text { Browne, and } \\
\text { Catton (1973a) }\end{array}$ & 120 & $1(<48)$ & $\begin{array}{l}\text { 1.7, } \\
\text { pain: ? }\end{array}$ & $\begin{array}{l}\text { P: mep }{ }^{4)}, \mathrm{pmz}^{4)} \\
\text { I: fen, dro, thp } \\
\text { M: fen, dro, N } 20 \\
\text { R: } \mathrm{dtc}^{4)}, \text { pan }^{4)}\end{array}$ \\
\hline $\begin{array}{l}\text { Browne, and } \\
\text { Catton (1973b) }\end{array}$ & 112 & $1(<48)$ & $\begin{array}{l}1.8,(2.7), \\
\text { pain: } 0\end{array}$ & $\begin{array}{l}\text { P: mep, pmz } \\
\text { I: thp, fen }{ }^{4)}, \mathrm{dro}^{4)} \\
\text { M: } \mathrm{N} 20, \mathrm{dro}^{4)} \\
\text { R: } \mathrm{dtc}^{4)}, \text { pan }^{4)}\end{array}$ \\
\hline $\begin{array}{l}\text { W ilson et al. } \\
\text { (1975) }\end{array}$ & 490 & $2(24,48-72)$ & $\begin{array}{l}0.6,(0.8), \\
\text { pain: } 0\end{array}$ & 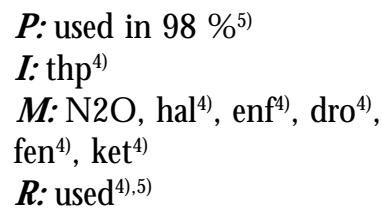 \\
\hline $\begin{array}{l}\text { Agarwal, and } \\
\text { Sikh (1977) }\end{array}$ & 138 & $2(i, 4-8)$ & 0 & $\begin{array}{l}\text { P: } \mathrm{dia}^{4)} \text {, mep }{ }^{4)} \\
\text { I: thp } \\
\text { M: N } 20 \\
\text { R: suc, dtc }\end{array}$ \\
\hline $\begin{array}{l}\text { D esiderio, and } \\
\text { Thorne (1990) }\end{array}$ & 11 & $\begin{array}{l}2 \text { (i, 1st post- } \\
\text { operative day) }\end{array}$ & 0 & $\begin{array}{l}\text { P: mid } \\
\text { I: alf, mid } \\
\text { M: alf, mid } \\
\text { R: vec }\end{array}$ \\
\hline
\end{tabular}


Table 2. Continued.

\begin{tabular}{|c|c|c|c|c|}
\hline Reference & $\begin{array}{l}\text { N umber of } \\
\text { patients }\end{array}$ & $\begin{array}{l}\text { N umber of } \\
\text { interviews, (time } \\
\text { of the interviews } \\
\text { [h] after } \\
\text { anesthesia } a^{1)} \text { ) }\end{array}$ & $\begin{array}{l}\text { Incidence of } \\
\text { explicit awareness } \\
(\%)^{2)}\end{array}$ & Anesthetics used ${ }^{31}$ \\
\hline $\begin{array}{l}\text { Liu et al. } \\
(1991)\end{array}$ & 1,000 & $1(20-35)$ & 0.2 & 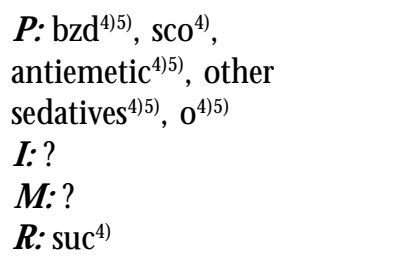 \\
\hline $\begin{array}{l}\text { Sandin, and } \\
\text { N ordström } \\
\text { (1993) }\end{array}$ & $2,500^{6)}$ & $\begin{array}{l}1 \text { (i), } 2 \text { for the } \\
\text { last } 1727 \\
\text { patients (i, on } \\
\left.\text { leaving PACU }{ }^{7)}\right)\end{array}$ & $\begin{array}{l}0.2, \\
\text { pain: } 40\end{array}$ & $\begin{array}{l}\text { P: dix, kbe } \\
\text { I: alf, pro } \\
\text { M: alf, pro } \\
\text { R: vec }\end{array}$ \\
\hline $\begin{array}{l}\text { M iller et al. } \\
\text { (1996) }\end{array}$ & 90 & $1(24-48)$ & 6.7 & $\begin{array}{l}\text { P: - } \\
\text { I: alf, pro, mid } 4 \text { ) } \\
\text { M: alf, pro } \\
\text { R: atr }\end{array}$ \\
\hline $\begin{array}{l}\text { Nordström et } \\
\text { al. (1997) }\end{array}$ & 1,000 & $\begin{array}{l}3(\mathrm{i}, 12-81 \\
72-1,392)^{8)}\end{array}$ & $\begin{array}{l}0.2,(0.3), \\
\text { pain: } 50\end{array}$ & $\begin{array}{l}\text { P: } \text { dix }^{4)}, \mathrm{mid}^{4)}, 0^{4) 5)} \\
\text { I: alf, pro } \\
\text { M: alf, pro } \\
\text { R: used in all patients }\end{array}$ \\
\hline $\begin{array}{l}\text { Sandin et al. } \\
(2000)\end{array}$ & 11,785 & $\begin{array}{l}3(i, 24-36, \\
168-336)\end{array}$ & $\begin{array}{l}\text { D efinite: } 0.05, \\
\text { Probable: } 0.06, \\
\text { Possible: } 0.03 \text {. } \\
\text { Awake paralysis: } \\
\text { one case. } \\
\text { All: } 0.16 \\
\text { Pain reported by } \\
37 \% \text { of all cases } \\
\text { of awareness }\end{array}$ & $\begin{array}{l}\text { P: o }(97.1 \%) \text {, } \\
\text { bzd }(17.7 . \%) \\
\text { I: pro }(54.9 \%) \text {, } \\
\text { thp }(44.5 \%) \text {, sev }(0.31 \%) \text {, } \\
\text { ket }(0.24 \%) \\
\text { M: N } 20(93.6 \%), \\
\text { sev }(66.7 \%) \text {, iso }(33.3 \%) \text {, } \\
\text { pro }(2.8 \%) \\
\text { R: suc }(8.7 \%) \text {, } \\
\text { ndr }{ }^{5)}(65.8 \%)\end{array}$ \\
\hline
\end{tabular}

1) $\mathrm{i}=$ immediately after emergence from the anesthesia

2) Incidence of clear awareness is given first, incidence of clear and doubtful awareness is given second (in parenthesis) if that can be estimated by the data given in the publication, and incidence of painful awareness (as a percentage of the total cases of clear awareness) is given third.

3) Abbreviations of anesthetics used:

$\mathbf{P}=$ Premedication, $\mathbf{I}=$ Induction, $\mathbf{M}=\mathrm{M}$ aintenance, $\mathbf{R}=\mathrm{M}$ uscle relaxation,

alf =alfentanil, atr = atracurium, bar =barbiturate, bzd = benzodiazepine, dia =diazepam, dix =dixyrazine, dro=droperidol, $\mathrm{dtc}=\mathrm{d}$-tubocurarine, $e e=$ ethyl ether, enf = enflurane, fen =fentanyl, hal =halothane, iso =isoflurane, ket =ketamine, $\mathrm{kbe}=$ ketobemidone, mep = meperidine, $\mathrm{mhx}=$ methohexital, $\mathrm{mid}=$ midazolam, mor = morphine, $\mathrm{mxf}=$ methoxyflurane, $\mathrm{ndr}=$ non-depolarizing muscle relaxant, $\mathrm{N}_{2} \mathrm{O}=$ nitrous oxide, $0=$ opioid; pan = pancurone, pro = propofol, pmz = promethazine, 
Table 2. Continued.

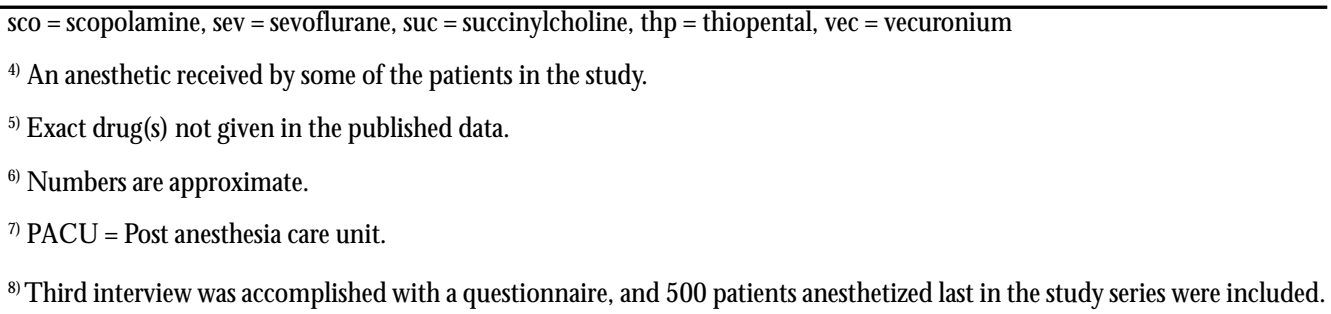

decline in recent decades (Liu et al., 1991; M oerman et al., 1995; Table 2) but the vast majority of studies continue to report a measurable incidence of this complication. The decline of incidencehas been explained by the tendency to use progressively deeper levels of anesthesia (Cormack, 1993). A higher incidence is often cited to be associated with certain types of procedures, especially cardiac surgery, obstetrics, and trauma surgery (G honeim, and Block, 1992; Ghoneim, and Block, 1997). Theincidence of explicit intraoperative awareness during different types of procedures is reviewed below.

Another source reflecting the frequency of awareness during general anesthesia, are the complication databases. In the Australian Incident M onitoring Study of 2,000 reported complications, awareness during anesthesia was the reason for reporting in 16 cases ( 0.8 $\%$ ) (O sborne et al., 1993). In a study using the closed claims database from the U.S.A., claims concerning awareness during general anesthesia resulted in 79 of the 4,183 claims (1.9\%) (Domino et al., 1999).

\subsubsection{Cardiac surgery}

There are several studies on the incidence of awareness and recall during cardiac anesthesia. The incidence figures are given in Table 3. O ne has to note, that in one study interviews during hypnosis were used (Goldmann et al., 1987). Therefore, the results of that study are not directly comparable with other studies, which have used standard post-operative interview methods.

\subsubsection{Other types of surgery}

Thestudies on the incidence of awareness with recall during operative obstetrics are summarized in Table 4.

The study by C rawford is one of the very few studies with a reasonable number of patients comparing different anesthetic protocols in relation to awareness and recall (Crawford, 1988). The incidence of awareness and recall during elective caesarean section was $3.7 \%$ in a group receiving thiopental induction and maintenance of anesthesia with $67 \%$ nitrous oxide $\left(\mathrm{N}_{2} \mathrm{O}\right)$. In a group that received similar anesthesia with the addition of $0.1 \%$ methoxyflurane after the delivery, the incidence of awareness was $0 \%$, $p<0.045$. Similarly, in the group of all operative obstetric cases (elective and emergency section plus vaginal deliveries) the incidence of awareness was 3.1 vs. $0.3, p<0.003$.

An incidence of awareness and recall during caesarean section of $2.8 \%$ has been re ported in a study group of 777 patients (C rawford et al., 1985) H owever, a structured interview method was probably not used in this study.

In themost recent largestudy, the incidence of awareness with recall during cesarean section during the years 1982 through 1989 was followed. The mean incidence of awareness and recall among the 3.076 patients was 0.9 $\%$. Until and including 1985, the incidence of awareness and recall was $1.3 \%$ and it decreased to $0.4 \%$ thereafter. The anesthetic protocol was changed during 1986: The induction dose of thiopental was increased from 
Table 3. Incidence of awareness and recall during cardiac anesthesia.

\begin{tabular}{|c|c|c|c|c|}
\hline Reference & $\begin{array}{l}\text { N umber of } \\
\text { patients }\end{array}$ & $\begin{array}{l}\text { N umber of } \\
\text { interviews, (time } \\
\text { of the interviews } \\
\text { [h] after } \\
\text { anesthesia) }\end{array}$ & $\begin{array}{l}\text { Incidence of } \\
\text { explicit awareness } \\
(\%)^{1)}\end{array}$ & Anesthetics used ${ }^{2)}$ \\
\hline $\begin{array}{l}\text { M aunuksela } \\
\text { (1977) }\end{array}$ & 139 & $\begin{array}{l}1 \text { (1st post- } \\
\text { operative week) }\end{array}$ & 5.8 & 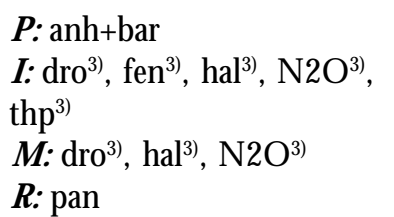 \\
\hline Kim (1978) & 56 & $1(24-71)$ & $\begin{array}{l}3.6,(8.9), \\
\text { pain: } 50\end{array}$ & $\begin{array}{l}\text { P: hxz, scb } \\
\text { I: dro, fen, thp } \\
\text { M: fen }{ }^{3)} \text {, thp }{ }^{3)}, \mathrm{N}_{20}{ }^{3)} \text {, hal } \\
\text { R: } \\
\text { Ran }\end{array}$ \\
\hline $\begin{array}{l}\text { Goldman et al. } \\
\text { (1987) }\end{array}$ & 30 & $1(168-240)$ & $\begin{array}{l}6.7,\left(23.3^{4)}\right) \text {, } \\
\text { pain: } 0\end{array}$ & $\begin{array}{l}\text { P: } \mathrm{pap}^{3)}, \mathrm{sco}^{3)},\left(\mathrm{lor}^{3)}\right. \\
\text { I: } \mathrm{fen}^{3)}, \mathrm{hal}^{3)}, \mathrm{N} 2 \mathrm{O}^{3)} \\
\text { M: } \mathrm{fen}^{3)}, \mathrm{hal}^{3)}, \mathrm{N} 2 \mathrm{O}^{3)} \\
\text { R: ? }\end{array}$ \\
\hline $\begin{array}{l}\text { Phillips et al. } \\
\text { (1993) }\end{array}$ & 700 & $1(96-120)$ & $\begin{array}{l}0.6,(1.1), \\
\text { pain: } 50\end{array}$ & $\begin{array}{l}\text { P: ? } \\
\text { I: dia or mid, fen, thp }{ }^{3)} \\
\text { M: fen, } \text { mid }^{3)}, \text { dia }^{3)}, \text { (or }^{3)} \\
\text { R: pan }\end{array}$ \\
\hline $\begin{array}{l}\text { Dowd et al. } \\
\text { (1998) }\end{array}$ & 608 & $\begin{array}{l}1 \text { (18 hours after } \\
\text { extubation) }\end{array}$ & 0.3 & $\begin{array}{l}\text { P: dia }{ }^{3)},\left(\mathrm{or}^{3)}, \mathrm{mor}^{3)}\right. \\
\text { I: fen, thp }{ }^{3)} \\
\text { M: before bypass iso, mid. } \\
\text { D uring bypass pro, iso3), } \\
\text { after bypass pro } \\
\text { R: pan }\end{array}$ \\
\hline
\end{tabular}

\footnotetext{
1) Incidence of clear awareness is given first, incidence of clear and doubtful awareness is given second (in parenthesis) if that can be estimated by the data given in the publication, and incidence of painful awareness (as a percentage of the total cases of clear awareness) is given third.

2) Abbreviations of anesthetics used:

$\mathbf{P}=$ Premedication, $\mathbf{I}=$ Induction, $\mathbf{M}=\mathbf{M}$ aintenance, $\mathbf{R}=$ M uscle relaxation,

anh=antihistamine, bar=barbiturate, dia =diazepam, dro=droperidol, fen =fentanyl, hal =halothane, hxz =hydroxyzine, iso =isoflurane, lor =lorazepam, mid =midazolam, mor =morphine, $\mathrm{N} 20$ =nitrous oxide, pan = pancurone, pap = papaveretum, pro = propofol, $\mathrm{scb}=$ secobarbital, $\mathrm{sco}=$ scopolamine, thp $=$ thiopental

${ }^{3)} \mathrm{A}$ drug received by some of the patients in the study.

4) Interviewed under hypnosis.
}

5 to $7 \mathrm{mg} / \mathrm{kg}$, the maintenance volatile anesthetic was changed from halothane to isoflurane, and the use of a potent inhaled anesthetic was allowed after the delivery (Lyons, and M acdonald, 1991).

In a study of the incidence of awareness 
Table 4. Incidence of awareness and recall during general anesthesia for operative obstetrics. A structured interview method is used in these studies.

\begin{tabular}{|c|c|c|c|c|}
\hline Reference & $\begin{array}{l}\text { Number of } \\
\text { patients }\end{array}$ & $\begin{array}{l}\text { Number of } \\
\text { interviews, (time } \\
\text { of the interviews } \\
\text { [h] after } \\
\text { anesthesia 1)) }\end{array}$ & $\begin{array}{l}\text { Incidence of } \\
\text { explicit awareness } \\
(\%)^{21}\end{array}$ & Anesthetics used 31 \\
\hline $\begin{array}{l}\text { Bergström, and } \\
\text { Bernstein } \\
\text { (1968) }\end{array}$ & 17 & 1 (i) & $\begin{array}{l}11.8,(35.3) \\
\text { pain: } 50\end{array}$ & $\begin{array}{l}\text { P: } s\left(0^{4)}\right. \\
\text { I: } N 20, h x z^{4)} \\
\text { M: } N 20, h x z \\
\text { R: suc }\end{array}$ \\
\hline $\begin{array}{l}\text { Wilson, and } \\
\text { Turner (1969) }\end{array}$ & 150 & $2(\mathrm{i},<36 \mathrm{~h})$ & 2.0, pain: 675$)$ & $\begin{array}{l}\text { P: ? } \\
\text { I: thp } \\
\text { M: N } 20\end{array}$ \\
\hline $\begin{array}{l}\text { Crawford } \\
\text { (1971) }\end{array}$ & $880^{6)}$ & $\begin{array}{l}1 \text { (1st post- } \\
\text { operative day) }\end{array}$ & $1.6^{7)}$ & $\begin{array}{l}\text { P: } \mathrm{cdz}^{4)}, \mathrm{mep}^{4)}, \mathrm{pr}^{4)} \\
\text { I: sco, thp } \\
\text { M: N } 20, \mathrm{mep}^{4)}, \mathrm{mxf} \mathrm{f}^{4)} \\
\text { R: suc }\end{array}$ \\
\hline $\begin{array}{l}\mathrm{Ng} \text {, and } \\
\text { Gurubatham } \\
\text { (1974) }\end{array}$ & 138 & $\begin{array}{l}1 \text { (1st post- } \\
\text { operative day) }\end{array}$ & 2.2, pain: $67^{81}$ & N ot reported \\
\hline $\begin{array}{l}\text { Abouleish, and } \\
\text { Taylor (1976) }\end{array}$ & 68 & $1(24-36)$ & 1.5, pain: 0 & $\begin{array}{l}\text { P: ? } \\
\text { I: tia } \\
\text { M: } \mathbf{N} 20 \text {, dia, mor } \\
\text { R: dtc, pan, suc }\end{array}$ \\
\hline $\begin{array}{l}\text { Farnsworth } \\
\text { (1978) }\end{array}$ & 80 & $\begin{array}{l}1 \text { (1st post- } \\
\text { operative day) }\end{array}$ & 5.0 & $\begin{array}{l}\text { P: ? } \\
\text { I: thp } \\
\text { M: N } 20, \text { enf() } \\
\text { R: suc, dtct }\end{array}$ \\
\hline $\begin{array}{l}\text { Schultetus et al. } \\
\text { (1986) }\end{array}$ & 36 & $\begin{array}{l}2 \text { (i, 1st post- } \\
\text { operative day) }\end{array}$ & 8.3, pain: 0 & $\begin{array}{l}\text { P: ? } \\
\text { I: } \mathrm{ket}^{4)} \text {, thp } \mathrm{th}^{4)} \\
\text { M: N 20, fen } \\
\text { R: suc }\end{array}$ \\
\hline $\begin{array}{l}\text { Baraka et al. } \\
\text { (1989) }\end{array}$ & 50 & $\begin{array}{l}2 \text { (i, 1st post- } \\
\text { operative day) }\end{array}$ & 4 & $\begin{array}{l}\text { P: - } \\
\text { I: } \mathrm{ket}^{4)} \text {, thp }{ }^{4)} \\
\text { M: hal(4), N 20 }{ }^{4)} \\
\text { R: suc }\end{array}$ \\
\hline $\begin{array}{l}\text { Bogod et al. } \\
\text { (1990) }\end{array}$ & 74 & $1(24)$ & $\begin{array}{l}2.7,\left(12.2^{91}\right) \text {, } \\
\text { pain: } 50\end{array}$ & $\begin{array}{l}\text { P: - } \\
\text { I: thp } \\
\text { M: enf, N } 20 \\
\text { R: } \operatorname{tat}^{4}{ }^{4}, \mathrm{vec}^{4)}\end{array}$ \\
\hline
\end{tabular}


Table 4. Continued.

\begin{tabular}{|c|c|c|c|c|}
\hline Reference & $\begin{array}{l}\text { N umber of } \\
\text { patients }\end{array}$ & $\begin{array}{l}\text { Number of } \\
\text { interviews, (time } \\
\text { of the interviews } \\
\text { [h] after } \\
\text { anesthesia 1)) }\end{array}$ & $\begin{array}{l}\text { Incidence of } \\
\text { explicit awareness } \\
(\%)^{2)}\end{array}$ & Anesthetics used 3 ) \\
\hline $\begin{array}{l}\text { Lyons, and } \\
\text { M acdonald } \\
\text { (1991) }\end{array}$ & 3,076 & $1^{10)}$ & $0.9^{11)}$ & $\begin{array}{l}\text { P: ? } \\
\text { I: thp } \\
\text { M: hal }{ }^{4)}, \text { iso }^{4)}, \text { N 20, pap } \\
\text { R: suc, ndr' }{ }^{12)}\end{array}$ \\
\hline
\end{tabular}

\footnotetext{
1) i =immediately after emergence from the anesthesia

${ }^{2}$ Incidence of clear awareness is given first, incidence of clear and doubtful awareness is given second (in parenthesis) if that can be estimated from the data, and incidence of painful awareness (as a percentage of the total cases of clear awareness) is given third.

3) Abbreviations of anesthetics used:

$\mathbf{P}=$ Premedication, $\mathbf{I}=$ Induction, $\mathbf{M}=\mathbf{M}$ aintenance, $\mathbf{R}=$ M uscle relaxation,

alf = alfentanil, atr = atracurium, $c d z=$ chlordiazepoxide, dia =diazepam, dtc =d-tubocurarine, enf = enflurane,

fen =fentanyl, hal =halothane, $\mathrm{hxz}=$ hexobarbitone, iso =isoflurane, ket =ketamine, mep = meperidine, mor = morphine, $\mathrm{mxf}=$ methoxyflurane, $\mathrm{ndr}=$ non-depolarizing muscle relaxant, $\mathrm{N} 20$ = nitrous oxide, pan = pancurone, pap = papaveretum, $\mathrm{prz}=$ promazine, $\mathrm{sco}=$ scopolamine, suc $=$ succinylcholine, thp =thiopental, tia =thiamylal, vec = vecuronium

4) A drug received by some of the patients in the study.

5) In addition to three patients classified as having experienced awareness, there were 23 (15.3\%) patients with unpleasant dreams and seven of these patients also experienced intraoperative pain.

6) Includes 218 patients undergoing postpartum sterilization

7) $D$ ifferent incidences of awareness for the two study groups, see text for details.

${ }^{8)}$ In addition to three patients classified as having experienced awareness, there were nine (6.5\%) patients with unpleasant dreams and seven of these patients also experienced intraoperative pain.

9) Includes patients reported to have "had dreams or heard voices".

10) Time of postoperativeinterview not specified.

${ }^{11)}$ Study reported awareness and recall during eight years (1982-1989). Incidence differed over time, see text for details.

12) Exact drug(s) not given in the published data.
}

with recall during surgery for major trauma, 51 operated patients were divided into two groups: to those who received anesthetics for the intubation and for maintenance of anesthesia during surgery, and to those who did not receive any anesthetic for the intubation and / or did not receive anesthetics for at least twenty minutes during surgery because of unstable hemodynamic condition or because of unconsciousness on arrival at theemergency room. The incidence of awareness with recall, found in two consecutive structured interviews, was $11 \%$ in the former group, and 43 $\%$ in the latter (Bogetz, and Katz, 1984). In a recent study, these findings were not confirmed, but rather, the investigators were not able to find any convincing evidence of explicit memories in a series of 96 trauma patients. These patients wereanesthetized according to a standardized protocol consisting of etomidate, fentanyl, and isoflurane (Lubke et al., 1999). 
M oerman et al. (1995) studied the incidence of awareness with recall during cardioverter defibrillator implantation: the patients received diazepam premedication; induction with etomidate and alfentanil, and maintenance with a propofol infusion; an atracurium infusion was used for muscle relaxation. Two of the $33(6.1 \%)$ patients recalled the defibrillation shocks delivered during the cardioverter implantation. The authors suggest that awareness was due to extravasation of the anesthetic through a hole in the subclavian vein created for the central lead of the defibrillator.

In a study trying to find out the incidence of awareness and recall during intubation 160 patients were interviewed; three $(1.9 \%)$ reported intraoperative awareness. H owever, only two were able to remember the intubation while the third patient recalled paralysis (M cK enna, and W ilton, 1973). In a more recent study, 30 patients were anesthetized with different doses of etomidate $(0.2-0.4 \mathrm{mg} / \mathrm{kg})$ and fentanyl. The patients' consciousness was monitored during intubation by the isolated forearm technique (IFT). Positive IFT response was found in 80,70 , and $20 \%$ of the patients receiving $0.2,0.3$, and $0.4 \mathrm{mg} / \mathrm{kg}$ etomidate, respectively. 0 ne of the patients with positive IFT response recalled awareness in a postoperative interview, giving an incidence of awareness with recall of $3.3 \%$ during intubation in this study (St Pierre et al., 2000).

An incidence of awareness and recall of 4.0 $\%$ has been reported in patients anesthetized with thiopental for broncho- or laryngoscopy. (Barr, and Wong, 1973). In another study that investigated awareness during bronchoscopy the incidence of awareness with recall was 6.7 $\%$ in a group of 104 patients. The anesthetic consisted of thiopental $0.4-1.9 \mathrm{mg} / \mathrm{kg} / \mathrm{min}$, and succinylcholinefor relaxation (M oore, and Seymour, 1987).

\subsection{Reasons for awareness with recall during general anesthesia}

\subsubsection{General considerations}

The causes of awareness with recall have been estimated from cases reported to the British M edical D efence Union ( $H$ argrove, 1987; Table 5). $\mathrm{C}$ ases of faulty anesthetic technique include reliance on $\mathrm{N}_{2} \mathrm{O}$ only in maintaining anesthesia, and cases where the anesthesiologist considered light anesthesia justified without apparent reasons. Failure to check apparatus includescases in which a correctable fault in the anesthetic apparatus caused awareness.

The authors considered that if a patient was in danger of dying on the operating table, the use of light anesthesia was justified.

The anesthetic care was defined substandard in $54 \%$ of cases of awareness in a report of closed claims analysis in the U nited States (D omino et al., 1999).

There are few case reports where tolerance to anesthetic agents has been implemented as a reason for recall (Walder, 1995). In general, these cases form a very small minority of the reported cases of awareness with recall. H owever, it seems that consumption of alcohol, tobacco, or coffee is associated with increased fentanyl requirement during induction of high-dosefentanyl anesthesia (Stanley, and De Lange, 1984).

The majority of cases of awareness and re

Table 5. Causes of awareness with recall reported to the British Medical Defence Union between 1982 and 1986 (Hargrove, 1987).

Causes Percentage of cases

Faulty anesthetic technique 70

Failure to check apparatus 20

Genuine apparatus failure 5

Spurious claims

Justified risks / unknown cause 
call seem to be due to preventable problems in the anesthetic apparatus and administration of anesthesia. A smaller fraction of patients seem to suffer from this complication because of individual differences in pharmacokinetics and pharmacodynamics of anesthetic agents. Important differencesare known to exist in the distribution of drugs and in their entry into the effector site. The differences between drug concentration and effect are, however, smaller than differences between drug dose and effect (Scheinin, 1999). As many anesthetic drugs are used in standard doses it is likely that the complication of awareness will continue to exist unless the drug effect can be titrated against a specific monitor of consciousness.

\subsubsection{Anesthetics}

A very largenumber of studies have compared the effect of different doses of anesthetic agents on learning and memory.

\subsubsection{The concepts of minimum alveolar concentration and effective concentration}

M ovement as a response to a noxious stimulus has been used as a measure of the relative potency of volatile anesthetics. O riginally, movement as a response variable was chosen because it is an easily observable, categorical variable, and no other simple and unequivocal responsevariables existed (Eger, 2002). The minimum alveolar concentration (MAC) is the concentration of a volatile anesthetic necessary to eliminate movement in response to surgical stimulation, usually skin incision, in $50 \%$ of subjects (Eger et al., 1965). M AC values of several anesthetic agents are considered to be additive (Eger, 1989). The M AC concept, however, only relates to movement, a response probably mediated by lower, spinal centers of the central nervous system (Rampil, 1994). A concept of M AC-awake has been proposed to describe the concentration needed to abolish consciousness in $50 \%$ of the subjects (Stoelting et al., 1970). M AC is useful in comparing the potencies of different volatile anesthetics (Jones, 2000), however, M AC is based on population studies, and by definition, $50 \%$ of patients are still conscious at $M A C_{\text {awake }}$ value. Furthermore, several individual factors like hypothermia, hypotension, hypercarbia, acidosis, and electrolyte disturbances affect M AC. U sually, the effector site (central nervous system) concentration may be estimated by the end-tidal expiratory gas concentration after a reasonable equilibration period. $\mathrm{H}$ owever, ventilation-perfusion mismatch may causea variable difference between the end-tidal and arterial blood gas concentration (Q uasha et al., 1980). These factors render $M A C$ alone unsuitable for monitoring unconsciousness or depth of anesthesia in an individual patient.

An analogous value for intravenous (i.v.) anesthetics, $\mathrm{EC}_{50}$ (effective concentration) has been defined as the blood concentration necessary to prevent movement in response to surgical stimulation in $50 \%$ of subjects (Scheinin, 1999; Jones, 2000). Significant interindividual differences exist in drug distribution and entry into the effector site (Scheinin, 1999). This, in addition to the obvious difficulties in obtaining the concentration values in a clinical situation, makes even $\mathrm{EC}_{50}$-values unsuitable for monitoring an individual patient.

\subsubsection{Potent volatile anesthetic agents}

$M C_{\text {awake }}$ val ues for desflurane, isoflurane, and sevoflurane are roughly $33-35 \%$ of the M AC value of the anesthetic. $M A C_{\text {awake }}$ valskin incision halothane and $\mathrm{N}_{2} \mathrm{O}$ are $52-58 \%$ of their MAC ${ }_{\text {skin incision }}$ values. Therefore, desflurane, isoflurane, and sevoflurane may be considered more potent amnestic anesthetics than halothane (Eger, 2001).

A M AC awake of $2.6 \%$ has been estimated for desflurane based on a volunteer study (C hortkoff et al., 1995). D esflurane has been 
found to suppress both implicit and explicit memory formation at a concentration of 0.6 M AC ${ }_{\text {skin incision }}$ (G onsowski et al., 1995).

Conscious memory was suppressed by administration of $0.45 \mathrm{MAC}_{\text {skin incision of }}$ isoflurane to a population of 17 volunteers. The $\mathrm{EC}_{50}$ for isoflurane for preventing conscious memories was $0.20 \mathrm{MAC}_{\text {skin incision }}$ in the study (D wyer et al., 1992). I soflurane has also been reported to suppress both implicit and explicit memory formation at a concentration of $0.6 \mathrm{M} \mathrm{AC}_{\text {skin incision }}$ (Gonsowski et al., 1995).

A low concentration of sevoflurane $(0.3 \%$ and $0.6 \%$, end-tidal) produced a greater degree of amnesia, psychomotor impairment and drowsiness than $15 \%$ and $30 \%$ end-tidal $\mathrm{N}_{2} \mathrm{O}$, which was equipotent with the sevoflurane concentration in terms of M AC (G alinkin et al., 1997). Based on mid-latency auditory evoked potential (M LAEP) studies, end-expiratory concentrations of sevoflurane greater than $1.5 \%$ should suppress auditory perception, memory formation and implicit and explicit recall (Schwender et al., 1996).

\subsubsection{Intravenous anesthetics}

$\mathrm{EC}_{50 \text { awake }}$ values for propofol (measured as blood concentration) follow the same pattern as for volatile anesthetics, $\mathrm{EC}_{50 \text { awake }}$ being 40 $\%$ of the $\mathrm{EC}_{50 \text { skin incicision }}$ of propofol (Jones, 2000). A case of awareness with recall has been reported, where propofol was used as a sole anesthetic in a microlaryngeal procedure. The induction dose of propofol was $2.1 \mathrm{mg} / \mathrm{kg}$ and the maintenance dose was $200 \mu \mathrm{g} / \mathrm{kg} / \mathrm{min}$ (Kelly, and Roy, 1992).

Thiopental increases the latency and decreases the amplitude of the M LAEPs. The change is comparable to that seen with e.g. propofol and potent inhalational anesthetics (Schwender, Klasing et al., 1994). W ilderSmith et al. (1995) compared EEG arousal reactions during intubation in patients randomized to have anesthetic induction with either thiopental $6 \mathrm{mg} / \mathrm{kg}$ or propofol $3 \mathrm{mg} /$ $\mathrm{kg}$. The degree of cortical EEG depression was similar in both groups, but the degree of EEG arousal reactionswas significantly lower in the propofol group.

In a study by Baraka et al. (1989), induction of anesthesia for an elective caesarean section with ketamine $1.5 \mathrm{mg} / \mathrm{kg}$ produced significantly lower incidence of reactions in the isolated forearm ( $70 \%$ vs. $13 \%, p<0.05)$ than thiopental $4 \mathrm{mg} / \mathrm{kg}$. There was, however, no difference between the groups in recall of awareness in the postoperative interview.

Ketamine does not seem to produce changes in M LAEP amplitudes or latencies (Schwilden, 1994). This seems to imply that the primary processing of the auditory sensory information remains intact, but that there is disruption of sensory processing at a higher level reflected by EEG changes (Schwilden, 1994). Ketamine also has been shown to disrupt thememory retrieval process unlikemany other drugs (Ghoneim, and Block, 1992).

\subsubsection{Opioids}

There are case reports of awareness during general anesthesia with very high doses of fentanyl (72-96 $\mu \mathrm{g} / \mathrm{kg}$ ) (M ummaneni et al., 1980; $H$ ilgenberg, 1981; M ark, and G reenberg, 1983), and it may therefore be regarded that opioids al one cannot guarantee surgical anesthesia (Wong, 1983).

\subsubsection{Benzodiazepines}

Benzodiazepines (diazepam, midazolam, and lorazepam) have been used for the maintenance of anesthesia in cardiac surgical patients. The dose of benzodiazepines, or opioids, did not differ between patients with and without awareness and recall (Phillips et al., 1993).

In a study of the frequency of awareness with recall during arthroscopy, patients received either placebo or midazolam 15, 30, or $45 \mu \mathrm{g} / \mathrm{kg}$ i.v. in the operating room before the induction of anesthesia. Anesthesia was 
induced and maintained with propofol which was titrated to maintain heart rate and systolic blood pressure within $\pm 20 \%$ of preoperative values. There were four patients with awareness (19.1\%) in the group of 21 patients receiving placebo ), while the incidence of awareness was $2 / 69(2.9 \%)$ in the groups receiving midazolam $(p<0.04)$ (M iller et al., 1996).

A group of cardiac surgical patients received flunitrazepam $0.01 \mathrm{mg} / \mathrm{kg}$ for the induction and $1.2 \mathrm{mg} / \mathrm{h}$ for maintenance of anesthesia. There was only a slight increase in the latency or decrease in amplitude of M LAEPs. These patients al so reacted to loud sound (the sound of the sternotomy saw) with an increase in heart rate, arterial pressure, and pulmonary capillary wedge pressure. These changes where not noticed in two groups of patients whose anesthesia was induced with etomidate, and maintained with isoflurane, or propofol, re spectively (Schwender, H aessler et al., 1994).

\subsubsection{Nitrous oxide}

Conscious memories were not totally abolished by $0.6 \mathrm{MAC}$ of $\mathrm{N}_{2} \mathrm{O}$ in a population of 17 volunteers. $\mathrm{The} \mathrm{EC}_{50}$ for $\mathrm{N}_{2} \mathrm{O}$ in preventing conscious memories was estimated to be $0.50 \mathrm{M} \mathrm{AC}_{\text {skin incision }}$ (D wyer et al., 1992). Similarly, it has been shown that cortical auditory evoked potentials (AEP) were suppressed significantly less by $\mathrm{N}_{2} \mathrm{O}$ at $0.6 \mathrm{MAC}_{\text {skin incision }}$ than by isoflurane at $0.6 \mathrm{M} \mathrm{AC}_{\text {skin incision }}(\mathrm{N}$ ewton et al., 1989). There is evidence that $\mathrm{N}_{2} \mathrm{O}$ may even antagonizethe suppression of learning induced by isoflurane (Chortkoff et al., 1993), as well as EEG depression caused by isoflurane (Yli-H ankala et al., 1993).

In a study by Russell, theincidence of wake fulness as assessed by the isolated forearm method was $44 \%$ in the group receiving 66 $\% \mathrm{~N}_{2} \mathrm{O}$ in oxygen for the maintenance of anesthesia. The incidence of wakefulness was $7 \%$ in the group receiving etomidate $10 \mu \mathrm{g} /$ $\mathrm{kg} / \mathrm{min}$. The incidence of awareness with re call was $4 \%$ in the group receiving $\mathrm{N}_{2} \mathrm{O}$ for maintenance, and zero in the etomidate group (Russell, 1986). A conclusion was reached in a recent study that an anesthetic consisting of $\mathrm{N}_{2} \mathrm{O}$ and bolus dosing of an opioid carries an unacceptably high risk of awareness and recall. The incidence of awareness with recall in the group of patients receiving $70 \% \mathrm{~N}_{2} \mathrm{O}$ supplemented with fentanyl boluses was six percent (Ghoneim et al., 2000).

There is, however, a study of 138 patients none of whom reported awareness with recall after thiopental $7 \mathrm{mg} / \mathrm{kg}$ for induction followed by $66 \% \mathrm{~N}, 0$. Thepatients underwent various abdominal procedures with a mean duration of anesthesia of 80 minutes. Recall was tested with three consecutive structured interviews immediately after awakening and at 30-45 min and 3-4 $\mathrm{h}$ later(Agarwal, and Sikh, 1977).

The effect of $\mathrm{N}_{2} \mathrm{O}$, which is, at room temperature, a gas, is dependent on its partial pressure. Therefore, the effect of $\mathrm{N}_{2} \mathrm{O}$ is reduced at high altitudes. Considering the earth's surface, a vast population lives, and is anaesthetized, at high altitudes (James, 1994).

\subsubsection{Neuromuscular blocking agents}

M ost cases of awareness are recorded during so-called balanced anesthesia which includes the use of N M Bs. Therefore, it is often recommended that N M Bs be used as sparingly as possible (M ainzer, 1979; Ponte, 1995). There are, however, a small number of case reports of awareness in patients who received no N M Bs at all (Saucier et al., 1983; O sborne et al., 1993; Cundy, 1995; Sandin et al., 2000).

\subsection{Prevention of awareness with recall}

\subsubsection{General recommendations}

Several authors have expressed as a goal the prevention of awareness with recall during general anesthesia by all possible means 
(Anonymous, 1976, 1980)

Several recommendations have been published on avoiding awareness with recall. These usually include avoiding or limiting muscle relaxant use (Hug, 1990; Lunn, and Rosen, 1990; G honeim, 2000), defining therapeutic windows for anesthetics, and also, defining factors modifying those windows ( $\mathrm{H} \mathrm{ug}$, 1990).

There are recommendations not to rely solely on $\mathrm{N}_{2} \mathrm{O}$, but to supplement it with a volatile agent concentration of at least $0.6 \%$ M AC skin incision (Lunn, and Rosen, 1990; G honeim, 2000), to administer at least 0.8-1 $M A C{ }_{\text {skin incision }}$ when volatile anesthetics are used alone, and to use drugs that produce amnesia when only light anesthesia is tolerated (Ghoneim, 2000).

\subsubsection{Methods of monitoring consciousness during general anesthesia}

$M$ any methods have been used to monitor the anesthetic state, especially to detect an insufficient depth of general anesthesia. These methods do not measure learning or possibility for later recall, but consciousness. There is a thorough review of the methodology by H eier and Steen (1996), and an update including the most recent methods by D rummond (2000).

\subsubsection{Clinical signs}

W hen anesthesia becomes too light, the patient may move or show signs of sympathetic activity. M ovement is obviously not possible if large doses of N M Bs have been used. M oreover, not all patients with intraoperative aware ness move during the procedure (Saucier et al., 1983; Cundy, 1995).

Signs of sympathetic activity: tachycardia, hypertension, sweating, pupillary dilatation, lacrimation and sweating are often used as clinical signs of an inadequate level of anesthesia. H owever, the signs of increased autonomic activity may be absent during treat- ment with many drugs: opioids, cholinergic and beta-adrenergic antagonists, vasodilators, and antihypertensive agents (Ghoneim, and Block, 1992). Epidural anesthesia may also obtund the sympathetic responses (Schwender, Faber-Zullig et al., 1994). Furthermore, it seems that not all patients with intraoperative awareness, even with pain, show signs of increased sympathetic activity. In one study, propofol infusion was controlled to keep heart rate and systolic blood pressure within \pm 20 $\%$ of the patient's preoperative values. $\mathrm{H}$ owever, a $19 \%$ incidence of awareness and recall of wasfound in oneof thestudy groups (M iller et al., 1996).

Scoring methods have been developed for measuring the anesthetic state based on sympathetic activity (Evans, and D avies, 1984). H owever, the correlation of these scores with other measures of the anesthetic depth has been poor (Russell, 1993). Neither was a group of experienced anesthesiologists ableto discriminate between patients with and without awareness in a study by Moerman and colleagues (M oerman et al., 1993).

\subsubsection{The isolated forearm technique}

The technique of isolating one forearm from circulation before giving N M Bs is described by Tunstall in 1977 (Tunstall, 1977). After induction of general anesthesia by anesthetic drugs but before giving N M Bs, a blood pressure cuff is inflated on one arm to isolate that forearm from the circulation. The forearm remains isolated from the effects of $\mathrm{N} \mathrm{M} \mathrm{Bs}$ once these drugs are administered, and therefore, the patient may use the isolated forearm e.g. for signaling. The method is limited by the ischemia produced by the inflated blood pressure cuff. H owever, the tourniquet may be pressurized several times consecutively if one assures that the concentration of $\mathrm{N} \mathrm{M} \mathrm{BS}$ is low at the time of deflation. The patient may respond by voluntary movement of the isolated forearm to questions posed by the 
investigator. M ost of the patients responding by intraoperative forearm movement have no recall afterwards. IFT has been reported to be an unhel pful indicator of patients with awareness and postoperative recall (Bogod, 1990). Indeed, it has been shown that the responses of the isolated forearm, though representing complex responses to verbal commands, may not necessarily represent a conscious response (Thornton, and Jones, 1993). Some authors have found the method impossible to use because it interferes with the surgical activity (Breckenridge, and Aitkenhead, 1981).

\subsubsection{Electroencephalography}

The electroencephalogram (EEG) is the summary result of the activity of the cortical neurons (Bailey, and Jones, 1997). In general, there is a decrease of the fast activity and an increasein the high-amplitude, slow-frequency components in the EEG during anesthesia (Bailey, and Jones, 1997). H owever, the magnitude of change and exact patterns vary between anesthetic agents (Clark, and Rosner, 1973). Furthermore, there is considerable interference in the EEG recording caused by different electrical devices present in theoperating room environment (Rampil, 1998). Therefore, raw EEG is not very suitable for assessing anesthetic state, at least in inexperienced hands.

$M$ any forms of processed EEG signal have also been evaluated for the monitoring of depth of anesthesia. At least the following methods have been used: spectral array, pe riod-amplitude analysis, spectral edge frequency, median frequency, and aperiodic analysis (Rampil, 1998). N one of these methods have proven to be of practical value in monitoring the anesthetic state produced by anesthetic drug combinations (Ghoneim, and Block, 1992; Bailey, and Jones, 1997).

The bispectral index (BIS) is an empirically derived algorithm that reflects the state of the brain in relation to sedation (Sigl, and
Chamoun, 1994; Rosow, and M anberg, 1998). It was developed by a statistical analysis of a large number of EEG samples on subjects whose level of sedation was known. BIS incorporates power spectral analysis of the EEG , components of theEEG that are due to phase relationships, and the degree of burst suppression (Rampil, 1998; D rummond, 2000; Kerssens, and Sebel, 2001).

TheBIS seems to function well as a practical clinical on-line trend monitor of the level of sedation. The correlation of conscious re sponses and memory function at a population level is good, but there are considerable interindividual differences in these parameters, particularly at the lower end of the scale (D rummond, 2000; Kerssens, and Sebel, 2001).

The principle of auditory evoked responses (AER) is that the subject listens to 'click'stimuli while his EEG is recorded, and an average response, the $A E R$, is extracted from the background EEG that, in this context, is considered noise (Thornton, and Sharpe, 2001). The mid-latency auditory evoked potentials (M LAEP) are recorded 15-100 ms after the stimulus, and represent the primary non-cognitive cortical processing of auditory impulses (H eier, and Steen, 1996). All volatile anesthetics, propofol and thiopental reduce the amplitudes of M LAEPs and increase their latency in a dose-dependent fashion (H eier, and Steen, 1996; Yli-H ankala, 2000).

A correlation between short latencies of the auditory evoked signal and signaling of awareness by the isolated forearm method has been shown (Thornton et al., 1989).

It has been shown that when the early cortical potential s of M LAEPs are preserved during general anesthesia, auditory information may be processed and remembered postoperatively (Schwender, Kaiser et al., 1994). H owever, AER does not predict movement to noxious stimulation during $1 \mathrm{M} \mathrm{AC}_{\text {skin incision }}$ concentration of isoflurane and $\mathrm{N}_{2} \mathrm{O}$ (Kochs 
et al., 1999). Thus, AER reflectsthe conscious state of the patient in relation to anesthesia and surgical stimulation and not solely in relation to anesthetic depth.

\subsection{After-effects of awareness with recall during general anesthesia}

\subsubsection{Mental after-effects}

The potential for mental consequences after neuromuscular paralysis was first described by M eyer and Blacher in 1961 in cardiac surgery patients (M eyer, and Blacher, 1961). Themain features of the patients were anxiety, irritability, and repetitive nightmares. H owever, the patients did not have clear recollection of intra-operative awareness, and they were uncertain of the cause of their symptoms.

$M$ ental after-effects are due to the very stressful experience of awareness during general anesthesia. It is, however, difficult for the patient to distinguish between periods immediately before and after anesthesia and the anesthesia itself. Patients have been described who claim to have been aware during anesthesia, even though only sedation or local anesthesia had been used. After-effects have been similar to those after awareness during intended general anesthesia (M oerman et al., 1993; Cundy, 1995). This also applies to awareness and recall during waking up from an anesthesia: the time scale of the patient is distorted, and a patient may have serious psychiatric sequelae after recalling waking up intubated and during transport, even though he is no longer anesthetized from the standpoint of the anesthesiologist ( $\mathrm{H} \mathrm{O}, 2001)$. It has also been claimed that awareness per se is not the important issue but rather, the sense of passively experiencing something over which one has no control, where the feeling is that things are not going as expected, and yet, they cannot be corrected by calling for help (Blacher, 1984). Muscle relaxation (Wang, 2000), pain and fear of dying (C undy, and
D asey, 1996) have been cited as worst stressors causing the after-effects. Furthermore, it has been suggested that patients who have been forewarned of the possibility of being aware during surgery, and of the reasons for it, may not develop psychiatric after-effects (Holt, and Yate, 1993). In patient satisfaction studies, dissatisfaction scores aretypically extremely high in cases of awareness with re call during general anesthesia (M yles et al., 2000).

Typical symptoms after an experience of awareness during general anesthesia are irritability, insomnia, repetitivenightmares, anxiety, depression, and preoccupation with death. There may also be morbid fear of hospitals or doctors, and of the need for future surgery (Blacher, 1975, 1984; Payne, 1994). The patients al so typically find it difficult to discuss their experience of awareness (Blacher, 1975). This may be made worse by the medical and nursing staff if it is suggested that the experience had been imagined, or, even worse, the patient is blamed for it because of e.g. overweight (Payne, 1994). When a patient reported an experience of awareness during anesthesia to the hospital staff $37 \%$ of the personnel responded with disbelief, ignorance, or anger. An additional $14 \%$ of patients were told that their experience was "just a bad dream", "all in your imagination", or that they "were mad or hallucinating", or "had a seventh sense" (Cobcroft, and Forsdick, 1993).

In the study of Moerman et al. (1993), $70 \%$ of patients who had experienced awareness during general anesthesia had unpleasant after-effects; $6 \%$ of patients had needed psychotherapeutic help. In the study by Shwender and co-workers $48.9 \%$ of the patients had after-effects, anxiety (55.0\%) and nightmares $(52.4 \%$ ) being the most common ones. Post-traumatic stress disorder (PTSD) wasfound in $14.3 \%$ (Schwender et al., 1998). Both studies recruited patients by advertising or via referral from colleagues.

of the long term after-effects, the most 
important is PT SD . PT SD ischaracterized by three symptom clusters: 1) re-experiencing, 2) avoidance and numbing, and 3) increased arousal which follows a traumatic event (O sterman, and Van Der Kolk, 1998). PT SD is chronic or recurring in a high proportion of those in whom it develops ( 0 sterman, and Van Der Kolk, 1998). In a prospective study, four out of six patients had mental reactions after a year of the precipitating anesthesia (Bergström, and Bernstein, 1968), and in another study $56.3 \%$ of the subjects with intraoperative awareness had PTSD after a mean of 17.9 postoperative years ( 0 sterman et al., 2001). In a prospectivefollow-up study, all eight patients with intraoperative awareness experienced fear when falling asleep from time to time. All had anxiety concerning future anesthetics (Jordening, and Pedersen, 1991). A recent study (Lennmarken et al., 2002) tried to evaluate all patients with previously experienced awareness and recall found in another large study (Sandin et al., 2000). The investigators were able to interview nine of the 18 original patients. Four of the nine interviewed patientsfulfilled all D SM -IV criteria for PTSD median of 27 months after the unsuccessful anesthesia. Three other patients had some PTSD symptoms, but did not fulfill the diagnostic criteria. Six of the original 18 patients refused the interview, which the authors partly interpret as avoidance be havior typical of PTSD (Lennmarken et al., 2002).

Recommendations for treating a patient who has just experienced awareness with re call have been published. The anesthesiologist should always visit the patient complaining awareness with recall and acknowledge patient's account of events as real. The anesthesiologist should apologizeto thepatient and assure that the event will be recorded in the hospital notes. A possible error that has lead to the event of awareness with recall should be admitted (Aitkenhead, 1990; G honeim, 2000). It is al so suggested that a patient with intraoperative awareness needs to feel a sense of safety and connection to the surgical and anesthesia teams ( 0 sterman, and Van D er Kolk, 1998). C are should be taken not to ascribe blame on the patient. H owever, it is the opinion of someauthorsthat explanation and simple reassurance are not adequate measures for preventing serious psychiatric complications of awareness with recall ( $M$ acleod, and M aycock, 1992). Indeed, based on the possibly large incidence of PTSD after, at least, painful awareness ( 0 sterman et al., 2001), and the chronic nature of PTSD, a psychiatric consultation is usually warranted in these cases (O sterman, and Van Der Kolk, 1998; Lennmarken et al., 2002).

\subsubsection{Medico-legal after-effects}

Very large compensations, GBP 20,000 to 100,000 , have been awarded for awareness during general anesthesia in Great Britain (Payne, 1994). In one of the cases, the compensation was particularly large, in part, be cause the anesthesiologists refused to see the patient after surgery even though she complained about her awareness (Payne, 1994). In the malpractice claims involving awareness during general anesthesia in the U nited States, the cost of settlement or jury awards have ranged from USD 1,000 to 600,000 (D omino et al., 1999). In this analysis, factors associated with claims for recall during general anesthesia compared to other general anesthesia claims were: no volatile anesthetic agent used, female gender, obstetric or gynecologic procedure, intraoperative opioid, and intraoperative muscle relaxant (D omino et al., 1999).

N o precedent based on a case of intraoperative awareness and recall has been issued by the Finnish Supreme Court according to the Finlex database kept by the M inistry of Justice of Finland (Anonymous, 2002). 


\section{Aims of the study}

1. To study the incidence of awareness with recall during anesthesia for general surgery. (Study1)

2. To study the incidence of awareness with recall during anesthesia for cardiac surgery. (Studies 1 and 2)

3. To find out possibledifferences in anesthetic drug dosing between patients with and without awareness and recall (Studies 1 and 3)

4. To study whether or not it is possible to detect awareness with recall by analyzing changes in variables commonly monitored during general anesthesia with conventional statistical methods or artificial intelligence neural networks. (Study 4)

5. To evaluate the utility of giving feedback information to the anesthesiologistsin lowering the incidence of awareness. (Study 2)

6. To study the psychiatric consequences of awareness with recall. (Studies 1,2,3 and 5)

7. To study the medico-legal consequences of awareness with recall in Finland in theform of patient insurance claims. (Study 5) 


\section{Patients and methods}

\subsection{Patients}

These studies were carried out at the Päijät$\mathrm{H}$ äme Central H ospital, Lahti, Finland (Study 1), and the M eilahti H ospital D epartment of Surgery, H elsinki U niversity Central Hospital, H elsinki, Finland (Studies 2 and 3). In addition, patient records were obtained through the Patient Insurance Association (PIA) of Finland and through advertisements in the Journal of the Finnish Society of Anaesthesiologists (Finnanest 1997: 30: 38). Thetotal number of enrolled patient cases was 3,868 (1,485 male and 2,383 female). Taking into account the fact that some patients had been operated more than once, the total number of individual sincluded in these studies is 3,739 (1,463 male, 2,276 female). Permissions of local ethical committees were obtained for the studies. The number of cases in the individual Studies is shown in Figure 1.

In Study 1 all elective general surgery patients over 12 years of age operated between August 1994 and August 1995 in the Päijät$\mathrm{H}$ äme $\mathrm{C}$ entral $\mathrm{H}$ ospital, Lahti, Finland were included in the study. A total of 4,818 (1,215 male, 3,603 female) such patients were operated on during the study period, and 2612 (54.2\%, 608 male, 2,004 female) of them wereinterviewed. 121 of theincluded patients were operated more than once, and hence, interviewed more than once. Therefore, the total number of different patients included is
2,484 (586 male and 1,898 female). Failure to enter all elective patients into the study re sulted from time constraints imposed by other duties on the anesthesia nurses who did the screening interviews.

In Study 2, a random sample of 99 (74 male, 25 female) patients who underwent open heart surgery between June, 1992 and September, 1992 was selected first. The second part of study included all open heart surgery patients operated on between September, 22 and N ovember, 23, 1993, altogether 236 patients. Thirty two patients were excluded, leaving 204 (86\%; 147 male, 57 female) for the analysis. Excluded were those transferred to other hospital sbeforethe screening interviews, patients with Intensive care unit (ICU) stays over ten days, patients with neurological complications making the screening interview impossible, and patients who did not survive until the interview. The total number of patients in Study 2 was 303 (221 male, $82 \mathrm{fe}$ male).

In Study 3, all open heart surgery patients operated on between January 13, 1995 and January 13, 1996 were evaluated for enrollment. There were 1,218 $(870$ male, $348 \mathrm{fe}$ male) such patients, and 929 ( $76 \%$; 653 male, 276 female) of those were included in the study. The reasons for exclusion were: 148 patients could not be reached before they left the ward after the operation, 62 stayed in the 
INTERVIEW STUDIES

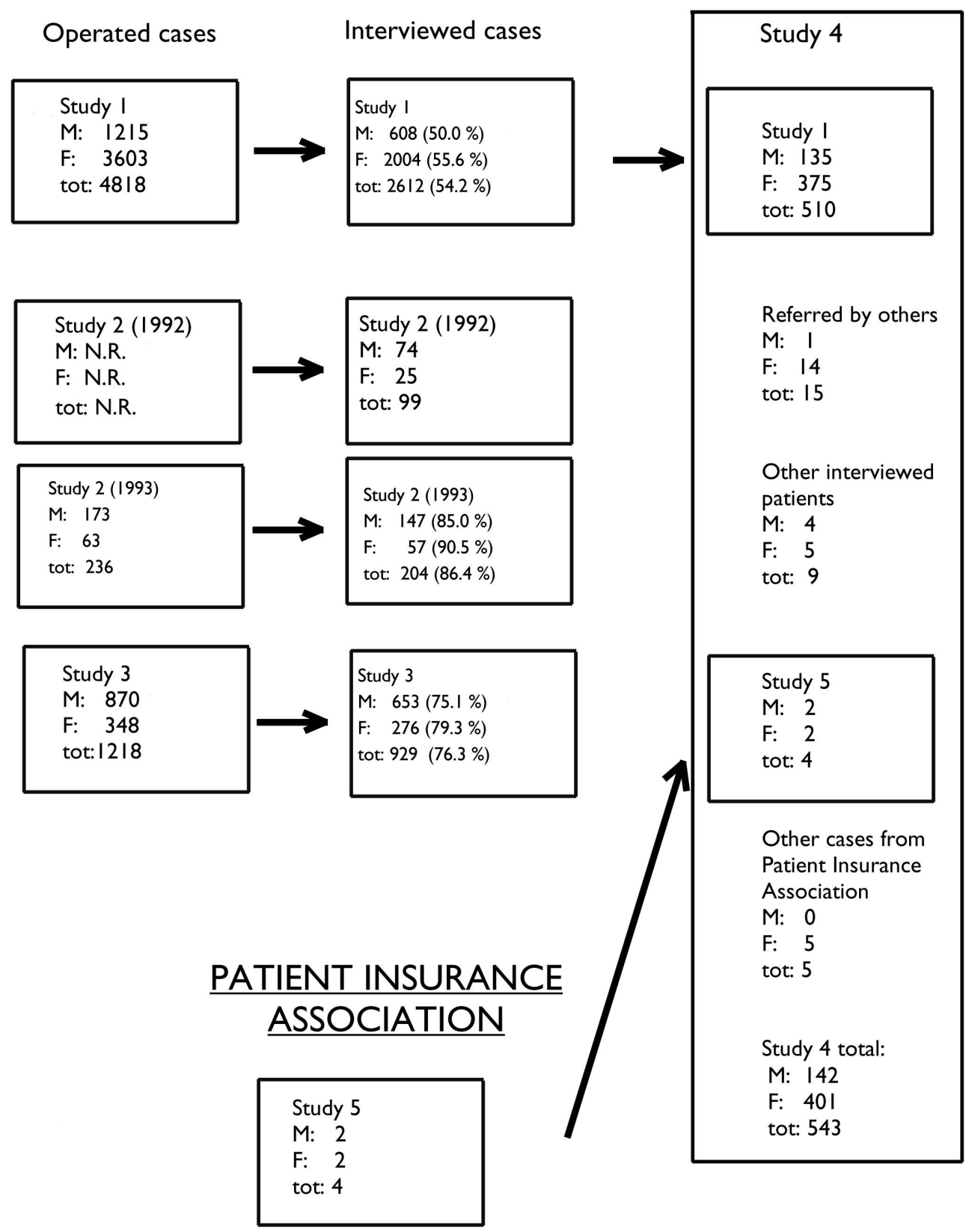

Figure 1. Number and flow of patients in the studies. Operated and actually interviewed cases (interview percentage) are shown for the interview studies 1,2, and 3. Use of patient cases from these and other sources for the artificial intelligence study (4) are shown by arrows. 
ICU for morethan 5 days, 38 died before the interview, 25 developed neurological symptoms preventing the screening interview, 6 did not speak Finnish, 2 had psychiatric syndromes preventing interview, and 7 had various other reasons preventing interview.

In Study 4, patients with awareness and recall were recruited from Study 1 ( $n=9,2$ male, 7 female), Study 5 ( $n=4,2$ male, 2 female), from claims filed in the PIA ( $n=5$, all female), and from information received from colleague anesthesiologists ( $n=15,1$ male, 13 female, one of whom had experienced awareness twice). The total number of patients with awareness and recall was, there fore, 33 ( 5 male, 28 female). The control patients ( $n=510,137$ male, 373 female) were randomly gathered from the patients without conscious awareness and recall in Study 1 (n $=501,133$ male, 368 female) and from patients interviewed after general surgery in M eilahti H ospital ( $n=9,4$ male, 5 female). Altogether, in Study 4, there were 543 (142 male, 401 female) patient cases, and 542 individuals (142 males, 400 females).

In Study 5, there were 4 patient records collected from the claims of compensation filed in the PIA between M ay 1, 1987 and D ecember 31, 1993. Two of these patients were male and two female.

\subsection{Interviews and classification}

The screening interviews used questions de scribed earlier (Briceet al., 1970, Table 1) and the patients were interviewed only once. In Study 1 , the interviews were conducted by recovery room nurses before the patient left the recovery room. The nurses notified the investigators immediately of clear cases of intraoperative awareness. After the completion of the studies, the interview forms completed by the nurses were analyzed by the investigators. The cardiac surgery patients in studies 2 and 3 were interviewed in the postoperative wards by the investigators.

When interpreting the answers to the struc- tured interview questions, importance was placed on the subjective feeling of the patient regarding awareness during anesthesia. The answers were also graded to three groups according to objective memories that could be traced back to the time of anesthesia, and the duration of awareness (Table 6).

Table 6. Grouping of structured interview answers.

\begin{tabular}{ll}
\hline Group & D efinition \\
\hline Group 1 & $\begin{array}{l}\text { Patients with unclear memories or } \\
\text { dreams, which could be of intra- } \\
\text { operative origin. }\end{array}$
\end{tabular}

Group 2 Patients with short periods of awareness occurring either intraoperatively or during the period of awakening from anesthesia.

Group 3 Patients with long-lasting, clear, and undisputed recall of the intraoperative period.

\subsection{Medications}

Anesthesia records were used as a source of information regarding the anesthetic medications used during the studies. In Studies 1, 2, and 3 the total dose of medications given i.v. was recorded. The dose of the inhaled anesthetics was calculated from the anesthetic records as follows: Theinspired concentration of the anesthetic was multiplied by the time (in minutes) that this concentration was used; the concentration-time products were then added to a grand total. The anesthetic time was recorded, and a mean dose of both i.v. and inhal ed anesthetic agents was cal culated. Furthermore, continuous or intermittent anesthetic delivery was also noted. Continuous administration of an anesthetic was defined as an inhaled or i.v. anesthetic started within 15 minutes after induction and continued until theend of surgery without interruptions lasting longer than $15 \mathrm{~min}$.

In Study 1, the doses of anesthetics used 
for general anesthesia were estimated from random samples collected as follows: First, a sample of 103 anesthetic records was collected from the three-month period immediately preceding the interview period. We assume that this period represents the standard practice of the anesthesiologists in the hospital. D uring each four three-month interview periods, a sample of 108 anesthetic records was collected. Thus, wehad a database of 535 random anesthetic records, which allowed detection of possible change in the doses of anesthetics over time, and comparison between doses received by patients with or without awareness. This database was also used for Poisson regression analysis. W hen comparing the doses of anesthetics received by the patients with or without awareness, the records of patients not interviewed for some reason were excluded. After this exclusion, 247 records were left for analysis.

In Study 2, the anesthetic records of all interviewed patients were included in the analysis.

In Study 3, a random sample of 308 anesthetic records was selected from the group of interviewed patients. Later, the anesthetic records of 16 patients with awareness and five patients with unpleasant dreams were included. Thus the total number of anesthetic records used for the analysis of medications was 329.

In Study 5, the anesthetic records of all four patients were analyzed.

\subsection{Artificial neural networks}

Artificial neural networks are a form of artificial intelligence with the ability to discover non-linear dependencies between input and output patterns even when they are difficult or impossibleto detect with conventional statistical methods. In practice, an artificial neural network is simulated in a computer program and is configured and trained to perform a specific task. A network is trained by presenting examples of input records with correct output from a training data set. The network 'learns' to associate a given input with correct output by altering its internal weights. A successfully trained network can correctly classify input patterns that aresimilar, but not necessarily identical to the training patterns

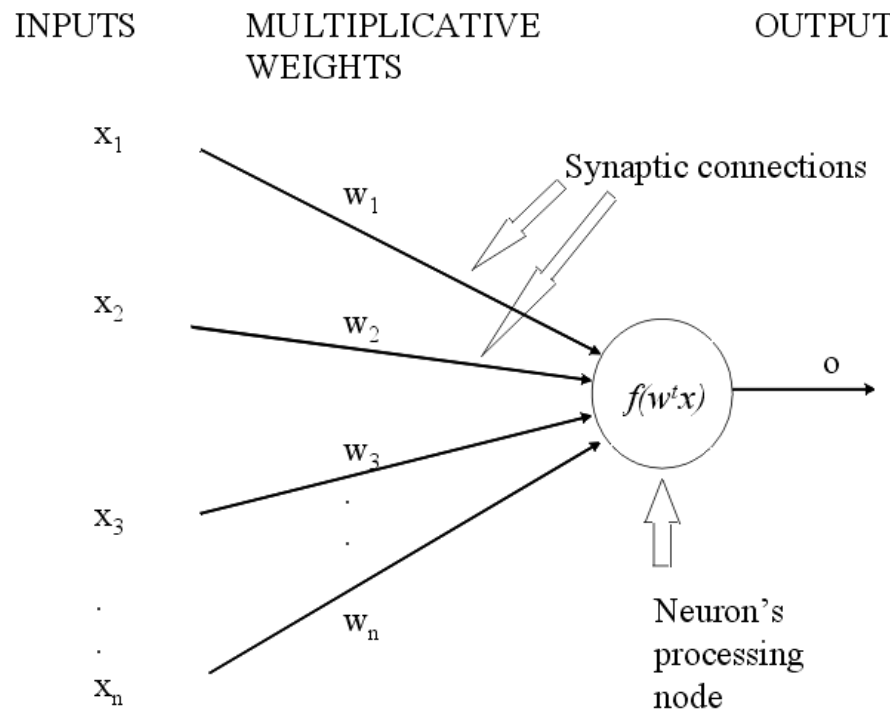

Figure 2. General representation of an artificial neural network neuron consisting of a processing node and synaptic input and output connections. 
(Veselis et al., 1991; Zurada, 1992; C ross et al., 1995).

There are many different types of artificial neural models that usedifferent configurations and learning rules (Zurada, 1992). A schematic representation of an artificial neuron is shown in Figure 2.

The neuron output signal is given by the following general rule:

$$
\begin{gathered}
0=f\left(\mathrm{w}^{\mathrm{t}} \mathrm{x}\right) \\
\text { or } \\
o=f\left(\sum_{i=1}^{n} w_{i} x_{i}\right)
\end{gathered}
$$

where $w$ is the weight vector and $x$ is the input vector. All vectors defined here are column vectors, and superscript $t$ denotes a transposition. The function $f\left(w^{t} x\right)$ is called the activation function (Zurada, 1992).

In this thesis, the hidden and output neurons of the neural models follow continuous nonlinear activation functions of the type:

$$
o_{j}=\frac{1}{1+e^{-\sum_{i} w_{j i} o_{i}+w_{j} \theta}}
$$

where 0 denotes output of a neuron, $\mathrm{w}_{\mathrm{i}}$ denoteconnection weights, o denotes the output of a neuron in the previous layer, $w_{i} \theta$ denotes the adjustable threshold for the neuron, i denotes the number of inputs to the neuron from the previous layer and $j$ denotes the current neuron (Anonymous, 1998).

Training of the network in this study followed the delta learning rule, and first involved initializing the connection weights to small random numbers. The network then calculated its own output value from the first input record and compared this to the target value presented to the output neuron. The difference was the error signal. If there was no error then no learning took place. 0 therwise, the interconnecting weights were changed to reduce the error by an amount proportional to the product of the error signal and the first derivative of the nonlinear activation function (the delta learning rule; Zurada, 1992; Anonymous, 1998):

$$
r=\left[d_{i}-f\left(w_{i}^{t} x\right)\right] f^{\prime}\left(w_{i}^{t} x\right)
$$

$N$ eural networks have been used in various applications in clinical medicine. Examples are diagnostic problems (appendicitis, myocardial infarction, pulmonary embolism), image analysis, waveform analysis (ECG, EEG), and outcome prediction. Best artificial neural models have performed as well, or better, than experienced clinicians (Baxt, 1995).

In Study 4, artificial neural models were used for analyzing the physiologic data in the following fashion: All individual data points for heart rate, systolic and diastolic blood pressure, end-tidal carbon dioxide $\left(\mathrm{PetC}_{2}\right)$ concentration, and arterial blood oxygen saturation $\left(\mathrm{SpO}_{2}\right)$ throughout the duration of each anesthetic were entered manually from the anesthesia records into a database, along with age, gender, weight and height. M aximum, minimum and mean values of these variables were calculated for each patient. The use of anticholinergic or sympathetic agonist medication may influence themeasured physiologic parameters. Therefore, the dose $(\mathrm{mg} / \mathrm{kg})$ of atropine, ethilephrine, or ephedrine given to patients with or without awareness was analyzed and compared with $M$ ann-W hitney test.

The artificial neural networks were configured using commercially available neural network software (N N M odel $32^{\circledR}$, N eural Fusion, N ew York, NY) running on a desktop computer. The variables used in the analysis, were first normalized using the N O RM DIST function in M icrosoft Excel 5.0 spreadsheet (M icrosoft Corporation, Redmond, WA) and subsequently divided to training and testing data sets in a random fashion. The training data set consisted of 412 patients without awareness and 20 patients with awareness. The complete data of the 20 patients with aware ness were multiplied fivefold resulting in a 
training database of 100 records with awareness, and 412 without awareness. These records were presented to the neural network program in a random order. The remaining data of 13 patients with awareness and 98 patients without awareness were reserved for the testing of the trained network.

We used a threelevel back-error propagation neural network model, fully interconnected between layers (Zurada, 1992; C ross et al., 1995). The summary functions of the physiologic and demographic parameters in different combinations formed the in put values to the network, and the outcome was reported by a single continuous-function output neuron designating target $1=$ awareness and $0=$ no awareness. The number of neurons in the intermediate (hidden) layer of the network was changed between three and ten. A learning rate of 0.75 and a momentum constant $\alpha=0.8$ were used for all neural models (H aykin, 1999). The training data matrix was presented to the network 1,000 times or until error tolerance of $\pm 5 \%$ of the total error was reached, whichever came first. The resulting models were analyzed by feeding the test data matrix values into the network.

The success of randomization of patients into training and testing groups was evaluated by comparing these groups with chisquared and Student's t-tests. The goodness of the neural models in indicating awareness with recall in the testing data set were estimated by cal culating the sensitivity and specificity of any given model. Subsequently, the likelihood ratio was calculated as

$$
L R=\frac{\text { sensitivity }}{1-\text { specificity }}
$$

The best neural models were chosen using the likelihood ratio as the criterion. Themodels generated by the study were compared with the $M$ ann-W hitney test.
The positive and negative predictive values of the test were cal culated using the Bayes' theorem (Altman, 1991). The prevalence of the condition of interest necessary for this calculation was assumed to be $0.5 \%$. Also, prediction probability $\left(P_{k}\right)$ as suggested by Smith et al. (1996) was calculated for the neural models.

The training of the neural models includes reduction of error. The success of this process may be estimated by calculating the root-mean square normalized error:

$$
E_{r m s}=\frac{1}{P K} \sqrt{\sum_{p=1}^{P} \sum_{k=1}^{K}\left(d_{p k}-o_{p k}\right)^{2}}
$$

where $P$ is the number of training patterns, $K$ is the number of outputs, $d$ is the desired (target) output, and 0 is the observed output (Zurada, 1992).

Classifying networks, like those in the present study, may further beevaluated in the classifying task by calculating the decision error of the network:

$$
E_{d}=\frac{N_{e r r}}{P K}
$$

where $\mathrm{N}_{\text {er }}$ is the total number of bit errors resulting at $K$ thresholded outputs over the complete training cycle (Zurada, 1992).

\subsection{Feedback information}

In Study 2, feedback information for the cardiac anesthesiologists was used to examinethe effect of that information as a possible way of reducing the incidence of awareness with recall. The feedback consisted of general information of possibilities to reduce conscious awareness during general anesthesia. Written information of the same matter was also included in theeducation files of the clinic where the study was performed. This information recommends continuous use of either inhalation or i.v. anesthetic agents, monitoring of 
end-tidal concentrations of inhalation anesthetic agents, minimizing neuromuscular blockade, and encourages noticing clinical signs of light anesthesia. Also specific suggestions of dosages for some anesthetic agents commonly used in cardiac anesthesia were given.

\subsection{Psychiatric interview and testing}

In Study 1, the patients with awareness were recruited to a psychiatric interview, testing, and follow-up. Simultaneously matched control patients were included in similar psychiatric scrutiny. Thematching was made for the following factors: age \pm 5 years, sex, weight \pm $5 \mathrm{~kg}$, body mass index $\pm 3 \%$, type of surgery, date of surgery \pm 3 weeks, and ASA physical status.

If the patients with the experience of aware ness and the matched control patients were able and willing to giveinformed consent, they were interviewed by a psychiatrist immediately after the operation. If the patient had already left the hospital, the first interview was done over the telephone and the first face-to-face interview within two weeks after the operation. The patients were reinterviewed 2 and 6 months after the operation.

The interviewer was blinded to the presence of absence of awareness during the operation. All diagnoses were made according to strict D SM -III-criteria by using the Structured C linical Interview for DSM -III-R N on Patient edition (SCID -NP) (Spitzer et al., 1990a) and Structured Clinical Interview for DSM -III-R-Personality D isorders (SCID - II) (Spitzer et al., 1990b).

Patients completed the Symptom-C hecklist-90-Revised (SCL-90-R), a measure of psychological distress (D egoratis et al., 1973). SCL-90-R was used to make the diagnostic structured interview complete. Patients were also asked to fill out the I mpact of Event Scale
(IES), a measure which indexes symptomsthat characterize PT SD (H orowitz et al., 1979).

\subsection{Statistical methods}

D ifferences in frequencies were compared with the chi-squared test (with Yate's continuity correction, as appropriate), except in Study 2 where Fisher's exact test also was used. For other paired comparisons, Student's t-test or the $M$ ann-W hitney $U$-test was used, according to the distribution of the data. Analysis of variance (AN O VA) was used to detect statistical significance of changesin the use of medications over time (Study 1). Post-hoc comparisons were performed with Tukey's honestly significant test.

The Poisson regression model, a conventional statistical technique which allows an adjustment for a rare event such as awareness with recall, was used in Studies 1, 3 and 4. In the Poisson regression, the relationship between an observed count and a set of explanatory variables is analyzed with a Poisson distribution. For large $n$ and small p, e.g., awareness with recall during general anesthe sia, binomial probabilities are approximated by the Poisson distribution. The outcome (awareness or no awareness) formed the dependent factor in these regression models. Possible factors explaining intraoperative awareness were entered in the regression as independent factors. For significant explanatory factors, relative risk for one unit change of the explaining factor was calculated.

For some categorical comparisons of two groups with respect to the risk of awareness and recall, relativerisk estimation was also used (Altman, 1991). 95 \% Cl based on the N ormal distribution or the Poisson distribution, according to the distribution of the data, were al so calculated.

For all statistical tests, a $p$-value less than 0.05 was considered statistically significant. 


\section{Results}

5.1.The nature of the experience of awareness during general anesthesia

The patients with awareness and recall from all the Studies 1-5 are summarized in the Appendix. There were seventy patients who suffered from awareness and recall during general anesthesia. The anesthetics for these patients wereadministered between 1976 and 1998 with a median of 1994 . Forty (57 \%) of the patients were female, and thirty (43\%) male. The experience of these patients during the episode of awareness is summarized in Table 7.

\subsection{Incidence of awareness with recall during general surgery}

The incidence of awareness with recall during non-cardiac surgery procedures requiring general anesthesia is shown in Table 8

\subsection{Incidence of awareness with recall during open heart surgery}

The incidence of awareness with recall during

Table 7. Experiences during episode of awareness. Numbers of patients and percentages of those who responded to the question are shown.

\begin{tabular}{|c|c|c|c|c|c|c|c|c|c|}
\hline & \multicolumn{9}{|c|}{ Recollection } \\
\hline & Auditory & Visual & Tactile & Pain & $\begin{array}{l}\text { Tried to } \\
\text { move }\end{array}$ & $\begin{array}{l}\text { Able to } \\
\text { move }\end{array}$ & $\begin{array}{l}\text { Immediate } \\
\text { understanding }\end{array}$ & $\begin{array}{l}\text { Immediate } \\
\text { anxiety }\end{array}$ & $\begin{array}{l}\text { Awareness as the most } \\
\text { unpleasant experience } \\
\text { during operation }\end{array}$ \\
\hline Yes & $\begin{array}{c}42 \\
(62.7)\end{array}$ & $\begin{array}{c}12 \\
(17.9)\end{array}$ & $\begin{array}{c}43 \\
(64.2)\end{array}$ & $\begin{array}{c}22 \\
(31.9)\end{array}$ & $\begin{array}{c}28 \\
(82.4)\end{array}$ & $\begin{array}{c}6 \\
(20.0)\end{array}$ & $\begin{array}{c}53 \\
(82.8)\end{array}$ & $\begin{array}{c}29 \\
(61.7)\end{array}$ & $\begin{array}{c}7 \\
(16.7)\end{array}$ \\
\hline No & $\begin{array}{c}25 \\
(37.3)\end{array}$ & $\begin{array}{c}55 \\
(82.1)\end{array}$ & $\begin{array}{c}24 \\
(35.8)\end{array}$ & $\begin{array}{c}47 \\
(68.1)\end{array}$ & $\begin{array}{c}6 \\
(17.6)\end{array}$ & $\begin{array}{c}24 \\
(80.0)\end{array}$ & $\begin{array}{c}11 \\
(17.2)\end{array}$ & $\begin{array}{c}18 \\
(38.3)\end{array}$ & $\begin{array}{c}35 \\
(83.3)\end{array}$ \\
\hline $\begin{array}{l}\text { N umber } \\
\text { responded }\end{array}$ & 67 & 67 & 67 & 69 & 34 & 30 & 64 & 47 & 42 \\
\hline $\begin{array}{l}\text { No } \\
\text { response }\end{array}$ & 3 & 3 & 3 & 1 & 36 & 40 & 6 & 23 & 28 \\
\hline Total & 70 & 70 & 70 & 70 & 70 & 70 & 70 & 70 & 70 \\
\hline
\end{tabular}


Table 8. Incidence of awareness during non-cardiac procedures requiring general anesthesia (Study 1).

\begin{tabular}{lll}
\hline Awareness Group & Awareness / Number of interviews & Percentage $(95 \% \mathrm{Cl})$ \\
\hline Group 1 & 9 / 2,612 & $0.34(0.16-0.65)$ \\
Group 2 & $6 / 2,612$ & $0.23(0.08-0.50)$ \\
Group 3 & $4 / 2,612$ & $0.15(0.04-0.39)$ \\
Groups 2-3 & $\mathbf{1 0 ~ / ~ 2 , 6 1 2 ~}$ & $\mathbf{0 . 3 8 ( 0 . 1 8 - 0 . 7 0 )}$ \\
Total & $\mathbf{1 9} / \mathbf{2 , 6 1 2}$ & $\mathbf{0 . 7 3 ( 0 . 4 4 - 1 . 1 4 )}$ \\
\hline
\end{tabular}

open heart surgery is shown in Table 9.

\subsection{Differences in anesthetic drug dosing between patients with and without awareness}

Possible differences in anesthetic agent dosing were studied using Poisson regression models. There were differences in the dosing of isoflurane and propofol during anesthesia for general surgery (Study 1), and midazolam during cardiac surgery (Study 3) as summarized in Tables 10 and 11, respectively.

\subsection{Conventional statistical methods and artificial neural networks in detecting awareness from monitored physiologic variables}

Artificial neural modelsand conventional sta- tistical methods (Poisson regression) werecompared in Study 4 in relation to their ability to discriminate between patients with and without intraoperative awareness. A total of 52 different neural models were tested. The two best neural models by their ability to identify patients with awareness in the test data set both had a likelihood ratio of 11.3. T heir sensitivity and specificity in the discriminating task were $23 \%$ and $98 \%$, respectively (Figure 3).

Both models had 20 input values: mean, minimum, maximum and number of recorded measurements for end-tidal carbon dioxide concentration, arterial blood oxygen saturation, systolic and diastolic blood pressure, and heart rate. The models had 7 and 8 intermediate layer neurons, and output ranges from 0.299 to 1.176 and from -0.331 to 1.090 in

Table 9. The incidence of awareness during open heat surgery.

\begin{tabular}{llll}
\hline Study & Awareness Group & Awareness / Number of interviews & Percentage $(95 \% \mathrm{Cl})$ \\
\hline $\begin{array}{l}\text { Study 2, } \\
\text { year 1992 }\end{array}$ & Group 3 & $\mathbf{4} / \mathbf{9 9}$ & $\mathbf{4 . 0}(\mathbf{1 . 1 - 1 0 . 3 )}$ \\
Study 2. & Group 2 & $1 / 204$ & \\
year 1993 & Group 3 & $2 / 204$ & $0.49(0.01-2.73)$ \\
& Total & $\mathbf{3} / \mathbf{2 0 4}$ & $0.98(0.12-3.54)$ \\
Study 3, & Group 1 & $16 / 929$ & $\mathbf{1 . 5}(\mathbf{0 . 3 - 4 . 3 )}$ \\
Year 1995 & Group 2 & $4 / 929$ & $1.72(0.98-2.80)$ \\
& Group 3 & $1 / 929$ & $0.43(0.12-1.10)$ \\
& Groups 2-3 & $\mathbf{5} / \mathbf{9 2 9}$ & $0.11(0.003-0.60)$ \\
& Total & $\mathbf{2 1} / \mathbf{9 2 9}$ & $\mathbf{0 . 5 4}(\mathbf{0 . 1 7 - 1 . 2 6 )}$ \\
& & & $\mathbf{2 . 2 6}(\mathbf{1 . 4 0 - 3 . 4 6 )}$ \\
\hline
\end{tabular}


Table 10. Dose of anesthetic agents given to patients with awareness and recall (groups 1-3) and control patients during general surgery. The probability of the Poisson regression model as well as the relative risk derived from the model is also given.

\begin{tabular}{|c|c|c|c|c|c|c|c|c|}
\hline \multirow[b]{3}{*}{ Anesthetic } & \multicolumn{3}{|c|}{ Patients with awareness } & \multicolumn{3}{|c|}{ Patients without awareness } & \multirow[b]{3}{*}{$\begin{array}{l}p \text { (Poisson } \\
\text { regression model) }\end{array}$} & \multirow[b]{3}{*}{$\begin{array}{l}\text { Relative risk for one } \\
\text { unit change in dose }\end{array}$} \\
\hline & \multirow[b]{2}{*}{$\mathrm{n}$} & \multicolumn{2}{|c|}{ Dose } & \multirow[b]{2}{*}{$n$} & \multicolumn{2}{|c|}{ Dose } & & \\
\hline & & M edian & Range & & M edian & Range & & \\
\hline $\begin{array}{l}\text { Thiopental } \\
\text { (mg/kg) }\end{array}$ & 8 & 6.0 & $4.2-8.3$ & 130 & 5.6 & $2.2-8.9$ & 0.59 & N.A. \\
\hline $\begin{array}{l}\text { Propofol } \\
\text { ( } \mu \mathrm{g} / \mathrm{kg} / \mathrm{min})\end{array}$ & 10 & 73 & $23-357$ & 90 & 228.2 & $22-760$ & 0.03 & 0.99 \\
\hline $\begin{array}{l}\text { Isoflurane } \\
\left(\text { FiAA\%/min }{ }^{11}\right)\end{array}$ & 12 & 0.42 & $0.12-0.75$ & 118 & 0.65 & $0.05-1.71$ & 0.003 & 0.70 \\
\hline $\begin{array}{l}\text { Enflurane } \\
\left(\text { FiAA\%/min }{ }^{1)}\right)\end{array}$ & 2 & 0.69 & $0.26-1.11$ & 32 & 0.58 & $0.28-1.10$ & N.A. & N.A. \\
\hline $\begin{array}{l}\text { Fentanyl } \\
\text { (ng/kg/min) }\end{array}$ & 16 & 41 & $23-99$ & 163 & 42.6 & $18-230$ & 0.82 & N.A. \\
\hline $\begin{array}{l}\text { Alfentanil } \\
(\mu \mathrm{g} / \mathrm{kg} / \mathrm{min})\end{array}$ & 3 & 1.2 & $0.6-1.8$ & 57 & 1.54 & $0.2-4.0$ & N.A & N.A. \\
\hline $\begin{array}{l}\text { Atracurium } \\
(\mu \mathrm{g} / \mathrm{kg} / \mathrm{min})\end{array}$ & 13 & 9.3 & $4.4-12.4$ & 149 & 8.1 & $2.4-67.3$ & 0.72 & N.A. \\
\hline $\begin{array}{l}\text { D iazepam as } \\
\text { premedication } \\
(\mathrm{mg} / \mathrm{kg})\end{array}$ & 6 & 0.14 & $0.07-0.19$ & 131 & 0.15 & $0.07-029$ & N.A & N.A. \\
\hline
\end{tabular}

1) The inspiratory concentration that would have been delivered had the total dose of the volatile anesthetic agent been divided equally to the whole duration of anesthesia.

the test data set, respectively. The root-meansquare normalized errors for thesemodels were 0.967 and 0.922 , respectively. D ecision errors in the training data set were 0 and 0.0098 , respectively. In the test data set, the values indicated by the neural models were not different between groups of patients with and without awareness by $M$ ann-W hitney test. The prediction probabilities $\mathrm{P}_{\mathrm{k}}$ (SE) for the best neural models were $0.66(0.08)$ and 0.60 $(0.10)$, respectively. If we assume that the incidence of awareness with recall is $0.5 \%$, we can calculate a negative predictive value of 99.6 $\%$ for the artificial neural models.

Theprognostic significance of themeasured variables as analyzed with the Poisson regres- sion are given in Table 12. In this analysis, high systolic blood pressure, high minimum diastolic blood pressure, and high mean and maximum heart rate were significant predictors of intraoperative awareness with recall.

\subsection{The possibility of reducing the incidence of awareness by giving feedback information to the anesthesiologists}

In study 2, the incidence of awareness fell (from $4 \%$ to $1.5 \%, n s$.) after the cardiac anesthesiologists received general and feedback information about awareness during anesthe sia. The relative risk of awareness and recall $(95 \% \mathrm{Cl}$ ) in 1992 was $275 \%$ (range 63 - 
Table 11. Dose of anesthetic drugs during cardiac surgery given to patients with and without awareness and recall.

\begin{tabular}{|c|c|c|c|c|c|c|c|c|}
\hline \multirow[b]{3}{*}{ Anesthetic } & \multicolumn{3}{|c|}{ Patients with awareness } & \multicolumn{3}{|c|}{ Patients without awareness } & \multirow[b]{3}{*}{$\begin{array}{l}\mathrm{P} \text { (Poisson } \\
\text { regression } \\
\text { mode) }\end{array}$} & \multirow[b]{3}{*}{$\begin{array}{l}\text { Relative risk for one } \\
\text { unit change in dose }\end{array}$} \\
\hline & \multirow[b]{2}{*}{$n$} & \multicolumn{2}{|c|}{ Dose } & \multirow[b]{2}{*}{$n$} & \multicolumn{2}{|c|}{ Dose } & & \\
\hline & & M edian & Range & & M edian & Range & & \\
\hline $\begin{array}{l}\text { Diazepam } \\
(\mu \mathrm{g} / \mathrm{kg} / \mathrm{min})\end{array}$ & 11 & 0.47 & $0.24-0.96$ & 113 & 0.60 & $0.11-2.01$ & 0.149 & N.A. \\
\hline $\begin{array}{l}\text { Lorazepam } \\
(\mu \mathrm{g} / \mathrm{kg} / \mathrm{min})\end{array}$ & 2 & 0.14 & $0.10-0.18$ & 33 & 0.17 & $0.08-0.53$ & 0.491 & N.A. \\
\hline $\begin{array}{l}\text { M idazolam } \\
(\mu \mathrm{g} / \mathrm{kg} / \mathrm{min})\end{array}$ & 10 & 0.88 & $0.46-1.94$ & 157 & 1.14 & $0.29-3.18$ & 0.047 & 0.13 \\
\hline $\begin{array}{l}\text { Propofol } \\
\text { ( } \mu \mathrm{g} / \mathrm{kg} / \mathrm{min} \text { ) }\end{array}$ & 2 & 26.5 & $4.5-48.6$ & 24 & 4.4 & $0.4-88.2$ & 0.653 & N.A. \\
\hline $\begin{array}{l}\text { Thiopental } \\
(\mu \mathrm{g} / \mathrm{kg} / \mathrm{min})\end{array}$ & 2 & 11.4 & $4.8-18.0$ & 65 & 9.7 & $2.4-49.7$ & 0.713 & N.A. \\
\hline $\begin{array}{l}\text { Alfentanil } \\
(\mu \mathrm{g} / \mathrm{kg} / \mathrm{min})\end{array}$ & 1 & & 1.01 & 35 & 1.45 & $0.29-3.99$ & 0.319 & N.A. \\
\hline $\begin{array}{l}\text { Fentanyl } \\
(\mu \mathrm{g} / \mathrm{kg} / \mathrm{min})\end{array}$ & 13 & 0.22 & $0.11-0.32$ & 189 & 0.22 & $0.02-6.45$ & 0.841 & N.A. \\
\hline $\begin{array}{l}\text { Sufentanil } \\
(\mu \mathrm{g} / \mathrm{kg} / \mathrm{min})\end{array}$ & 7 & 0.04 & $0.02-0.05$ & 79 & 0.04 & $0.01-0.18$ & 0.711 & N.A. \\
\hline $\begin{array}{l}\text { Pancuronium } \\
\text { ( } \mu \mathrm{g} / \mathrm{kg} / \mathrm{min})\end{array}$ & 20 & 0.52 & $0.35-0.82$ & 297 & 0.56 & $0.06-1.00$ & 0.277 & N.A. \\
\hline $\begin{array}{l}\text { Enflurane } \\
\left(\text { FiAA\%/min }{ }^{11}\right)\end{array}$ & 7 & 0.12 & $0.09-0.63$ & 91 & 0.37 & $0.04-0.87$ & 0.106 & N.A. \\
\hline $\begin{array}{l}\text { Isoflurane } \\
\left(\text { FiAA\%/min }{ }^{11}\right)\end{array}$ & 13 & 0.34 & $0.14-0.60$ & 205 & 0.33 & $0.02-0.95$ & 0.789 & N.A. \\
\hline
\end{tabular}

1) The inspiratory concentration that would have been delivered had the total dose of the volatile anesthetic been divided equally to the whole duration of anesthesia.

$1204 \%$ ) of the risk in 1993. Simultaneously, the use of continuous infusions, or the use of a combination of an anesthetic infusion and inhalation, increased significantly, from $14 \%$ of the anesthetics to $36 \%(p<0.001)$ and 19 $\%$ to $56 \%(p \varangle 0.001)$, respectively. Also, the doses of diazepam, fentanyl, and enflurane increased while doses of pancuronium decreased (Table 13).

In Study 1, there was an increase in the dosing of isoflurane over time during the course of the study. Simultaneously, a decreasing trend in awareness was noted. Therewere, however, no significant changes in the incidence of awareness over timeduring the study (Table 14).

\subsection{Psychiatric consequences of awareness during anesthesia}

In Study 1, seven patients with awareness and recall were evaluated for psychiatric interview and follow-up. Two patients had to be ex- 

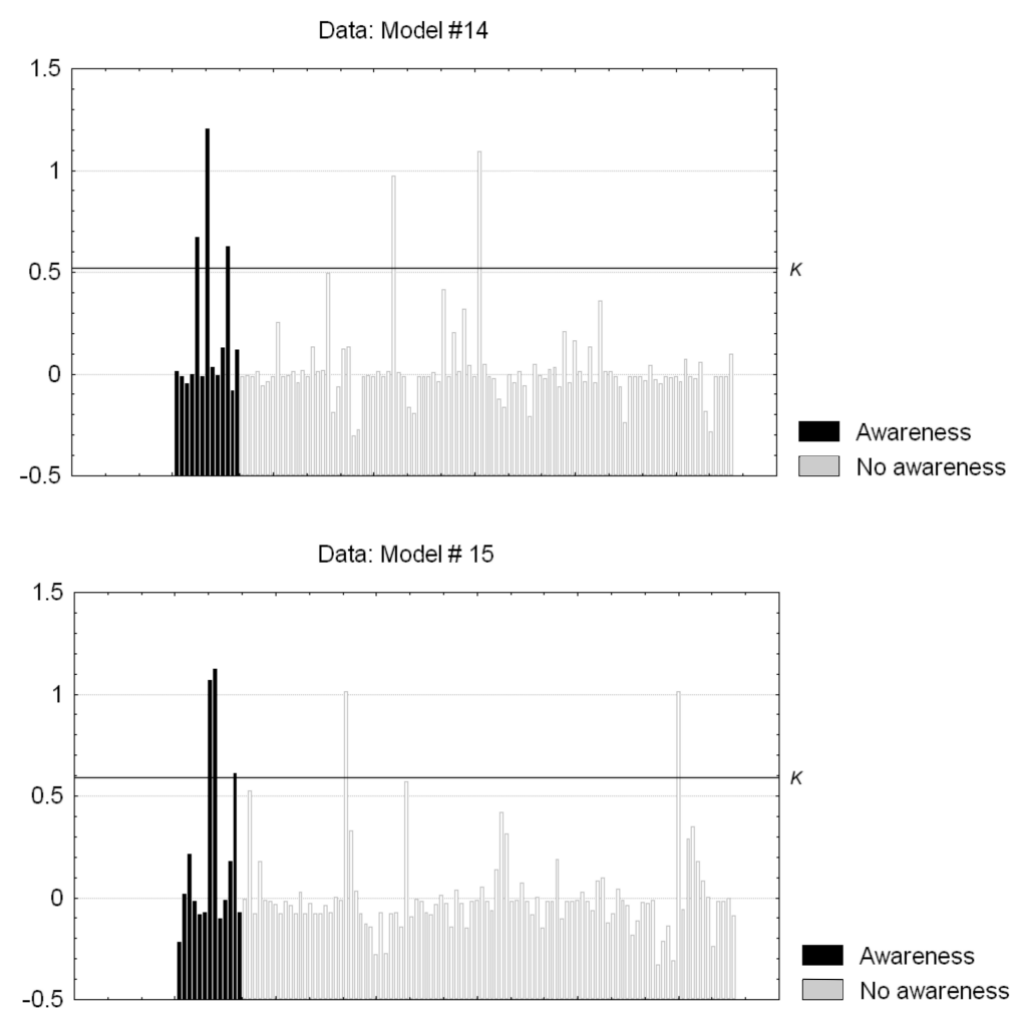

Figure 3. The values indicated by the two best neural model for each case of the test data set. Each individual bar in the graphs represents the value given by the neural model to each patient in the test data set. Patients with awareness are shown by black bars and patients without awareness are shown in gray. Value close to 1 indicates awareness with recall while value close to 0 indicates no awareness. The decision threshold $(K)$ between awareness and no awareness is shown as a straight line.

cluded from theinterview, one because hewas in very poor physical condition and did not remember the experience of awareness, and the other because she was too incoherent to follow the structured psychiatric interview. 0 ne of the fiveremaining patients felt intense fear during the experience of awareness and had some sleep disturbances afterwards. $\mathrm{H}$ owever, she did not meet the criteria of PTSD . $\mathrm{N}$ one of the other patients followed-up experienced any after-effects. Three of five patients with awareness had a history of major depression, and preoperative symptoms of depression and anxiety. N one of the control group patients had any preoperative psychiatric disorders. The mental state of the two depressive patients did not significantly change after the operation, but one patient was treated with antidepressant medication and recovered.

\subsection{Medico-legal consequences of awareness with recall in Finland}

Four insurance claims concerning awareness during anesthesia were filed in the PIA be tween M ay 1, 1987 and D ecember 31, 1993 (Study 5). This represents $0.02 \%$ of all Patient Insurance claims ( $n=23,363$ ) filed during that period. Further cases were collected for Study 4: between Jan 1, 1994 and June 15, 1997 another seven claims, concerning awareness at least as a part of the complaint, werefiled. Thedetails of all these 11 cases with 
Table 12. Demographic and monitored parameters for patients with awareness and recall and those without. Number of patients analyzed, median (ranges), and results of the Poisson regression model are given.

\begin{tabular}{|c|c|c|c|c|c|c|}
\hline \multirow[b]{3}{*}{ Age (years) } & \multicolumn{2}{|c|}{ Patients with awareness } & \multicolumn{2}{|c|}{ Patients without awareness } & \multicolumn{2}{|c|}{ Poisson regression } \\
\hline & $n$ & median (range) & $n$ & median (range) & $p$ & $\begin{array}{l}\text { Relative risk for one } \\
\text { unit increase in the } \\
\text { value of the variable }\end{array}$ \\
\hline & 33 & $37(23-82)$ & 510 & $43(12-90)$ & 0.20 & \\
\hline $\operatorname{Sex}(f / m)$ & $28 / 5$ & & $373 / 137$ & & 0.16 & \\
\hline H eight (cm) & 31 & $168(150-180)$ & 507 & $167(145-194)$ & 0.73 & \\
\hline Weight (kg) & 32 & $70(28.5-112)$ & 509 & $68(40-142)$ & 0.94 & \\
\hline Body M ass Index & 31 & $24.5(16.4-37.9)$ & 507 & $24.4(15.4-42.9)$ & 0.74 & \\
\hline ET CO 2 mean $(\%)$ & 28 & $4.7(3.7-6.0)$ & 418 & $4.7(3.6-6.2)$ & 0.55 & \\
\hline $\begin{array}{l}\text { ET CO2 minimum } \\
(\%)\end{array}$ & 28 & $4.5(3.4-6.0)$ & 418 & $4.4(3.2-6.2)$ & 0.60 & \\
\hline $\begin{array}{l}\text { ET CO } 2 \text { maximum } \\
(\%)\end{array}$ & 28 & $4.9(3.7-7.8)$ & 418 & $5.0(3.7-6.8)$ & 0.42 & \\
\hline SaO 2 mean (\%) & 26 & $98(92-100)$ & 497 & $98(82-100)$ & 0.33 & \\
\hline SaO 2 minimum (\%) & 25 & $97(90-100)$ & 496 & $97(60-100)$ & 0.90 & \\
\hline SaO 2 maximum (\%) & 26 & $99(96-100)$ & 497 & $99(94-100)$ & 0.75 & \\
\hline $\begin{array}{l}\text { Systolic BP mean } \\
(\mathrm{mmH} \mathrm{g})\end{array}$ & 33 & $129(75-201)$ & 508 & $118(80-206)$ & 0.0005 & 1.03 \\
\hline $\begin{array}{l}\text { Systolic BP minimum } \\
\text { (mmH g) }\end{array}$ & 33 & $108(55-180)$ & 506 & $100(55-175)$ & 0.0022 & 1.03 \\
\hline $\begin{array}{l}\text { Systolic BP maximum } \\
\text { ( } \mathrm{mmH} \mathrm{g})\end{array}$ & 33 & $150(100-233)$ & 508 & $145(85-258)$ & 0.0083 & 1.02 \\
\hline $\begin{array}{l}\text { Diastolic BP mean } \\
(\mathrm{mmH} \mathrm{g})\end{array}$ & 29 & $77(42-123)$ & 410 & $75(48-140)$ & 0.11 & \\
\hline $\begin{array}{l}\text { Diastolic BP } \\
\text { minimum (mmH g) }\end{array}$ & 29 & $60(34-112)$ & 410 & $60(35-105)$ & 0.0395 & 1.03 \\
\hline $\begin{array}{l}\text { D iastolic BP } \\
\text { maximum (mmH g) }\end{array}$ & 29 & $92(56-152)$ & 410 & 95 (55-145) & 0.8563 & \\
\hline $\begin{array}{l}\text { Heart rate mean } \\
(/ \mathrm{min})\end{array}$ & 33 & 77 (58-117) & 508 & $74(50-120)$ & 0.0288 & 1.03 \\
\hline $\begin{array}{l}\text { H eart rate minimum } \\
\text { (/min) }\end{array}$ & 33 & $66(43-105)$ & 507 & $65(40-105)$ & 0.2521 & \\
\hline $\begin{array}{l}\text { Heart rate maximum } \\
\text { (/min) }\end{array}$ & 33 & 95 (70-150) & 508 & $90(55-160)$ & 0.0002 & 1.03 \\
\hline
\end{tabular}


Table 13. Intravenous anesthetic agents used during the two years of Study 2; number of patients and dose (median and $90 \%$ (central range).

\begin{tabular}{lcc}
\hline & 1992 & 1993 \\
\hline $\begin{array}{l}\text { Diazepam } \\
(\mu \mathrm{g} / \mathrm{kg} / \mathrm{min})\end{array}$ & 66 & 168 \\
Lorazepam & $0.67(0.21-1.16)$ & $0.78(0.24-1.57)^{* * *}$ \\
$(\mu \mathrm{gg} / \mathrm{kg} / \mathrm{min})$ & 6 & 11 \\
M idazolam & $0.16(0.12-0.19)$ & $0.17(0.12-0.30)$ \\
$(\mu \mathrm{g} / \mathrm{kg} / \mathrm{min})$ & 12 & 41 \\
Thiopental & $1.2(0.4-2.2)$ & $0.8(0.5-1.4)^{* *}$ \\
(mg/kg/min) & 44 & 75 \\
Propofol & $0.010(0.003-0.037)$ & $0.008(0.003-0.032)$ \\
$(\mu \mathrm{g} / \mathrm{kg} / \mathrm{min})$ & 7 & 15 \\
O ther & $2.1(0.7-3.8)$ & $3.2(0.3-55.5)$ \\
Fentanyl & - & 4 \\
$(\mu \mathrm{gg} / \mathrm{kg} / \mathrm{min})$ & 95 & 191 \\
O ther analgesics & 1 & $0.24(0.11-0.34) * * *$ \\
Pancuronium & $0.15(0.08-0.27)$ & 14 \\
$(\mu \mathrm{g} / \mathrm{kg} / \mathrm{min})$ & 1 & 202 \\
Vecuronium & 97 & $0.58(0.38-0.94) * * *$ \\
$(\mu \mathrm{gg} / \mathrm{kg} / \mathrm{min})$ & $0.69(0.37-1.02)$ & 2 \\
\hline
\end{tabular}

** $p<0.01,{ }^{* * *} p<0.001$

Table 14. Interviews and awareness with recall and mean doses of isoflurane and atracurium during the year of Study 1.

\begin{tabular}{lcccccc}
\hline \multirow{2}{*}{ Time period } & \multicolumn{3}{c}{ Number of patients and percentage of total } & \multicolumn{3}{c}{ D ose } \\
\cline { 2 - 7 } & $\begin{array}{c}\text { Number of } \\
\text { interviews }\end{array}$ & $\begin{array}{c}\text { Awareness } \\
\text { group 1 }\end{array}$ & $\begin{array}{c}\text { Awareness } \\
\text { group 2 }\end{array}$ & $\begin{array}{c}\text { Awareness } \\
\text { group 3 }\end{array}$ & $\begin{array}{c}\text { Isoflurane } \\
(\mathrm{Fi} \%)\end{array}$ & $\begin{array}{c}\text { Atracurium } \\
(\mu \mathrm{g} / \mathrm{kg} / \mathrm{min})\end{array}$ \\
\hline $\begin{array}{l}\text { Three months } \\
\text { preceding the study }\end{array}$ & - & - & - & - & 0.55 & 7.9 \\
$\begin{array}{l}\text { 1st quarter of the } \\
12 \text { months }\end{array}$ & 948 & $5(0.5 \%)$ & $3(0.3 \%)$ & $1(0.1 \%)$ & 0.58 & $10.5^{1)}$ \\
$\begin{array}{l}\text { 2nd quarter of the } \\
12 \text { months }\end{array}$ & 740 & $1(0.1 \%)$ & $3(0.4 \%)$ & $2(0.3 \%)$ & $0.70^{1)}$ & 8.6 \\
$\begin{array}{l}\text { 3rd quarter of the } \\
12 \text { months } \\
\text { 4th quarter of the }\end{array}$ & 452 & $1(0.2 \%)$ & 0 & $1(0.2 \%)$ & 0.68 & 8.6 \\
$\begin{array}{l}12 \text { months } \\
\text { Total }\end{array}$ & 471 & $2(0.4 \%)$ & 0 & 0 & $0.73^{1)}$ & 8.7 \\
\end{tabular}

\footnotetext{
1) $p \varangle 0.05$ vs. the three month period preceding the study.

${ }^{2)}$ Total number of interviews was 2612 . We were unable to locate the operation day of one patient, as the matching social security number could not be found in the hospital computer files.
} 
Table 15. The patient claims filed because of awareness during general anesthesia, and the compensations granted.

\begin{tabular}{|c|c|c|c|c|}
\hline $\begin{array}{l}\text { Age } \\
\text { (yrs) }\end{array}$ & $\begin{array}{l}\text { Sex } \\
(\mathrm{m} / \mathrm{f})\end{array}$ & Experience & Operation & $\begin{array}{l}\text { Compensation } \\
\text { (FIM) }\end{array}$ \\
\hline 53 & $\mathrm{~m}$ & $\begin{array}{l}\text { D etails of a thoracotomy } \\
\text { operation, pain. }\end{array}$ & Thoracotomy & 4,000 \\
\hline 27 & $\mathrm{~m}$ & $\begin{array}{l}\text { Intubation, operation details, } \\
\text { pain }\end{array}$ & Appendectomy & 9,600 \\
\hline 41 & $f$ & Pain, impossibility to move. & $\begin{array}{l}\text { Evacuation of abdominal } \\
\text { hematoma }\end{array}$ & 5,000 \\
\hline 36 & $f$ & Pain, inability to move. & Laparoscopic sterilization & 7,000 \\
\hline 37 & $f$ & Pain, heard discussions. & Tonsillectomy & 4,500 \\
\hline 40 & $\mathrm{~m}$ & Pain, inability to signal awareness & Thoracotomy & None \\
\hline 45 & $\mathrm{~m}$ & $\begin{array}{l}\text { Accidental extubation followed } \\
\text { by reintubation using long-acting } \\
\text { muscle relaxants. After that } \\
\text { inability to move, shortness of } \\
\text { breath while on ventilator } \\
\text { without anesthesia or sedation, } \\
\text { extreme anxiety }\end{array}$ & $\begin{array}{l}\text { Post-op treatment in the } \\
\text { recovery room after } \\
\text { resuturation of a laparotomy } \\
\text { wound }\end{array}$ & None \\
\hline 25 & $f$ & $\begin{array}{l}\text { Intubation, insertion of operative } \\
\text { instruments, pain }\end{array}$ & Laparoscopic cholecystectomy & None \\
\hline 47 & $f$ & Inability to move or breath & $\begin{array}{l}\text { Excision of a mammary gland } \\
\text { and axillary lymph nodes }\end{array}$ & 4,500 \\
\hline 26 & $f$ & $\begin{array}{l}\text { Feeling of paralysis, tracheal tube } \\
\text { in the throat, insertion of } \\
\text { operative instruments, pain, } \\
\text { heard discussions }\end{array}$ & Laparoscopic cholecystectomy & 8,000 \\
\hline 56 & $f$ & $\begin{array}{l}\text { Pain, inability to signal awareness } \\
\text { and pain }\end{array}$ & Incision of a foot abscess & 5,000 \\
\hline
\end{tabular}

the compensation granted, if any, is shown in Table 15. The mean age of the 11 cases was 39.4 years; four patients were male and seven female. The mean compensation paid was
FIM 4,327 (EUR 727), or FIM 5,950 (EUR 1,001 ) if the patients who were not compensated are excluded. The compensation was technically granted because of pain. 


\section{Discussion}

\subsection{Patients' experiences during the episode of intra-anesthetic awareness}

Seventy patients with awareness during general anesthesia were analyzed in the present thesis. Tactile perceptions (recalled by $64 \%$ of patients) were the most common sensory modality during theepisode of awareness. This was followed by pain (32\%) and visual recollections (18\%) (Table 7). Paralysis was recalled by $80 \%$ of the thirty patients who responded to this question. These figures are similar to thosereported previously (M oerman et al., 1993; Schwender et al., 1998; Sandin et al., 2000). Lower incidence of painful awareness or sensory perceptions have also been reported (D omino et al., 1999). H owever, based on the present thesis and other recent studies (Sandin, and N ordström, 1993; N ordström et al., 1997; Sandin et al., 2000) theincidence of painful awarenessis likely to be higher than previously suggested (J ones, 1994). The majority ( $83 \%$ ) of patients understood immediately that they are aware of the operation and did not consider their situation as a dream or hallucination. Immediate anxiety over what is going on was felt by $62 \%$ of the patients but, perhaps astonishingly, only $17 \%$ of the patients with awareness considered the episode of awareness as the worst perioperative experience in the early post-operative interview.

\subsection{Methods used in the present studies}

\subsubsection{Interviews}

Structured post-operative interview was used in Studies 1-3 to detect patients with awareness and recall. Interviews are obviously the only currently available method to find out experiences and recollections of another person. H owever, the results of an interview, if negative, al ways leave some doubt (Kihlstrom, and Schacter, 1990). The results of an interview are not al ways easy to interpret, and the contents of a post-operative interview range from no memories through vague, dream-like recollections to exact verbatim descriptions of the occurrences in the operating room. $\mathrm{H}$ owever, the patient's interpretation of his or her memories is of importance, and consequently, if the patient interprets a vague memory meaning intraoperative awareness, mental after-effects may follow. To complicatethings further, it has been shown that recollections immediately after a very traumatizing incident contain little or no narrative component, and the patient may react to the post-operative interview only with crying, for example (Van $D$ er Kolk, and 0 sterman, 2000). It has also been shown by Sandin and co-workers that more than one interview several weeks apart is needed as new cases of patients with awareness and recall could be found in each inter- 
view (Sandin et al., 2000). All these problems accompanied by the low incidence of aware ness, and consequently, large samples needed, make the interviews both laborious and timeconsuming.

In Study 1, interviews were performed by PACU nurses. Two problems arose from this arrangement: first, a large number of patients were not interviewed because the nurses were engaged in other activities, and second, some cases suggestive of awareness and recall were not always immediately identified but were noted only after screening of interview sheets by the investigators. The problem of low interview-rates is not rare in largeinterview studies (Kapur, 1994), and the investigators were convinced that the sample in the Study 1 was representative of the whole surgical population. The second problem prevented the re cruitment all possible cases of awareness, which were eventually found, to the psychiatric interviews. This was a major draw-back since we were not able to describe the pattern of possible psychiatric after-effects in a prospective manner.

Still another problem is that very sick patients that were treated in the ICU were excluded form the study. It may be that these patients do not receive as much anesthetic as other patients because of the severity of their disease. Therefore, they may be predisposed to awareness. On the other hand, interviewing these patients after the ICU is difficult, because the ICU period itself likely produces confusing recollections (Aitkenhead, 1989; Fu-jin et al., 1997).

As usual during the time of the studies, only one screening interview was used in Studies 1-3 and, therefore, we probably did not identify all cases of awareness and recall.

\subsubsection{Anesthetic records}

$\mathrm{M}$ anual anesthetic charts were used for calculating the anesthetic drug doses (Studies 1-3) and values of the measured physiologic vari- ables (Study 4). It has been shown in many studies that manual anesthetic charts tend to include errors, particularly in the measured variables (Junger et al., 1999; Sado, 1999). It is, therefore, likely that using computer based data would have been superior to manual records. H owever, computerized charting was not available at the time of these studies.

Some of the cases with awareness and recall in Study 4 dated from the 1970s. There may be systematic changes in the practice of anesthesiology between those days and the 1990s when the control patients' data were recorded. H owever, thestudy concentrated on physiologic reactions to intraoperative aware ness which are not likely to change over this time span. Furthermore, there were no differences in anticholinergic or sympathomimetic drug dosing between the patients with and without awareness, and the median date of general anesthesia for the patients studied was 1994. Therefore, it is unlikely that the time of the anesthesia during which awareness occurred would have had large effect on the study.

\subsection{Incidence of awareness with recall during general surgery}

In Study 1, an overall incidence of awareness with recall during general anesthesia was found to be $0.73 \%$ (Table 8 ). The incidence of awareness when counting only patients with some form of objective memories was 0.38 $\%$. H owever, even these cases included many which probably would not be considered to represent awareness during general anesthesia, as they include patients recalling extubation (Patients \# 2, 9, 11, 16, 19 in Appendix). If all these patients are dropped, we are left with an incidence of $0.19 \%$.

Certain difficulties exist in comparing incidence figures of awareness with recall during general anesthesia between different studies. Firstly, to eval uate recall, one needs to rely on the story of the patient. In terms of objec- 
tive, verifiable facts recalled, different grades of memories exist, and consequently, classifying patients' memories becomes more or less subjective and obscure. Secondly, authors of the studies define the time of wakeup from general anesthesia differently. Some feel that extubation or residual relaxation and associated breathing difficulties are not awareness during anesthesia. We did include these cases, because from a patient's point of view, there is often no difference between the intraoperative and the immediate postoperative periods ( $\mathrm{H} \mathrm{O}, 2001)$. Thirdly, very sick patients often are excluded from the studies, many times for practical reasons. These patients are cared for in the ICU, postoperative ventilator therapy and sedation may be needed for variable lengths of time. All this poses considerable difficulties for the postoperative interviews. Furthermore, the sickest patients may receive less anesthetics than other patients, and therefore, may be prone to awareness during anesthesia. Fourthly, the methodology of assessing awareness and recall varies between studies: structured interview is the most popular method, but non-structured interviews and interviews during hypnosis also have been used. Fifthly, the timing and number of interviews used to detect awareness vary between studies.

In Study 1, the incidence of clear, intraoperative, long-lasting awareness ( $G$ rade 3 ) was $0.15 \%$. This is very similar to the incidence reported by the most recent largestudy, which reported an incidence of $0.16 \%$ (Sandin et al., 2000). The criteria behind these figures seem to be somewhat similar, although the 19 patients reported in the study by Sandin and co-workers were further classified into definite, probable, and possible categories. These incidence figures are also of the same order of magnitude as those published by Liu et al. in 1991 (0.2\%). Earlier large studies have usually reported slightly higher incidences (Table 2).
Sandin and co-workers interviewed their patients three times, and found that only six of 18 patients recalled awareness in the first interview in the PACU, 12/18 patients recalled awareness in the second interview 1-3 days after anesthesia, and 17/18 in the third interview 7-14 days after anesthesia. Based on these figures it is likely that in the present Study 1 (patientsinterviewed in the PACU only), and in the studies by Liu et al. (one interview 2036 hours postoperatively) and by Pedersen and Johansen (1989) (one interview on first postoperative day), the observed incidence of awareness underestimates the true incidence. It seems, therefore, that the incidence of awareness and recall is declining.

In the present Study 1, there were five patients $(0.2 \%)$ with recollections related to unpleasant extubation or breathing difficulties on awakening. Some of these patients may bein danger of developing post-operativepsychiatric complications similar to those with definite intraoperative awareness.

\subsection{Incidence of awareness with recall during cardiac surgery}

In Study 2, we report an incidence of awareness of $4 \%$ in 1992, and $1.5 \%$ in 1993. In this study, grading of memories was not used but all of the reported patients recollected memories likely of intraoperativeorigin. Later, one patient (Patient \#24 in Appendix) in the second half of Study 2, was considered a shortlasting case of awareness and graduated to Group 2.

In Study 3, an overall incidence of aware ness with recall during general anesthesia was found to be $2.3 \%$ (Table 9). These patients almost certainly include some whose memories originatein the ICU while patients themselves interpret the memories as intraoperative. The incidence of awareness when counting only patients with some form of objective memories was $0.54 \%$. In this case too, there were two patients (Patients \# 28 
and 29 in Appendix) with memories probably originating during transport from angioplasty into an emergency CABG operation (\# 28) and from ICU to the operating room for emergency re-sternotomy because of bleeding (\#29). If these patients are omitted, the incidence of patients with likely intraoperative awareness was $0.3 \%$.

Interpreting the results of studies on aware ness during cardiac anesthesia is influenced by the same factors as the studies on general surgery. In addition, all patients are treated in the ICU for a variable period of time and patients' interpretation of their recollectionscan be different from the interpretation of the hospital or study personnel. The longer the postoperative intensive care lasts, the more complicated matters become. We have there fore decided not to includepatients with postoperative ICU stay over five days.

The incidence found in Study 3 is similar to that found by D owd et al. (1998) (0.3\%) if only likely cases of true intraoperative aware ness are counted. It also seems that incidence of awareness during cardiac surgery has diminished over the years and is of similar order of magnitude, or only slightly higher, than during general surgery (Table 3).

\subsection{Differences in anesthetic drug dosing between patients with and without awareness}

There are few other studies (Phillips et al., 1993) except thosepresented in this thesis that have compared the doses of primary anesthetic drugs between patients with and without awareness. We noted differences in the dosing of isofluraneand propofol in Study 1 , and in the dosing of midazolam during cardiac surgery in Study 3. The mean doses of anesthetics are smaller in patients with awareness, and therefore a major contribution to the existence of this complication is that not enough anesthetics are administered to every patient.

O ne must interpret the results of Studies 1 and 3 cautiously in this respect. Firstly, the same problems apply as for assessing aware ness: if not all patients with awareness are found and if patients without awareness are included in the wrong groups, the results will be biased. Secondly, cal culating doses of single anesthetics may not be appropriate as general anesthesia is not usually the result of a single drug but a combination of drugs. Therefore, one should be able to create a summary measure of the anesthetic effect of a combination of i.v. and volatile anesthetics, which is of course, not currently possible. A third problem is that in these studies, awareness and recall are treated as one phenomenon. In reality, we are dealing with two linked phenomena: awareness during general anesthesia, and later recall. It seems that midazolam, and probably all benzodiazepines, induce profound amnesia but, based on the studies using IFT, not unconsciousness (Russell, 1993).

\subsection{Comventional statistical methods and artificial neural networks in detecting awareness from monitored physiologic parameters}

The conclusion from the literature is that standard physiologic monitoring is not helpful in detecting awareness during general anesthesia. In current anesthesiology practice, however, physiologic monitoring of heart rate, blood pressure, arterial blood oxygen saturation, and ventilatory gas composition comprise the standard monitoring (Rosenberg et al., 1992). N europhysiologic monitoring, even if becoming increasingly common, is much less often used. Even the current $\mathrm{N}$ ordic standards suggest that "state of consciousness should be clinically observed" (Rosenberg et al., 1992). The concept of following "clinical signs" in monitoring consciousness is also constantly brought to consideration when discussing awareness during general anesthesia (Gilston, 2000).

Artificial neural models have worked well 
in detecting complex combination patterns in imaging, waveform analysis, and diagnostics (Baxt, 1995). We therefore wanted to study the feasibility of this type of artificial intelligence in the analysis of data obtained from standard physiologic monitors. For a comparison, conventional statistical methods (Poisson regression) were used as well. The best neural models, picked by the likelihood ratio, had a high specificity ( $98 \%$ ) but a low sensitivity $(23 \%)$. In the Poisson regression analysis, patients with awareness had higher blood pressures and heart rates than patients without awareness. Together these findings seem to imply that some patients react to awareness by change of autonomic monitored parameters, and that these patients can be picked by the artificial neural model, while no pattern of constant in the group of patients with awareness emerges that can be used to detect them as a group. This further confirms that monitoring of heart rate, blood pressure, and other standard variables is not valuable in monitoring consciousness. H owever, awareness must be considered as one possible explanation for a tachycardia or high blood pressure during general anesthesia.

0 ur studies are limited by the fact that we were unable to retrospectively pinpoint the exact time of inadequate anesthesia in the patients who reported recall. Therefore, wehad to use statistical summary functions, such as mean, minimum and maximum, of the actual data. If one knew the timing of awareness, actual values measured during that time could be used for training the neural network models. This could increase the information value of the data. Furthermore, manual data records were used in these studies, as not many computerized records of patients with awareness and recall were available to us. M anual records contain errors; for example, truemeasured highest and lowest values tend to be missing in manual recordings (Edsall et al., 1993).

\subsection{The possibility of reducing the incidence of awareness by giving feedback information to the anesthesiologists}

Education of practitioners in the field of anesthesiology is a way to try to reduce awareness during general anesthesia (G honeim, 2001). We had noticed a fairly high incidence of awareness during cardiac anesthesia in our unit in 1992. Therefore, information about this anesthesia complication and about its avoidance was increased in the education files of the unit. We also decided to estimate the effect of this increased information and re peated thestructured interview in 1993 (Study 2).

Incidence of awareness decreased from 4 $\%$ to $1.5 \%$ between the study periods, and the relative risk for awareness in 1992 was 275 \% (95 \% Cl 63-1204 \%) of the risk in 1993 in our unit. Simultaneously, the use constant infusion of anesthetics or constant use of a volatile anestheticsincreased, consumption of primary anesthetic agents increased and consumption pancuronium (the primary muscle relaxant used in cardiac anesthesia at that time) decreased, all changes proposed in the educational materials.

The change in the incidence of awareness between the years 1992 and 1993 is not statistically significant. H owever, there seems to be a decreasing trend in awareness during cardiac surgery starting in 1992 (Table 9). It seems likely that informing the anesthesiologists about the possibility of awareness and recall during cardiac anesthesia is one reason for the decreasing incidence of this complication.

There are always many reasons for the change of behavior in anesthesiologists, as well as other human beings. Therefore, we cannot be sure that changes in the use of anesthetic drugs and concurrent decrease in the incidence of awareness weredue to theinformation given to the anesthesiologists. H owever, there are no other obvious explanations for the change 
in practice during that particular time. Our study seems to put forth further evidence in favor of the value of education in reducing awareness during anesthesia.

These findings are further supported by findings during anesthesia for general surgery in Study 1. In this study, the anesthesiologists were informed about the nature of the study but no specific suggestions were given. The mean dosing of isoflurane increased during the study compared to the threemonth period immediately preceding the study. Simultaneously, a decreasing trend in the incidence of awareness was noted, which, however, was not statistically significant at the $95 \%$ level. The anesthesiologists likely changed their way of anesthetizing patients because they knew they werebeing observed in conjunction with an ongoing study.

Another possible conclusion drawn from thesetwo studies may bethat thestudiesthemselves and not the information changed the behavior of the anesthesiologists. The effect of the measurement procedure on the measured variable ( $\mathrm{H}$ awthorne effect) is an inherent cause of bias in all empirical studies. It is very difficult to try to eliminatethe $\mathrm{H}$ awthorne effect by blinding the anesthesiologists to a large ongoing interview study. A possibility to quantify this bias might be estimating anesthetic drug dosing before, during, and after a study of this kind.

\subsection{Psychiatric consequences of awareness during anesthesia}

There is one recent small prospective study on the incidence of psychiatric complications after awareness with recall during general anesthesia. In this study, $22 \%$ of patients with previous awareness and recall had PTSD after a median of 20 months. The incidence of PTSD may be even higher because the investigators state that they have reasons to believe that the unwillingness of some patients to participate in thestudy constituted avoidance behavior, a typical symptom of PTSD. Fur- thermore, $11 \%$ of the patients with previous awareness experienced some symptoms of PTSD in thefollow-up, although they did not fulfill all criteria of PTSD (Lennmarken et al., 2002).

The studies that have used some form of advertising, or complication databases, to gather patients who have suffered from awareness during anesthesia, tend to have a high number of patients suffering PTSD, or other serious psychiatric after-effects (C obcroft, and Forsdick, 1993; M oerman et al., 1993; Schwender et al., 1998; D omino et al., 1999). In addition, it is likely that the most severely traumatized patients are not likely to be able to respond to the advertisements, and control groups are lacking in these studies (Wang, 2001).

In the study by Bergström and Bernstein, the incidence of psychiatric after-effects was very high: four out of six patients were suffering from after-effects a year after the anesthesia, and onewas in psychiatric care (Bergström, and Bernstein, 1968). In this study, all patients anesthetized by two different methods were followed.

We found that none of the five patients with awareness (Study 1), who were recruited for psychiatric interview and testing, developed any serious after-effects. 0 nepatient had intense fear that subsided spontaneously. Three of the five patients had suffered from depression in the past, and one of the three needed antidepressant medication after the awareness period. It seems that the experiences recalled by these patients were not very traumatizing and that serious psychiatric after-effects arenot very common. $\mathrm{O}$ the other hand, none of the control patients in our Study 1 had any psychiatric after-effects. Therefore, even if serious psychiatric after-effects of awareness are unlikely, sequelae of some sort may be much more common.

The number of patients included in the psychiatric interviews and testing, is however quitesmall, which makes definite conclusions 
impossible. We were not able to recruit all patients with possible awareness into the psychiatric interview and testing because these patients were only found in the retrospective scrutiny of the interview records. It has also been shown that very traumatic memoriestend to be primarily implicit memories with sensorimotor or affective nature but little narrative component. Patients with traumatizing memories are able to speak coherently about their traumatic recollections only after variabletimespan (Van D er Kolk, and O sterman, 2000). Therefore, it is possible that severely traumatized patients aremissed in the present Study 1 . This has also been found to be the case as patients may initially seem to be doing well after an awareness episode, but later do develop psychiatric problems (Lennmarken et al., 2002).

In conclusion, we do not know thecurrent incidence of psychiatric after effects of intraoperative awareness. It is likely that the incidence of severe psychiatric consequences is relatively high (probably 20-30\%), but also, that some patients will not develop any psychiatric after-effects. The scope of psychiatric after-effects ranges from nil to very traumatizing PT SD that may completely ruin thelife of the patient for many years. Information about this possibility should probably begiven to surgeons and primary care physicians who are more likely than anesthesiologists to meet the patient when the problems become manifest.

\subsection{Medico-legal consequences of awareness with recall in Finland}

To my knowledge, there have been no cases of litigation and trial resulting from intraoperative awareness in Finland. The Patient Injury Act, effective since M ay 1, 1987 in Finland, states that compensation for patient injury is payable after injury from medical treatment. The PIA handles all the claims, makes the decisions and pays the compensations. The basic principle of the no fault schemeis that the patient does not suethrough the courts, but submits an insurance claim which will bring compensation if the insurers are satiffied that the injury was caused by the treatment. Consideration will, however, be given to unavoidable consequences of therapy and to necessary risk-taking by health care providers. This insurance scheme allows patients to be compensated for injuries arising from medical treatment without the need to prove fault and causation through adversarial litigation.

In Study 5, we studied insurance claims submitted to PIA between M ay 1, 1987 and D ecember 31, 1993. Four claims because of awareness during general anesthesia had been filed representing one insurance claim for about 350,000 general anesthetics. D uring the same time period, 391 claims had been filed for anesthesia care, giving for awareness during general anesthesia a $1 \%$ share of claims against the anesthetic practice.

Between January 1, 1994 and June 15, 1997 another seven insurance claims resulting from anesthetic awareness werefiled (Study 4). 0 neinsurance claim every twenty months was filed from 1987 to 1993, and one every six months from 1994 to 1997. Compensation was granted in $73 \%$ of the cases; the average award was EUR 1,001.

Of the 4,183 claims in the ASA Closed Claims Project database (D omino et al., 1999) $79(1.9 \%)$ were filed because of awareness during anesthesia. Compensations ranged from U SD 1,000 to 600,000. High compensation (GBP 13,000) for awareness during anesthesia has also been reported in the U.K (D omino, and Aitkenhead, 2001).

In conclusion, the medicolegal consequences of awareness during general anesthe sia in Finland have been relatively rare, although there may be a slightly increasing trend. Compensations granted for pain and awareness during anesthesia have been small according to the policy of the PIA to keep compensations for immaterial loss low. 


\section{Conclusions}

1. The incidence of awareness during general anesthesia for general surgery seems to be in slow, constant decline. The current incidence of undisputed intraoperative aware ness is about $0.1-0.2 \%$ of all general anesthetics. If cases of unpleasant awakening are counted, the incidence is about $0.4 \%$, and if cases with possible awareness are included, the incidence is $0.7 \%$.

2. The incidence of awareness during anesthesia for cardiac surgery is also in decline. Current estimate of the incidence of undisputed intraoperative awareness is $0.3 \%$ of all cases of cardiac anesthesia. If all possible cases of awareness are counted, the incidence is $2.3 \%$. Incidence of awareness during cardiac surgery was previously much higher than during general surgery but it has come down to a level almost similar to the incidence during general surgery.

3. Lower doses of anesthetics were used for patientswith awareness than for those without, during anesthesia for general surgery: isoflurane $0.42 \mathrm{Fi} \%$ vs. $0.65 \mathrm{Fi} \%$ and propofol $73 \mu \mathrm{g} / \mathrm{kg} / \mathrm{min}$ vs. $228 \mu \mathrm{g} / \mathrm{kg} / \mathrm{min}$, respectively (Study 1).

Lower dose of midazolam was used during cardiac surgery: $0.8 \mu \mathrm{g} / \mathrm{kg} / \mathrm{min}$ vs. $1.1 \mu \mathrm{g} /$ $\mathrm{kg} /$ min (Study 3).

A principal factor for the existing measur- able incidence of awareness during anesthesia is the use of an insufficient concentration of anesthetic for the patient's need.

4. Standard physiologic monitoring is not re liablefor monitoring consciousness during general anesthesia. Even with computerbased artificial intelligence, it is currently not possible to create systems able to reliably distinguish between patients with and without awareness. H owever, patients with awareness as a group tend to have higher blood pressure and heart rate than patients without awareness.

5. Information about awareness during general anesthesia, and means of preventing it lead to a lowering trend of its incidence. Concurrently, therewas increasein the consumption of primary anesthetics and decrease in the consumption of pancuronium during cardiac surgery. All these changes were suggested in the information given. It is likely that information given to anesthesiologists leads into a change in their practice of anesthetizing patients.

6. Psychiatric after-effects of awareness during general anesthesia range from no effects to invalidating chronic PTSD. Current incidence of serious psychiatric after-effects is not known, but it is likely 
that a significant number (possibly 20-30 $\%$ ) of patients suffer from serious psychiatric consequences.

7. Awareness during general anesthesia has triggered a small number of Patient Insur- ance claims in Finland (about $1 \%$ of anesthesia-related claims). Seventy percent of the patients who have submitted insurance claims have received compensations for pain, the mean amount of compensation being EUR 1,000. 


\section{Practical considerations}

A practical goal for an anesthesiologist is a safe general anesthesia without awareness and, certainly, without post-operative recall. There is currently no evidence that any kind of premedication, or withholding premedication for that matter, would affect the incidence of awareness and recall. Therefore, the choice of premedication should be based on other considerations of patient safety, comfort, and requirements of surgery. There is currently no consensus on whether the patients should be forewarned about the possibility of awareness during general anesthesia. Some have, however, suggested that this might give the patient better chances of coping with possible awareness and that mental after-effects would be more unlikely (H olt, and Yate, 1993). Certainly, discussing this matter is wise if the anesthesiologist foresees a need for very light anesthesia for some reason.

General anesthesia may be induced with any inhaled or i.v. anesthetic drugs. T he dose of the chosen drug should be large enough to cover the stimulus of possible endotracheal intubation. If prolonged laryngoscopy is required, one should not forget to maintain general anesthesia with supplemental doses of the induction agent or with a potent inhalational anesthetic. During the operation, anesthesia should be maintained with continuous administration of an anesthetic, whether that be i.v. or inhaled. Anesthetics should be administered in such amounts that unconsciousness is maintained until the patient's trachea is extubated and muscle strength has recovered to sufficient amount to sustain normal breathing. A technique relying on $\mathrm{N}_{2} \mathrm{O}$, whether supplemented with an opioid or not, to maintain general anesthesia, is not acceptable. There is some evidence that deflurane, isoflurane, and sevoflurane cause unconsciousness and amnesia in lower concentration relative to their M AC skin incision than halothane (Eger, 2001). Therefore, the use of these inhaled anesthetics would be wise if hemodynamic instability is encountered. The maintenance of anesthesia with large doses of benzodiazepines, with or without opioid supplementation, would probably cause amnesia but not unconsciousness. Therefore, this technique is not as good as using potent inhaled or i.v. general anesthetics. H owever, there is currently no evidence that awareness without later recall is detrimental to the patient, and in critical hemodynamic situation using benzodiazepines instead of general anesthetics may be acceptable. N M Bs should be used as sparingly as possible unless indicated for surgery or intubation.

There is currently no evidence that aware ness and recall could be prevented by monitoring consciousness with sophisticated methods, such as AEP or BIS. H owever, any clinical signs are much more unreliable in this respect 
and, certainly, it would be wise to use EEG based monitoring if a patient has a history of awareness and recall under anesthesia. Some of these patients have abnormal pharmacokinetic or -dynamic profiles, and monitoring the effect of the anesthetic drugs on the effector site (brain) should be used.
If a patient after all has suffered form aware ness and recalls this postoperatively, psychiatric consultation and follow-up is recommended. Q uality control programs, such as postoperative interviews or surveys, should incorporate questions reveal ing possible cases of intraoperative awareness. 


\section{Future implications}

It seems that prospective, multi-center studies would be needed to establish after-effects of awareness and recall during anesthesia, as well as, the after-effects of awareness, or wakefulness, without recall. There is evidence, presented in this thesis, too, that awareness and recall may be followed by detrimental aftereffects, but less evidence exists about the possibility of negative after-effects after wakefulness without later recall. An associated question is the effect of drugs that have effect on memory but are not likely to be anesthetics in the sense of being able to suppress consciousness and prevent wakefulness during general anesthesia. Benzodiazepines are the most notorious example of such drugs. These drugs are also often used as component of modern general anesthesia.

The question of monitoring consciousness during general anesthesia is also important. $M$ onitoring the central nervous system function with currently available methods is fairly expensive. It is suggested, but not shown, that awareness and recall may be prevented by these modes of monitoring (Kelly et al., 2000). A particular problem of all the methods (BIS and AEP) available today is that they are retrospectivein the sense that the result displayed by the monitoring systems represents time 1030 seconds past the present. If the patient is conscious at the present time, it will only be displayed a minute later (Rosow, and
M anberg, 1998). It is not established, whether actions taken a few minutes after the occurrence of consciousness during general anesthesia are able to prevent all negative aftereffects.

The problem of all studies on awareness with and without recall is the large amount of patients needed ( 0 'Connor et al., 2001). Multi-center studies are obviously necessary to overcome these problems. In addition, the amount of labor needed, for example, to show a $50 \%$ fall in the incidence of awareness and recall from the current level using a hypothetical new technique, would requirethreeto five years of labor only to complete the structured interviews. Even though we are dealing with a very basic dilemma of anesthesiology - consciousness - it is questionable whether or not such an investment of time and money would be worthwhile.

There are no studies on the incidence of awareness and recall in children. The general anesthetics during childhood, however, may be somewhat different from that used in adults. The fact that the ability to conduct structured interviews diminishes as the age of the target group decreases, makes collection of accuratedata in children with current methodology difficult if not impossible. A technique suitable for evaluating awareness and recall in children would be most welcome. 


\section{Acknowledgements}

These studies were carried out at the $D$ epartment of Anaesthesiology and Intensive $\mathrm{C}$ are $M$ edicine, $\mathrm{H}$ elsinki University $\mathrm{C}$ entral $\mathrm{H}$ ospital and at the $D$ epartment of Anesthesiology, Päijät-H äme C entral H ospital, Lahti. Patient cases were also recruited from the archives of the Patient Insurance Association of Finland.

I express my sincere gratitude to the head of the Department of Anaesthesiology and Intensive $\mathrm{C}$ are $\mathrm{M}$ edicine, $\mathrm{H}$ elsinki University Central H ospital, Professor Per Rosenberg, $M D, P h D$. Professor Rosenberg has in many ways, both mentoring and financing, encouraged the process of creating this thesis. I will also wish to thank Professor Emeritus Tapani Tammisto, M D, PhD , the former head of the $D$ epartment of Anaesthesiology in the $\mathrm{H}$ elsinki U niversity $\mathrm{C}$ entral $\mathrm{H}$ ospital, for his great interest and support of my studies.

I am grateful to the head of the D epartment of Anesthesiology, Päijät-H ämeC entral H ospital, Lahti, D r. Timo Ali-M elkkilä, M D, $\mathrm{PhD}$. H e has co-authored one of the studies and made it possible to study the patients of his department.

D ocent $M$ arkku H ynynen, M D, PhD has supervised this thesis. H eintroduced mewith the subject of awareness during anesthesia; he has thought mebasic ideas of scientific thinking and hard work. $M$ arkku has always been promptly available despite of his many activi- ties when help has been needed. I owe him my sincere gratitude.

I wish to thank Professor $\mathrm{H}$ arry Scheinin, $M D, P h D$ and D ocent Arvi Yli-H ankala, $M D, P h D$ for the thorough and constructive criticism of this thesis.

I am grateful to Professor Jukka Räsänen, $M D, P h D$, for teaching me ideas of clinical science and basics of artificial intelligence. I will also thank Jukka for the language revision of this thesis.

I thank D ocent U lla Aromaa, M D, PhD, for an opportunity to do clinical and scientific work under her supervision. U lla has al so been an invaluable contact between me and the Patient Insurance Association.

I thank M s Johanna Saario, RN, and M S Pirkko H erranen, RN , for their great help in managing the patient interviews. The completion of this thesis would not have been possible without their contribution.

I am indebted to Dr. Riitta Laurila, MD, for performing the psychiatric interviews and testing Also, I wish to thank D r. Janne J ussila, $M D$, for his contribution in the study of awareness during cardiac anesthesia.

I am grateful to Professor Seppo Sarna, PhD for his advice with the statistical problems. I thank M r Arttu Laine, M Sc, and M s H anna Tolonen, M Sc, for performing the Poisson regressions of these studies.

I wish to thank all the nursing staff of the 
D epartment of Anesthesiology of the Päijät$\mathrm{H}$ äme C entral H ospital, Lahti, for their invaluablecontribution to the patient interviews. I also thank all of my colleagues in H elsinki and Lahti for their support.

I am most grateful to my parents, Eila and Veikko Ranta, for the best possible upbringing, creating an atmosphere of love in my childhood home, and for their never-ending support in all fields of life. I also thank my mother-in-law, Anna-Liisa Lahti, and my sis- ters and sisters and brothers-in-law for their interest and support.

The greatest gratitude of all I owe to my wife D r. Varpu Ranta, M D, PhD, and to our children Henrik and Kirsti.

Thisstudy was financially supported by the Finnish M edical Foundation, the Finnish $M$ edical Society D uodecim, theFinnish-N orwegian M edical Foundation, and the Instrumentarium Foundation of Science, which are gratefully acknowledged. 


\section{References}

Anonymous. Awareness during anaesthesia. BM 1: 977, 1976. Anonymous. Awarenessin general anaesthesia. BM280: 811, 1980. Anonymous. Webster's encyclopedic unabridged dictionary of the English language. New York: Portland House, 1989.

Anonymous. NNMbdel32 Version 1.0 User's manual. New York, NY: Neural Fusion, 1998.

Anonymous. Precedents of the Finnish Supreme Court. http:// www.finlex.fi/oikeus/index.html. Accessed: 4.1.2002.

Abouleish E, Taylor FH Effect of morphine-diazepam on signs of anesthesia, awareness, and dreams of patients under $\mathrm{N} 20$ for cesarean section. Anesth Analg 55: 702-5, 1976.

Agarwal G, Sikh SS. Awareness during anaesthesia. Aprospective study. Br J Anaesth 49: 835-8, 1977.

Aitkenhead AR Analgesia and sedation in intensive care. $\mathrm{Br} \mathrm{J}$ Anaesth 63: 196-206, 1989.

Aitkenhead AR Awareness during anaesthesia: what should the patient be told? Anaesthesia 45: 351-2, 1990.

Aldrete JA, Wright AJ. Concerning the acceptability of awareness during surgery. Anesthesiology 63: 460-1, 1985.

Altman DG. Practical statistes for medical research. London: Chapman \& Hall, 1991.

AndradeJ, Baddeley A Human memory and anesthesia. Int Anesth Clin 31: 39-51, 1993.

Baddeley A Human memory, theory and practice. Hove: Lawrence Erlbaum Associates, 1990.

Bailey AR, Jones JG. Patients' memories of events during general anaesthesia. Anaesthesia 52: 460-76, 1997.

Baraka A, Louis F, Noueihid R, Diab M, Dabbous A, Sibai A Awareness following different techniques of general anaesthesia for caesarean section. Br J Anaesth 62: 645-8, 1989.

Barr AM, Wong RM. Avareness during general anaesthesia for bronchoscopy and laryngoscopy using the apnoeic oxygenation technique. Br J Anaesth 45: 894-900, 1973.

Baxt WG. Application of artificial neural networks to clinical medicine. Lancet 346: 1135-8, 1995.
Bennett $H$ Response to intraoperative converation, in response. Br J Anaesth 58: 134-5, 1986.

Bergström $\mathrm{H}$, Bernstein $\mathrm{K}$ Psychic reactions after analgesia with nitrous oxide for caesarean section. Lancet 2: 541-2, 1968.

Blacher RS. On awakening paralyzed during surgery. Asyndrome of traumatic neurosis. JAMA 234: 67-8, 1975.

Blacher RS. Awareness during surgery. Anesthesiology 61: 1-2, 1984.

Bogetz MS, Katz JA Recall of surgery for major trauma. Anesthesiology 61: 6-9, 1984.

Bogod DG. Detecting awareness during general anaesthesia. Anaesthesia 45: 590, 1990.

Bogod DG, Orton JK, Yau HM, Oh TE. Detecting awareness during general anaesthetic caesarean section. An evaluation of two methods. Anaesthesia 45: 279-84, 1990.

Breckenridge J, Aitkenhead AR Isolated forearm technique for detection of wakefulness during general anaesthesia. Br J Anaesth 52: 665P, 1981.

Brice DD, Hetherington RR, Utting JE. Asimple study of aware ness and dreaming during anaesthesia. Br J Anaesth 42: 535-42, 1970.

Browne RA, Catton DV. A study of awareness during anesthesia. Anesth Analg 52: 128-32, 1973a.

Browne RA, Catton DV Awareness during anaesthesia: Acomparison of anaesthesia with nitrous oxide - oxygen and nitrous oxide - oxygen with Innovar ${ }^{\oplus}$. Canad Anaesth Soc J 20: 763-8, 1973b.

Chortkoff BS, Bennett HL, Eger EII. Does nitrous oxide antagonize isoflurane-induced suppression of learning? Anesthesiology 79: 724-32, 1993.

Chortkoff BS, Eger EII, Crankshaw DP, Gonsowski CT, Dutton $\mathrm{RC}$, Ionescu P. Concentrations of desflurane and propofol that suppress response to command in humans. Anesth Analg 81: 73743, 1995.

Clark DL, Rosner BS. Neurophysiologic effects of general anesthetics: I . The electroencephalogram and sensory evoked respons- 
es in man. Anesthesiology 38: 564-82, 1973.

Cobcroft MD, Forsdick C. Awareness under anaesthesia: the patients' point of view. Anaesth Intensive Care 21: 837-43, 1993.

Cormack RS. Conscious levels during anaesthesia. Br J Anaesth 71: 469-71, 1993.

Crawford JS. Awareness during operative obstetrics under general anaesthesia. Br J Anaesth 43: 179-82, 1971.

Crawford JS, Lewis M, Davies P. Maternal and neonatal responses related to the volatile agent used to maintain anaesthesia at cae sarean section. Br J Anaesth 57: 482-7, 1985.

Crawford JS. Fetal well-being and maternal awareness. Br J Anaesth 61: 247-9, 1988.

Critchley M. Butterworths Medical Dictionary (2 ed.). London: Butterworth \& Co (Publishers) Ltd, 1978, p. 1942.

Cross SS, Harrison RF, Kennedy RL. Introduction to neural networks. Lancet 346: 1075-9, 1995.

Cundy JM Post traumatic stress disorders. Br J Anaesth 75: 501-2, 1995.

Cundy JM, Dasey N. An audit of stress disorders related to anaesthesia. In: Memory and awareness in anaesthesia III, Bonke B, Bovill JG, Moerman N, eds. Assen: Van Gorcum, 1996: 143-50.

Degoratis LR, Lipman RS, Covi L An out-patient rating scale: preliminary report. Psychophramacol Bull 9: 13-28, 1973.

Desiderio DP, Thorne AC. Awareness and general anaesthesia. Acta Anaesthesiol Scand Suppl 92: 48-50, 1990.

Domino KB, Posner KL, Caplan RA, Cheney FW. Awareness during anesthesia: a closed claims analysis. Anesthesiology 90: 105361, 1999.

Domino KB, Aitkenhead AR. Medicolegal consequences of aware ness during anesthesia. In: Awareness during anesthesia, Ghoneim MM, ed. Oxford: Butterworth-Heinemann, 2001: 155-72.

Dowd NP, Cheng DC, Karski JM, Wong DT, Munro JAC, Sandler AN. Intraoperative awareness in fast-track cardiac anesthesia. Anesthesiology 89: 1068-73, 1998.

Drummond JC. Monitoring depth of anesthesia: with emphasis on the application of the bispectral index and the middle latency auditory evoked response to the prevention of recall. Anesthesiology 93: 876-82, 2000.

Dutton RC, Smith WD, Smith NT. Wakeful response to command indicates memory potential during emergence from general anesthesia.J Clin Monit 11: 35-40, 1995.

Dwyer R, Bennett HL, Eger EId, Heilbron D. Effects of isoflurane and nitrous oxide in subanesthetic concentrations on memory and responsiveness in volunteers. Anesthesiology 77: 888-98, 1992.

Edsall DW, Deshane P, Giles C, Dick D, Sloan B, FarrowJ. Computerized patient anesthesia records: less time and better quality than manually produced anesthesia records. J Clin Anesth 5: 27583, 1993.

Eger EI, Saidman LJ, Brandstater B. Minimum alveolar concentration: A standard of anesthetic potency. Anesthesiology 26: 756-
63, 1965.

Eger EI. Does $1+1$ = 2? Anesth Analg 68: 551-2, 1989.

Eger EI. Age, minimum alveolar anesthetic concentration, and minimum alveolar anesthetic concentration-awake. Anesth Analg 93: 947-53, 2001.

Eger EI. Abrief history of the origin of minimum alveolar concentration (MAC). Anesthesiology 96: 238-9, 2002.

Evans JM, Davies WL Monitoring anaesthesia. Cin Anasthesiol 2: 243-62, 1984.

Farnsworth GM. Enflurane and the incidence of awareness in Caesarean section. Anaesthesia 33: 553, 1978.

Fu-Jin S, Shu-Hsun C, Po-Jui Y, Wen-Yu H, Guey-Shiun H Tuming points of recovery from cardiac surgery during the intensive care unit transition. Heart Lung 26: 99-108, 1997.

Galinkin JL, Janiszewski D, Young CJ, Klafta JM, Klock PA, Coalson DW, Apfelbaum JL, ZacnyJP. Subjective, psychomotor, cognitive, and analgesic effects of subanesthetic concentrations of sevoflurane and nitrous oxide. Anesthesiology 87: 1082-8, 1997.

Ghoneim MM, Mewaldt SP. Benzodiazepines and human memory: a review. Anesthesiology 72: 926-38, 1990.

Ghoneim MM, Block RI. Leaming and consciousness during general anesthesia. Anesthesiology 76: 279-305, 1992.

Ghoneim MM, Block RI. Learning and memory during general anesthesia: an update. Anesthesiology 87: 387-410, 1997.

Ghoneim MM Awareness during anesthesia. Anesthesiology 92: 597-602, 2000.

Ghoneim MM, Block RI, Dhanaraj V, Todd MM, Choi WW, Brown CK. Auditory evoked responses and leaming and awareness during general anesthesia. Acta Anaesthesiol Scand 44: 13343, 2000.

Ghoneim MM Avareness during anesthesia. In: Awareness during anesthesia, Ghoneim MM, ed. Oxford: Butterworth-Heinemann, 2001: 1-22.

Gilston A Awareness during anaesthesia. Lancet 355: 1722, 2000.

Goldmann L, Shah MV, Hebden MW. Memory of cardiac anaesthesia. Psychological sequelae in cardiac patients of intra-operative suggestion and operating room conversation. Anaesthesia 42: 596-603, 1987.

Gonsowski CT, Chortkoff BS, Eger EII, Bennett HL, Weiskopf RB. Subanesthetic concentrations of desflurane and isoflurane suppress explicit and implicit learning. Anesth Analg 80: 568-72, 1995.

Griffiths D, Jones JG. Awareness and memory in anaesthetized patients. Br J Anaesth 65: 603-6, 1990.

Hargrove RL Awareness under anaesthesia. J Med Def Union 9: 9-11, 1987.

Harris TJB, Brice DD, Hetherington RR, Utting JE. Dreaming associated with anaesthesia: the influence of morphine premedication and two volatile adjuvants. Br J Anaesth 43: 172-8, 1971. 
Haykin SS. Neural networks: a comprehensive foundation. Upper Saddle River, New Jersey: Prentice Hall, 1999.

Heier T, Steen PA Assessment of anaesthesia depth. Acta Anaesthesiol Scand 40: 1087-100, 1996.

Hilgenberg JC. Intraoperative awareness during high-dose fentanyl-oxygen anesthesia. Anesthesiology 54: 341-3, 1981.

Ho AM 'Awareness' and 'recall' during emergence from general anaesthesia. Eur J Anaesthesiol 18: 623-5, 2001.

Holt GM, Yate PM Psychological responses to anaesthesia. In: Hazards and complications of anaesthesia (2. ed.), Taylor TH, Major E, eds. Edinburgh: Churchill Livingstone, 1993: 447-57.

Horowitz M, Wilner N, Alvarez W. Impact of event scale: a measure of subjective stress. Psychosomatic Medicine 41: 3, 1979.

Hug CC. Does opioid "anesthesia" exist? Anesthesiology 73: 1-4, 1990.

Hutchinson R. Awareness during surgery. Br J Anaesth 33: 463-9, 1960.

James MFM. Conscious levels during anaesthesia. Br J Anaesth 72: 496, 1994.

Jelicic M, Bonke B. The incidence of awareness during anaesthesia. Anaesthesia 44: 1004-5, 1989.

Jessop J, Jones JG. Conscious awareness during general anaesthesia-what are we attempting to monitor? Br J Anaesth 66: 635-7, 1991

Jones JG, Konieczko $\mathrm{K}$ Hearing and memory in anaesthetised patients. BM 292: 1291-3, 1986.

Jones JG. Awareness during general anaesthesia - what are we monitoring. In: Memory and awareness in anaesthesia IV, Jordan C, Vaughan DJA, Newton DEF, eds. London: Imperial College Press, 2000: 3-40.

Jordening H, Pedersen T. The incidence of conscious awareness in a general population of anesthetized patients. Anesthesiology 75: A1055, 1991.

Junger A, Benson M, Quinzio L, Jost A, Veit C, Köss T, Hempelmann G. Qualitätsdokumentation miteinem AnästhesieInformations-Management-System (AIMS). Anaesthetist 48: 523-32, 1999.

Kapur PA Multicenter study versus nausea outcomes: the value of large numbers and the limitations. Anesth Analg 78: 5-6, 1994.

Kelly JS, Roy RC. Intraoperative awareness with propofol-oxygen total intravenous anesthesia for microlaryngeal surgery. Anesthe siology 77: 207-9, 1992.

Kelly SJ, Myles PS, Bain D, Rosow C, Ramsay J. Case 8-2000. Intraoperative bispectral index monitoring and early extubation after cardiac surgery in patients with a history of awareness under anesthesia. J Cardiothorac Vasc Anesth 14: 726-30, 2000.

Kerssens C, Sebel PS. BIS and memory during anesthesia. In: Awareness during anesthesia (1. ed.), Ghoneim MM, ed. Oxford: Butterworth-Heinemann, 2001: 103-16.

Kihlstrom JF, Schacter DL. Anaesthesia, amnesia, and the cognitive unconscious. In: Memory and Awareness in Anaesthesia,
Bonke B, Fitch W, Millar K, eds. Amsterdam: Swets \& Zeitlinger Publishers, 1990: 21-44.

Kim CL Awareness during cardiopulmonary bypass. AANAJ 46: 373-83, 1978

KochsE, Kalkman CJ, Thornton C, Newton D, BischoffP, Kuppe H, Abke J, Konecny E, Nahm W, Stockmanns G. Middle latency auditory evoked responses and electroencephalographic derived variables do not predict movement to noxious stimulation during 1 minimum alveolar anesthetic concentration isoflurane/nitrous oxide anesthesia. Anesth Analg 88: 1412-7, 1999.

Lennmarken C, Bildfors K, Enlund G, Samuelsson P, Sandin RH Victims of awareness. Acta Anaesthesiol Scand 46: 229-31, 2002.

Liu WH, Thorp TA, Graham SG, Aitkenhead AR. Incidence of awareness with recall during general anaesthesia. Anaesthesia 46: 435-7, 1991.

Lubke GH, Kerssens C, Phaf H, Sebel PS. Dependence of explicit and implicit memory on hypnotic state in trauma patients. Anesthesiology 90: 670-80, 1999.

Lunn JN, Rosen M Anaesthetic awareness. BM 300: 938, 1990.

Lyons G, Macdonald R. Awareness during caesarean section. Anaesthesia 46: 62-4, 1991.

Macleod AD, Maycock E Awareness during anaesthesia and post traumatic stress disorder. Anaesth Intensive Care20: 378-82, 1992.

Mainzer J, Jr. Awareness, muscle relaxants and balanced anaesthesia. Can Anaesth Soc J 26: 386-93, 1979.

Mark JB, Greenberg LM Intraoperative awareness and hypertensive crisis during high-dose fentanyl-diazepam-oxygen anesthesia. Anesth Analg 62: 698-700, 1983.

Maunuksela E-L Hemodynamic response to different anesthetics during open-heart surgery. Acta Anaesthesiol Scand Suppl. 65, 1977.

McCleane GJ, Cooper R. The nature of pre operative anxiety. Anaesthesia 45: 153-5 issn: 0003-2409, 1990.

McKenna T, Wilton TNP. Awareness during endotracheal intubation. Anaesthesia 28: 599-602, 1973.

Meyer BC, Blacher RS Atraumatic neurotic reaction induced by succinylcholine chloride. N Y StateJ Med 61: 1255-61, 1961.

Miller DR, Blew PG, Martineau RJ, Hull KA Midazolam and awareness with recall during total intravenous anaesthesia. Can J Anaesth 43: 946-53, 1996.

Moerman A, Herregods L, Foubert L, Poelaert J, Jordaens L, L DH, Rolly G. Awareness during anaesthesia for implantable cardioverter defibrillator implantation. Recall of defibrillation shocks. Anaesthesia 50: 733-5, 1995.

Moerman N, Bonke B, Oosting J. Awareness and recall during general anesthesia. Facts and feelings. Anesthesiology 79: 454-64, 1993.

Moore JK, Seymour AH Awareness during bronchoscopy. Ann R Coll Surg Engl 69: 45-7, 1987. 
Mummaneni N, Rao TL, Montoya A Awareness and recall with high-dose fentanyl-oxygen anesthesia. Anesth Analg 59: 948-9, 1980.

Myles PS, Williams DL, Hendrata M, Anderson H, Weeks AM Patient satisfaction after anaesthesia and surgery: results of a prospective survey of 10811 patients. Br J Anaesth 84: 6-10, 2000.

Newton DEF, Thornton C, Creagh-Barry P, DoréJ. Early cortical auditory evoked response in anaesthesia: comparison of the effects of nitrous oxide and isoflurane. Br J Anaesth 62: 61-5, 1989.

$\mathrm{Ng} \mathrm{KH}$, Gurubatham AI. Awareness during caesarean section under general anaesthesia. Med J Aust 2: 774-6, 1974.

Nordström 0, Engström S, Persson S, Sandin R. Incidence of awareness in total i.v. anaesthesia based on propofol, alfentanil and neuromuscular blockade. Acta Anaesthesiol Scand 41: 978-84, 1997.

O'Connor MF, Daves SM, Tung A, Cook RI, Thisted R, Apfelbaum J. BIS monitoring to prevent awareness during general anesthesia. Anesthesiology 94: 520-2, 2001.

Osborne GA, Webb RK, Runciman WB. The Australian Incident Monitoring Study. Patient awareness during anaesthesia: an analysis of 2000 incident reports. Anaesth Intensive Care 21: 653-4, 1993.

Osterman JE, van der Kolk BA Awareness during anesthesia and posttraumatic stress disorder. Gen Hosp Psychiatry 20: 274-81, 1998.

Osterman JE, Hopper J, Heran WJ, Keane TM, van der Kolk BA Avareness under anesthesia and the development of posttraumatic stress disorder. Gen Hosp Psychiatry 23: 198-204, 2001.

Parkhouse J. Awareness during surgery. Postgrad Med J 36: 6747, 1960.

Payne JP. Awareness and its medicolegal implications. Br J Anaesth 73: 38-45, 1994.

Pedersen T, Johansen SH Serious morbidity attributable to anaesthesia. Considerations for prevention. Anaesthesia 44: 504-8, 1989.

Phillips AA, McLean RF, DevittJH, Harrington EM Recall of intraoperative events after general anaesthesia and cardiopulmonary bypass. Can J Anaesth 40: 922-6, 1993.

Ponte J. Neuromuscular blockers during general anaesthesia - less may be better. BM 310: 1218-9, 1995.

Prys-Roberts C. Anaesthesia: Apractical or impractical construct? Br J Anaesth 59: 1341-45, 1987.

Pöppel E, Schwender D. Temporal mechanisms of consciousness. Int Anesth Cin 31: 27-38, 1993.

Quasha AL, Eger EI, Tinker JH. Determination and applications of MAC. Anesthesiology 53: 315-34, 1980.

Rampil IJ. Anesthetic potency is not altered after hypothermic spinal cord transection in rats. Anesthesiology 80: 606-10, 1994.

Rampil IJ. A primer for EEG signal processing in anesthesia. Anesthesiology 89: 980-1002, 1998.
Rosenberg P, Gisvold SE, Flaatten H, Nuutinen L, Stenqvist O, Tryggvason B, Viby-Mogensen J. Guidelines for anaesthesia care in the Nordic countries. Acta Anaesthesiol Scand 36: 741-4, 1992.

Rosow C, Manberg PJ. Bispectral index monitoring. Anesth Cin North Am 2: 89-107, 1998.

Russell IF. Balanced anesthesia: does it anesthetize? Anesth Analg 64: 941-2, 1985.

Russell IF. Comparison of wakefulness with two anaesthetic regimens. Total i.v. v. balanced anaesthesia. Br J Anaesth 58: 965-8, 1986.

Russell IF. Midazolam-alfentanil: an anaesthetic? An investigation using the isolated forearm technique. Br J Anaesth 70: 42-6, 1993.

Russell IF, Wang M Absence of memory for intraoperative information during surgery under adequate general anaesthesia. $\mathrm{Br} \mathrm{J}$ Anaesth 78: 3-9, 1997.

Sado AS. Electronic medical record in the intensive care unit. Crit Care Cin 15: 499-522, 1999.

Sandin R, Nordström 0. Avareness during total i.v. anaesthesia. Br J Anaesth 71: 782-7, 1993.

Sandin RH, Enlund G, Samuelsson P, Lennmarken C. Aware ness during anaesthesia: a prospective case study. Lancet 355: 707$11,2000$.

Saucier N, Walts LF, Moreland JR. Patient awareness during nitrous oxide, oxygen, and halothane anesthesia. Anesth Analg 62: 239-40, 1983.

Scheinin H Lääkkeen pitoisuuden ja vaikutuksen korrelaatio. Duodecim 115: 2275-83, 1999.

Schultetus RR, Hill CR, Dharamraj CM, Banner TE, Berman LS. Wakefulness during cesarean section after anesthetic induction with ketamine, thiopental, or ketamine and thiopental combined. Anesth Analg 65: 723-8, 1986.

Schwender D, Faber-Zullig E, Kasing S, Poppel E, Peter K Motor signs of wakefulness during general anaesthesia with propofol, isoflurane and flunitrazepam/fentanyl and midlatency auditory evoked potentials. Anaesthesia 49: 476-84, 1994.

Schwender D, Haessler R, Klasing S, Madler C, Pöppel E, Peter K. Mid-latency auditory evoked potentials and circulatory response to loud sounds. Br J Anaesth 72: 307-14, 1994.

Schwender D, Kaiser A, Klasing S, Peter K, Poppel E. Midlatency auditory evoked potentials and explicit and implicit memory in patients undergoing cardiac surgery. Anesthesiology 80: 493-501, 1994.

Schwender D, Klasing S, Madler C, Pöppel E, Peter K Midlatency auditory evoked potentials and purposeful movements after thiopentone bolus injection. Anaesthesia 49: 99-104, 1994.

Schwender D, Klasing S, Conzen P, Finsterer U, Poppel E, Pe ter K Midlatency auditory evoked potentials during anaesthesia with increasing endexpiratory concentrations of desflurane. Acta Anaesthesiol Scand 40: 171-6, 1996. 
Schwender D, Kunze-Kronawitter H, Dietrich P, Klasing S, Forst $\mathrm{H}$, Madler C. Conscious awareness during general anaesthesia: patients' perceptions, emotions, cognition and reactions. Br J Anaesth 80: 133-9, 1998.

Schwilden H Neuropharmacology of anaesthetics. Curr Opin Anaesthesiol 7: 326-9, 1994.

Sigl JC, Chamoun NG. An introduction to bispectral analysis for the electroencephalogram. J Cin Monit 10: 392-404, 1994.

Smith WD, Dutton RC, Smith NT. Measuring the performance of anesthetic depth indicators. Anesthesiology 84: 38-51, 1996.

Spitzer RL, Williams JBW, Gibbon M, First MB. Sructured clinical interview for DSM-III-R non patient version (SCDD-NP). Washington D.C.: American Psychiatric Press, 1990a.

Spitzer RL, WilliamsJBW, Gibbon M, First MB. Sructured clinical interview for DSM-III-R personality disorder (SCD-II, version 1.0). Washington D.C.: American Psychiatric Press, 1990b.

St Pierre M, Landsleitner B, Schwilden H, Schuettler J. Awareness during laryngoscopy and intubation: quantitating incidence following induction of balanced anesthesia with etomidate and cisatracurium as detected with the isolated forearm technique.J Cin Anesth 12: 104-8, 2000.

Stanley TH, de Lange S. The effect of population habits on side effects and narcotic requirements during high-dose fentanyl anaesthesia. Can Anaesth Soc J 31: 368-76, 1984.

Stoelting RK, Longnecker DE, Eger EI. Minimum alveolar concentrationsin man on awakening from methoxyflurane, halothane, ether and fluroxene anesthesia: MAC Awake. Anesthesiology 33: 59, 1970.

Terrell RK, Sweet WO, Gladfelter JH, Stephen CR. Study of recall during anesthesia. Anesth Analg 48: 86-90, 1969.

Thornton C, Barrowcliffe MP, Konieczko KM, Ventham P, Dore CJ, Newton DE, Jones JG. The auditory evoked response as an indicator of awareness. Br J Anaesth 63: 113-5, 1989.

Thornton C, Jones JG. Evaluating depth of anesthesia: review of methods. Int Anesthesiol Cin 31: 67-88, 1993.

Thornton C, Sharpe RM. The auditory evoked responses and memory during anesthesia. In: Awareness during anesthesia, Ghoneim MM, ed. Oxford: Butterworth-Heinemann, 2001: 117-27.

Tunstall ME. Detecting wakefulness during general anaesthesia for caesarean section. BM 1: 1321, 1977.

Tunstall ME. The reduction of amnesic wakefulness during Caesarean section. Anaesthesia 34: 316-9, 1979.

Walder AD. Failure of anaesthesia with etomidate. Eur J Anaesthesiol 12: 325-7, 1995. van der Kolk BA, Osterman JE. The effects of trauma on memory: implications for awareness under anaesthesia. In: Memory and awareness in anaesthesia IV, Jordan C, Vaughan DJA, Newton DEF, eds. London: Imperial College Press, 2000: 193-202.

Wang M. The psychological consequences fo awareness during surgery. In: Memory and awareness in anaesthesia IV, Jordan C, Vaughan DJA, Newton DEF, eds. London: Imperial College Press, 2000: 315-24.

Wang M The psychological consequences fo explicit and implicit memories of events during surgery. In: Awareness during anesthesia, Ghoneim MM, ed. Oxford: Butterworth-Heinemann, 2001: 145-53.

Wells C. Insufficient anaesthesia. BM 1: 610, 1950.

Veselis RA, Reinsel R, Sommer S, Carlon G. Use of neural network analysis to classify electroencephalographic patterns against depth of midazolam sedation in intensive care unit patients. J Cin Monit 7: 259-67, 1991.

Wilder-Smith OHG, Hagon 0, Tassonyi E. EEG arousal during laryngoscopy and intubation: comparison of thiopentone or propofol supplemented with nitrous oxide. Br J Anaesth 75: 441-6, 1995.

Willenkin RL Management of general anesthesia. In: Anesthesia (3. ed.), Miller RR, ed. NewYork: Churchill Livingstone, 1990: 133546.

Wilson J, Turner DJ. Awareness during caesarean section under general anaesthesia. BM 1: 280-3, 1969.

Wilson SL, Vaughan RW, Stephen CR. Avareness, dreams, and hallucinations associated with general anesthesia. Anesth Analg 54: 609-17, 1975.

Winterbottom EH Insufficient anaesthesia. BM 1: 247-8, 1950.

Wolters G, Phaf RH Explicit and implicit measures of memory: evidence for two learning mechanisms. In: Memory and Aware ness in Anaesthesia, Bonke B, Fitch W, Millar K, eds. Amsterdam: Swets \& Zeitlinger Publishers, 1990: 57-63.

Wong KC. Narcotics are not expected to produce unconsciousness and amnesia. Anesth Analg 62: 625-6, 1983.

Yli-Hankala A, Lindgren L, Porkkala T, Jäntti V. Nitrous oxidemediated activation of the EEG during isoflurane anaesthesia in patients. Br J Anaesth 70: 54-7, 1993.

Yli-Hankala A Operating theatre-the patient is listening. Acta Anaesthesiol Scand 44: 131-2, 2000.

Zurada JM Introduction to artificial neural systems. Boston, MA: PWS Publishing Company, 1992. 


\section{Appendix}

Details of the patient cases with aw areness and recall during general anesthesia. Patient demographics, recalled experience, surgery and anesthesia details, details of the recalled experience, and after-effects are given. Comments refer to the author's comments on certain experiences.

\section{Abbreviations used}

$\begin{array}{ll}\text { AEP } & \text { Auditory evoked potential } \\ \text { CABG } & \text { Coronary artery bypass grafting } \\ \text { D \& C } & \text { Dilatation and curettage } \\ \text { EBT } & \text { Endobronchial tube } \\ \text { ETAGC } & \text { End-tidal anesthetic gas concentration } \\ \text { ETT } & \text { Endotracheal tube } \\ \text { F } & \text { Female } \\ \text { ICU } & \text { Intensive care unit } \\ \text { M } & \text { M ale } \\ \text { M VR } & \text { M itral valve replacement } \\ \text { N 2O } & \text { Nitrous oxide } \\ \text { N M B } & \text { N euromuscular blocker } \\ \text { OR } & \text { O perating room } \\ \text { Tx cordis } & \text { H eart transplantation }\end{array}$

\section{Awareness groups:}

1. Patients with unclear memories or dreams, which could be of intraoperative origin.

2. Patients with short periods of awareness occurring either intraoperative or during the period of awakening from anesthesia.

3. Patients with long-lasting, clear, and undisputed recall of the intraoperative period. 
Patient

\begin{tabular}{|c|c|c|c|c|c|c|c|}
\hline Patient & Study & $\begin{array}{c}\text { Year of } \\
\text { anesthesia }\end{array}$ & $\begin{array}{l}\text { Age } \\
\text { (years) }\end{array}$ & Sex & $\begin{array}{l}\text { Weight } \\
(\mathrm{kg})\end{array}$ & $\begin{array}{l}\text { H eight } \\
\text { (cm) }\end{array}$ & Surgery \\
\hline 1 & 1,4 & 1994 & 30 & $\mathrm{~F}$ & 80 & 172 & Gynecological laparoscopy \\
\hline 2 & 1,4 & 1994 & 65 & M & 72 & 180 & Laparotomy for malignancy \\
\hline 3 & 1 & 1994 & 47 & $\mathrm{~F}$ & 78.5 & 160 & Gynecological laparotomy \\
\hline 4 & 1,4 & 1995 & 31 & $\mathrm{~F}$ & 70 & 160 & Conisation \\
\hline 5 & 1,4 & 1995 & 82 & $\mathrm{~F}$ & 58 & 150 & Cholecystectomy \\
\hline 6 & 1,4 & 1994 & 62 & M & 112 & 172 & M icrolaryngoscopy \\
\hline 7 & 1 & 1995 & 64 & $\mathrm{~F}$ & 65 & 161 & Reconstruction of supraspinatus tendon \\
\hline 8 & 1 & 1995 & 47 & M & 70 & 174 & Excision of cutaneous melanoma \\
\hline 9 & 1,4 & 1995 & 53 & $\mathrm{~F}$ & 80 & 163 & Transposition of tendons in right leg \\
\hline 10 & 1,4 & 1995 & 36 & $\mathrm{~F}$ & 92 & 168 & Gynecological laparoscopy \\
\hline 11 & 1,4 & 1995 & 23 & $\mathrm{~F}$ & 70 & 167 & Knee arthroscopy \\
\hline 12 & 1 & 1994 & 20 & $\mathrm{~F}$ & 57 & 171 & Appendectomy \\
\hline 13 & 1 & 1994 & 49 & $\mathrm{~F}$ & 64 & 169 & $D \& C$ \\
\hline 14 & 1 & 1994 & 38 & $\mathrm{~F}$ & 60 & 154 & Laparoscopic cholecystectomy \\
\hline
\end{tabular}


Anesthetic details

Patient Recalled experience

Awareness Duration of Premedication group anesthesia

(min)

1 Clearly remembers the anesthetic induction, and extubation

3

$163 \quad$ None

of her trachea. In between, heard clear human voices and felt pain which she was not able to localize.

2 Recollects waking with intubation tube in the throat and many people around, given more medications which put him asleep again

3 Recollects a dream of lights of the operating room and several people around operating on her

4 Shortness of breath and anxiety at induction. $\mathrm{H}$ eard noises and a male voice and felt somebody touch her Felt extubation and at the same time intense fear. Believed that she was dying.

$5 \quad H$ eard discussions (both male and female voices), felt something done in her stomach; recurring pressure of blood pressure cuff on her arm, heard the ventilator; no pain

6 Felt the intubation tube in his throat and felt that nauseating, saw light and human figures, heard discussions, remembers somebody quote high blood pressure readings (could be confirmed by the anesthesia record)

7 Heard voices and discussions; does not herself know, if this was dream or real

8 Undefined memories; during awakening felt like coming from a fight

9 At awakening felt the intubation tube in her throat

2

170 Benzodiazepine

2

119 Benzodiazepine

$36 \quad$ None

3

$79 \quad$ None

3

$47 \quad$ Opioid

10 Heard discussions, and felt vaginal manipulation; pain in the abdomen, either intra- or postoperatively

11 At awakening felt the intubation tube in her throat

12 Unspecified "unpleasant feeling" during the operation

1

13 Heard music

1

14 Unspecified anxiety at awakening

1

13 None

173 Benzodiazepine

67 Benzodiazepine

$42 \quad$ None

$35 \quad$ None

50 Benzodiazepine

$77 \quad$ Opioid 
Anesthetic details

\begin{tabular}{|c|c|c|c|c|c|}
\hline Patient & Co-induction & Induction & M aintenance & $\mathrm{N} 20$ & $\begin{array}{l}\text { ETAGC } \\
\text { monitoring }\end{array}$ \\
\hline 1 & Fentanyl & Propofol & $\begin{array}{l}\text { Propofol (bolus dosing), } \\
\text { enflurane (non-continuous) }\end{array}$ & Yes & N ot recorded \\
\hline 2 & Fentanyl & Thiopental & Isoflurane & Yes & N ot recorded \\
\hline 3 & Fentanyl & Thiopental & $\begin{array}{l}\text { Thiopental (bolus dosing), } \\
\text { isoflurane (non-continuous) }\end{array}$ & Yes & $\mathrm{N}$ ot recorded \\
\hline 4 & Fentanyl & Propofol & Isoflurane & Yes & Not recorded \\
\hline 5 & Fentanyl & Thiopental & Isoflurane & No & $\mathrm{N}$ ot recorded \\
\hline 6 & Fentanyl & Propofol & Propofol (bolus dosing) & Yes & No \\
\hline 7 & Fentanyl & Thiopental & Isoflurane & Yes & N ot recorded \\
\hline 8 & Fentanyl & Thiopental & Isoflurane & Yes & N ot recorded \\
\hline 9 & Fentanyl & Propofol & Isoflurane & Yes & Not recorded \\
\hline 10 & Fentanyl & Propofol & Propofol (bolus dosing) & Yes & No \\
\hline 11 & Fentanyl & Propofol & Isoflurane & Yes & $\mathrm{N}$ ot recorded \\
\hline 12 & $\begin{array}{l}\text { Benzodiazepine, } \\
\text { Fentanyl }\end{array}$ & Ketamine & Isoflurane (non-continuous) & Yes & Not recorded \\
\hline 13 & Alfentanil & Propofol & Propofol (bolus dosing) & Yes & No \\
\hline 14 & Fentanyl & Thiopental & Enflurane & No & $\mathrm{N}$ ot recorded \\
\hline
\end{tabular}




\begin{tabular}{|c|c|c|c|c|c|c|c|c|c|}
\hline Patient & NMB & Airway & Pain & Auditory & Visual & Tactile & $\begin{array}{l}\text { Tried to } \\
\text { move }\end{array}$ & $\begin{array}{l}\text { Able to } \\
\text { move }\end{array}$ & $\begin{array}{l}\text { Immediate } \\
\text { understanding }\end{array}$ \\
\hline 1 & Atracurium & ETT & Yes & Yes & No & No & & & Yes \\
\hline 2 & Atracurium & ETT & No & & Yes & Yes & & & \\
\hline 3 & Vecuronium & ETT & No & No & Yes & No & & & Yes \\
\hline 4 & Atracurium & ETT & No & Yes & Yes & Yes & Yes & & Yes \\
\hline 5 & Atracurium & ETT & No & Yes & No & Yes & Yes & Yes & Yes \\
\hline 6 & Succinylcholine & ETT & No & Yes & Yes & Yes & Yes & & Yes \\
\hline 7 & Atracurium & ETT & No & Yes & No & No & & & No \\
\hline 8 & Atracurium & ETT & No & No & No & No & & & No \\
\hline 9 & Atracurium & ETT & No & No & No & Yes & & & Yes \\
\hline 10 & Atracurium & ETT & Yes & Yes & No & Yes & & & No \\
\hline 11 & Atracurium & ETT & No & No & No & Yes & & & Yes \\
\hline 12 & Atracurium & ETT & No & No & No & No & & & No \\
\hline 13 & None & M ask & No & Yes & No & No & & & \\
\hline 14 & Vecuronium & ETT & No & No & No & No & & & No \\
\hline
\end{tabular}


D etails of recollection and after-effects

\begin{tabular}{|c|c|c|c|c|}
\hline Patient & $\begin{array}{l}\text { Immediate } \\
\text { anxiety }\end{array}$ & $\begin{array}{l}\text { D uration of } \\
\text { awareness as } \\
\text { estimated by the } \\
\text { patient }\end{array}$ & $\begin{array}{l}\text { Awareness as the } \\
\text { most unpleasant } \\
\text { experience } \\
\text { during operation }\end{array}$ & After effects \\
\hline 1 & No & M inutes & No & \\
\hline \multicolumn{5}{|l|}{2} \\
\hline 3 & No & Short (seconds) & No & \\
\hline 4 & Yes & Long (minutes) & Yes & $\begin{array}{l}\text { Sleep disturbances, but did not meet the criteria } \\
\text { for post traumatic stress disorder (PT SD ) }\end{array}$ \\
\hline 5 & No & Long & No & \\
\hline 6 & No & $\mathrm{N}$ ot very long & Yes & $\begin{array}{l}\text { Treated with anti-depressant medication after } \\
\text { the experience, recovered. }\end{array}$ \\
\hline 7 & No & Long & & \\
\hline 8 & & Long & & \\
\hline 9 & & & No & \\
\hline
\end{tabular}

10

11

No

12

No

13

No

14 Yes 
Patient Comments

1

2 Recollection at the immediate post-operative interview only. D id not remember anything the next day.

3 Experience could also have been a dream or hallucination.

4

5 D id not find the experience of awareness at all unpleasant. Recalls having thought: " $\mathrm{N}$ ow, the doctors are working and I will lie down here"

6

7

8 Experience mixed with very unpleasant dreams.

9

10

11

12

13

14 
Patient

\begin{tabular}{|c|c|c|c|c|c|c|c|}
\hline Patient & Study & $\begin{array}{c}\text { Year of } \\
\text { anesthesia }\end{array}$ & $\begin{array}{c}\text { Age } \\
\text { (years) }\end{array}$ & Sex & $\begin{array}{l}\text { Weight } \\
\text { (kg) }\end{array}$ & $\begin{array}{l}\text { Height } \\
(\mathrm{cm})\end{array}$ & Surgery \\
\hline 15 & 1 & 1994 & 47 & $\mathrm{~F}$ & 70 & 160 & $D \& C C$ \\
\hline 16 & 1,4 & 1994 & 29 & $\mathrm{~F}$ & 44 & 164 & Gynecological laparoscopy \\
\hline 17 & 1 & 1995 & 50 & $\mathrm{~F}$ & 107 & 163 & $D \& C C$ \\
\hline 18 & 1 & 1995 & 71 & $\mathrm{~F}$ & 70 & 158 & Spinal laminectomy \\
\hline 19 & 1 & 1994 & 69 & $\mathrm{~F}$ & 71 & 165 & Laparotomy due to malignancy \\
\hline 20 & 2 & 1992 & 49 & M & 84 & 167 & CABG \\
\hline 21 & 2 & 1992 & 49 & M & 63 & 176 & CABG \\
\hline 22 & 2 & 1992 & 45 & $\mathrm{~F}$ & 48 & 144 & CABG \\
\hline 23 & 2 & 1992 & 44 & M & 123 & 175 & CABG \\
\hline 24 & 2 & 1993 & 44 & M & 72 & 174 & CABG \\
\hline 25 & 2 & 1993 & 51 & M & 87,5 & 178 & Tx cordis \\
\hline 26 & 2 & 1993 & 59 & $F$ & 49 & 159 & M VR \\
\hline
\end{tabular}


Anesthetic details

Patient Recalled experience

Awareness
group anation of Premedication
anesthesia

(min)

15 Unspecified intraoperative memories

1

10

None

16 Could not breathe at awakening

2

$46 \quad$ None

17 Unspecified "powerful feelings" during the operation

1

$15 \quad$ None

18 H eard noises and somebody moving around her.

1

75

Benzodiazepine

19 Felt difficult to breathe at awakening and felt something

2 taken out of her throat

20 Felt tearing sensation in his chest, "Like horses were tearing me in pieces." This was not painful, though. $\mathrm{H}$ e also heard "diffuse speech."

21 Felt the opening of his sternum starting from the upper end. There was no pain. Healso heard women voices but could not recall what was said. He did not feel this unpleasant and felt confident in his doctors all the time. $\mathrm{H}$ e also dreamt of cartoons.

22 Felt the opening of her chest, but this was not painful. She also heard her doctor saying, "T his won't take long." After this, she had no recall of operation.

23 H eard somebody call, "N ow there's a hurry!" He felt something done in his chest but felt no pain. He was alarmed, frightened and anxious and in vain tried to signal his consciousness. Then he felt an "electric shock" after which he became unconscious again.

24 Felt a scraping sensation on his chest twice. This sensation persisted only for few seconds, and the patient thought that, apparently, the operation has begun. He felt no pain, did not consider this sensation alarming.

25 He heard some discussion and thought, "The doctors don't know that I'm not asleep yet." He tried to say he was not asleep but felt paralyzed. Then he felt something pushed in his mouth and throat. After this he rapidly became unaware.

26 She had had a mitral valve commisurotomy made twice in the past. D uring the general anesthesia, she heard a discussion where a male voice said, "Shall we cut out the old

Scopolamine + opioid

254 Scopolamine + opioid

375 Scopolamine + opioid

320 Scopolamine + opioid scar?" Another voice replied, "Of cause we shall." Then she felt something pushed down her throat and further felt pressure and pain in her chest. She tried to wave her arm but could not. According to the patient, this all took about one minute. 
Anesthetic details

\begin{tabular}{|c|c|c|c|c|c|}
\hline Patient & Co-induction & Induction & M aintenance & N 20 & $\begin{array}{l}\text { ETAGC } \\
\text { monitoring }\end{array}$ \\
\hline 15 & Alfentanil & Propofol & Propofol (bolus dosing) & Yes & No \\
\hline 16 & Fentanyl & Propofol & $\begin{array}{l}\text { Isoflurane, Propofol (bolus } \\
\text { dosing) }\end{array}$ & No & $\mathrm{N}$ ot recorded \\
\hline 17 & Alfentanil & Propofol & Propofol (bolus dosing) & Yes & No \\
\hline 18 & Fentanyl & Thiopental & Isoflurane & Yes & $\mathrm{N}$ ot recorded \\
\hline 19 & Fentanyl & Thiopental & Isoflurane (non-continuous) & Yes & $\mathrm{N}$ ot recorded \\
\hline 20 & Fentanyl & Diazepam & $\begin{array}{l}\text { Fentanyl (bolus dosing), } \\
\text { isoflurane (non-continuous) }\end{array}$ & No & $\mathrm{N}$ ot recorded \\
\hline 21 & Fentanyl & Diazepam & Fentanyl (bolus dosing) & No & No \\
\hline 22 & Fentanyl & Diazepam & $\begin{array}{l}\text { Fentanyl (bolus dosing), } \\
\text { enflurane (non-continuous) }\end{array}$ & No & $\mathrm{N}$ ot recorded \\
\hline 23 & Fentanyl & D iazepam & $\begin{array}{l}\text { Fentanyl (bolus dosing), } \\
\text { diazepam (bolus dosing), } \\
\text { enflurane (non-continuous) }\end{array}$ & No & $\mathrm{N}$ ot recorded \\
\hline 24 & M orphine & Thiopental & $\begin{array}{l}\text { Thiopental-infusion (non- } \\
\text { continuous), fentanyl-infusion } \\
\text { (non-continuous), diazepam } \\
\text { (bolus-dosing), enflurane (non- } \\
\text { continuous) }\end{array}$ & No & $\mathrm{N}$ ot recorded \\
\hline 25 & Fentanyl & Diazepam & $\begin{array}{l}\text { Fentanyl-infusion, isoflurane } \\
\text { (non-continuous) }\end{array}$ & No & $\mathrm{N}$ ot recorded \\
\hline 26 & Fentanyl & Diazepam & $\begin{array}{l}\text { Thiopental (bolus dosing), } \\
\text { enflurane (non-continuous) }\end{array}$ & No & $\mathrm{N}$ ot recorded \\
\hline
\end{tabular}




\begin{tabular}{|c|c|c|c|c|c|c|c|c|c|}
\hline Patient & NMB & Airway & Pain & Auditory & Visual & Tactile & $\begin{array}{l}\text { Tried to } \\
\text { move }\end{array}$ & $\begin{array}{l}\text { Able to } \\
\text { move }\end{array}$ & $\begin{array}{l}\text { Immediate } \\
\text { understanding }\end{array}$ \\
\hline 15 & None & M ask & No & No & No & No & & & No \\
\hline 16 & Atracurium & ETT & No & No & No & No & & & Yes \\
\hline 17 & None & M ask & No & No & No & No & & & \\
\hline 18 & Atracurium & ETT & No & Yes & No & No & & & \\
\hline 19 & Atracurium & ETT & No & No & No & Yes & & & Yes \\
\hline 20 & Pancuronium & ETT & No & Yes & No & Yes & & & Yes \\
\hline 21 & Pancuronium & ETT & No & Yes & No & Yes & & & Yes \\
\hline 22 & Pancuronium & ETT & No & Yes & No & Yes & & & Yes \\
\hline 23 & Pancuronium & ETT & No & Yes & No & Yes & Yes & No & Yes \\
\hline 24 & Pancuronium & ETT & No & No & No & Yes & & & Yes \\
\hline 25 & Pancuronium & ETT & No & Yes & No & Yes & Yes & No & Yes \\
\hline 26 & Pancuronium & ETT & Yes & Yes & No & Yes & Yes & No & Yes \\
\hline
\end{tabular}


D etails of recollection and after-effects

\begin{tabular}{|c|c|c|c|}
\hline Patient & $\begin{array}{c}\text { Immediate } \\
\text { anxiety }\end{array}$ & $\begin{array}{l}\text { D uration of } \\
\text { awareness as } \\
\text { estimated by the } \\
\text { patient }\end{array}$ & $\begin{array}{l}\text { Awareness as the After effects } \\
\text { most unpleasant } \\
\text { experience } \\
\text { during operation }\end{array}$ \\
\hline
\end{tabular}

15

16

17

18

19 Yes

$20 \quad$ No

$21 \quad$ No

22

No

$23 \quad$ Yes

24 No Seconds

25 Yes 1-2 minutes

26 Yes Minutes
No

No

Yes

No

No

No

Yes Post-operative nightmares, flashbacks

No

Yes

No 
Patient Comments

15

16

17

18

19

20

21

22

23

24

25

26 
Patient

\begin{tabular}{|c|c|c|c|c|c|c|c|}
\hline Patient & Study & $\begin{array}{c}\text { Year of } \\
\text { anesthesia }\end{array}$ & $\begin{array}{c}\text { Age } \\
\text { (years) }\end{array}$ & Sex & $\begin{array}{l}\text { Weight } \\
(\mathrm{kg})\end{array}$ & $\begin{array}{l}\text { H eight } \\
(\mathrm{cm})\end{array}$ & Surgery \\
\hline 27 & 3 & 1995 & 54 & M & 82 & 170 & CABG \\
\hline 28 & 3 & 1995 & 68 & M & 83 & 170 & $C A B G$ \\
\hline 29 & 3 & 1995 & 47 & M & 97 & 180 & $C A B G$ \\
\hline 30 & 3 & 1995 & 53 & M & 99 & 177 & $C A B G$ \\
\hline 31 & 3 & 1995 & 71 & M & 80 & 171 & $C A B G$ \\
\hline 32 & 3 & 1995 & 72 & M & 90 & 176 & $C A B G$ \\
\hline 33 & 3 & 1995 & 70 & M & 71,5 & 168 & CABG \\
\hline 34 & 3 & 1995 & 53 & M & 90 & 186 & $C A B G+M V R$ \\
\hline 35 & 3 & 1995 & 60 & M & 75 & 176 & CABG \\
\hline
\end{tabular}

$\begin{array}{llllllll}36 & 3 & 1996 & 69 & M & 73 & 174 & \text { CABG }\end{array}$

$\begin{array}{llllllll}37 & 3 & 1995 & 82 & M & 62 & 172 & \text { CABG }\end{array}$ 
Anesthetic details

Patient Recalled experience
Awareness Duration of Premedication
group anesthesia

(min)

27 Suffered from serious mental depression before the 3

252

Benzodiazepine operation, and antidepressive medication was started a week before the operation. Recollects waking with much pain in his chest "like the chest was opened with a saw". Saw people moving around him and heard women laughing. Felt also pain his neck. Thinks that he was aware of what is going on around him for 2 to 3 hours.

28 This patient underwent an unsuccessful coronary angioplasty and was immediately transferred to the $O R$ for surgical CABG. The patient recollects discussions, pain in his neck and a tracheal tube in his throat.

29 The patient underwent a second operation because of postoperative bleeding six hours after the primary operation. The patient recollects being unable to open his eyes, shortness of breath and utmost anxiety. Then remembers falling asleep again.

30 Recollects the intubation.

2

$325 \quad$ None

$2239 \mathrm{~min}, \quad$ Scopolamine + reoperation opioid

$5,75 \mathrm{~h}$ later, reoperation $105 \mathrm{~min}$

2

265

Benzodiazepine

31 Recollects hearing a rattling noise which the patient attributes to sawing of the sternum. Recollects thinking that one should not hear this.

32 Pain which the patient attributes to the time of awakening

$33 \mathrm{H}$ eard male voices; the patient attributes this to the preoperative period in the $\mathrm{OR}$

34 M emories of movement. The patient can't attribute the recollection to a specified time.

Benzodiazepine

35 Remembers a discussion about reoperation. The patient underwent a reoperation because of inadequate hemostasis $61 / 2$ hours after the primary operation. Recollections are likely to have occurred during the interval between the operations.

Benzodiazepine

Benzodiazepine

1

514 Scopolamine +
opioid

240min, Scopolamine + reoperation opioid

6,75 hours

later, reoperation $49 \min$

36 O pened his eyes during the operation. Doesn't, however,

Scopolamine + remember this. On the other hand recollects loud male and female voices, "like in a noisy restaurant". The patient attributes this to the postoperative period in the ICU.

37 Unpleasant feeling coupled with nausea. The patient attributes this to the intraoperative period. 
Anesthetic details

\begin{tabular}{|c|c|c|c|c|c|}
\hline Patient & Co-induction & Induction & M aintenance & $\mathrm{N} 20$ & $\begin{array}{l}\text { ETAGC } \\
\text { monitoring }\end{array}$ \\
\hline 27 & Sufentanil & M idazolam & $\begin{array}{l}\text { Sufentanil-infusion, midazolam- } \\
\text { infusion, isoflurane (non- } \\
\text { continuous) }\end{array}$ & No & Yes \\
\hline 28 & Sufentanil & D iazepam & $\begin{array}{l}\text { Sufentanil-infusion, isoflurane } \\
\text { (non-continuous), thiopental } \\
\text { (bolus dosing) }\end{array}$ & No & Yes \\
\hline 29 & Sufentanil & D iazepam & Sufentanil-infusion, enflurane & No & $\mathrm{N}$ ot recorded \\
\hline 30 & Fentanyl & M idazolam & $\begin{array}{l}\text { Fentanyl-infusion, midazolam- } \\
\text { infusion, isoflurane (non- } \\
\text { continuous) }\end{array}$ & No & $\mathrm{N}$ ot recorded \\
\hline 31 & Sufentanil & D iazepam & Sufentanil-infusion, enflurane & No & Yes \\
\hline 32 & Fentanyl & D iazepam & $\begin{array}{l}\text { Fentanyl-infusion, propofol- } \\
\text { infusion }\end{array}$ & No & $\mathrm{N}$ ot recorded \\
\hline 33 & Sufentanil & D iazepam & $\begin{array}{l}\text { Sufentanil-infusion, enflurane } \\
\text { (non-continuous), isoflurane } \\
\text { (non-continuous) }\end{array}$ & No & $\mathrm{N}$ ot recorded \\
\hline 34 & Fentanyl & M idazolam & $\begin{array}{l}\text { Fentanyl-infusion, midazolam- } \\
\text { infusion, isoflurane (non- } \\
\text { continuous) }\end{array}$ & No & Yes \\
\hline 35 & Fentanyl & D iazepam & $\begin{array}{l}\text { Fentanyl-infusion, midazolam- } \\
\text { infusion, isoflurane (non- } \\
\text { continuous) }\end{array}$ & No & Yes \\
\hline 36 & Fentanyl & D iazepam & $\begin{array}{l}\text { Fentanyl-infusion, enflurane } \\
\text { (non-continuous) }\end{array}$ & No & Yes \\
\hline 37 & Fentanyl & $\begin{array}{l}\text { M idazolam, } \\
\text { thiopental }\end{array}$ & $\begin{array}{l}\text { Fentanyl-infusion, midazolam- } \\
\text { infusion, isoflurane (non- } \\
\text { continuous) }\end{array}$ & No & Yes \\
\hline
\end{tabular}




\begin{tabular}{|c|c|c|c|c|c|c|c|c|c|}
\hline Patient & NMB & Airway & Pain & Auditory & Visual & Tactile & $\begin{array}{l}\text { Tried to } \\
\text { move }\end{array}$ & $\begin{array}{c}\text { Able to } \\
\text { move }\end{array}$ & $\begin{array}{l}\text { Immediate } \\
\text { understanding }\end{array}$ \\
\hline 27 & Pancuronium & ETT & Yes & Yes & Yes & Yes & No & & Yes \\
\hline 28 & Pancuronium & ETT & Yes & Yes & No & Yes & & & Yes \\
\hline 29 & Pancuronium & ETT & No & Yes & No & No & Yes & No & Yes \\
\hline 30 & Pancuronium & ETT & No & No & No & Yes & No & & Yes \\
\hline 31 & Pancuronium & ETT & No & Yes & No & No & No & & Yes \\
\hline 32 & Pancuronium & ETT & Yes & No & No & & & & \\
\hline 33 & Pancuronium & ETT & No & Yes & No & No & & & Yes \\
\hline 34 & Pancuronium & ETT & No & No & & No & & & No \\
\hline 35 & Pancuronium & ETT & No & Yes & No & No & No & Yes & Yes \\
\hline 36 & Pancuronium & ETT & No & Yes & No & No & No & Yes & Yes \\
\hline 37 & Pancuronium & ETT & No & No & No & No & & & No \\
\hline
\end{tabular}


D etails of recollection and after-effects

\begin{tabular}{|c|c|c|c|}
\hline Patient & $\begin{array}{l}\text { Immediate } \\
\text { anxiety }\end{array}$ & $\begin{array}{l}\text { D uration of } \\
\text { awareness as } \\
\text { estimated by the } \\
\text { patient }\end{array}$ & $\begin{array}{l}\text { Awareness as the After effects } \\
\text { most unpleasant } \\
\text { experience } \\
\text { during operation }\end{array}$ \\
\hline 27 & Yes & $2-3$ hours & No \\
\hline 28 & & & No \\
\hline 29 & Yes & & Yes \\
\hline 30 & No & & No \\
\hline 31 & No & Seconds & No \\
\hline 32 & & & No \\
\hline 33 & No & & No \\
\hline 34 & & & No \\
\hline 35 & No & 30 seconds & No \\
\hline 36 & No & Not long & No \\
\hline 37 & & & No \\
\hline
\end{tabular}


Patient Comments

27

28 Coronary angioplasty and emergency CABG. Recollections may originate betwen these operations.

29

30

31

32 Possible post-operative recollection from the ICU

33

34

35 Reoperation anesthesia: diazepam, fentanyl and non-continuous isoflurane. Recollections possibly from the time between the operations.

36

37 
Patient

\begin{tabular}{|c|c|c|c|c|c|c|c|}
\hline Patient & Study & $\begin{array}{c}\text { Year of } \\
\text { anesthesia }\end{array}$ & $\begin{array}{l}\text { Age } \\
\text { (years) }\end{array}$ & Sex & $\begin{array}{l}\text { Weight } \\
\text { (kg) }\end{array}$ & $\begin{array}{l}\text { H eight } \\
(\mathrm{cm})\end{array}$ & Surgery \\
\hline 38 & 3 & 1995 & 61 & M & 71 & 168 & $C A B G$ \\
\hline 39 & 3 & 1995 & 53 & M & 81 & 178 & CABG \\
\hline 40 & 3 & 1995 & 52 & M & 81 & 174 & $C A B G$ \\
\hline 41 & 3 & 1995 & 53 & $\mathrm{~F}$ & 81 & 167 & CABG \\
\hline 42 & 3 & 1995 & 82 & M & 78 & 175 & $C A B G$ \\
\hline 43 & 3 & 1995 & 55 & M & 82 & 177 & CABG \\
\hline 44 & 3 & 1995 & 68 & M & 80,5 & 175 & $C A B G$ \\
\hline 45 & 3 & 1995 & 57 & M & 75 & 176 & CABG \\
\hline 46 & 3 & 1995 & 50 & M & 69 & 176 & CABG \\
\hline 47 & 3 & 1995 & 74 & $\mathrm{~F}$ & 68 & 155 & CABG \\
\hline 48 & 4,5 & 1987 & 53 & M & 75 & 171 & Thoracotomy \\
\hline
\end{tabular}


Anesthetic details

Patient Recalled experience
Awareness Duration of Premedication group anesthesia

(min)

38 Recollects that tubes were pulled out of his chest. This was accompanied with slight pain. The patient attributes this to the last phase of the operation. AEP monitoring was used during this operation but not after the cardiopulmonary bypass period.

39 Remembers someone talking to him. An unpleasant feeling in his throat. Cannot attribute the recollections to a specified time.

40 Recollects being transported form one place to another.

1

310

Benzodiazepine

41 Recollects having seen some lights.

42 Remembers feeling very bad, considered himself as dead

43 Recollects few people talking to him about fixing the intubation tube.

44 Recollects seeing tubes and drains.

45 Recollects falling asleep. Then felt pain in the chest and simultaneously heard somebody saying "we are removing something and you may feel pain". The patient attributes this to the preoperative period. That the patient was told that "you may feel pain" suggests that the recollections are not intraoperative.

46 The patient underwent a second operation because of postoperative bleeding four hours after the primary operation. Recollects hearing a discussion with a concerned tone. During that timethought that he is still in the middle of an operation.

47 Recollects dreaming about somebody slaughtering sheep in an attic. Simultaneously felt something in her throat. The feeling was very frightening.

48 Recollects positioning for thoracotomy, skin incision, diathermy of subcutaneous vessels, opening of intercostal muscles with cutting diathermy. Blood pressure cuff squeezing the arm. Discussion on a male voice.

1

1

1

1

1

1

1

3
260 Benzodiazepine

225 Benzodiazepine

337 Scopolamine + opioid

201 Benzodiazepine

240 Benzodiazepine

262 Benzodiazepine

273 Scopolamine + opioid

283 min, Benzodiazepine
reoperation
4 hours
later,
reoperation
49 min
$270 \quad$ O pioid
$94 \quad$ Benzodiazepine


Anesthetic details

\begin{tabular}{|c|c|c|c|c|c|}
\hline Patient & Co-induction & Induction & M aintenance & $\mathrm{N} 20$ & $\begin{array}{l}\text { ETAGC } \\
\text { monitoring }\end{array}$ \\
\hline 38 & Fentanyl & Lorazepam & Fentanyl-infusion, enflurane & No & Yes \\
\hline 39 & Sufentanil & M idazolam & $\begin{array}{l}\text { Sufentanil-infusion, midazolam- } \\
\text { infusion, isoflurane (non- } \\
\text { continuous) }\end{array}$ & No & Yes \\
\hline 40 & Fentanyl & D iazepam & $\begin{array}{l}\text { Fentanyl-infusion, isoflurane } \\
\text { (non-continuous) }\end{array}$ & No & Yes \\
\hline 41 & Fentanyl & M idazolam & $\begin{array}{l}\text { Fentanyl-infusion, midazolam- } \\
\text { infusion, isoflurane (non- } \\
\text { continuous) }\end{array}$ & No & $\mathrm{N}$ ot recorded \\
\hline 42 & Fentanyl & M idazolam & $\begin{array}{l}\text { Fentanyl-infusion, midazolam- } \\
\text { infusion, isoflurane (non- } \\
\text { continuous) }\end{array}$ & No & $\mathrm{N}$ ot recorded \\
\hline 43 & Sufentanil & D iazepam & Sufentanil-infusion, isoflurane & No & Yes \\
\hline 44 & Alfentanil & $\begin{array}{l}\text { M idazolam, } \\
\text { propofol }\end{array}$ & $\begin{array}{l}\text { Alfentanil-infusion, midazolam- } \\
\text { infusion, isoflurane (non- } \\
\text { continuous) }\end{array}$ & No & Yes \\
\hline 45 & Fentanyl & D iazepam & $\begin{array}{l}\text { Fentanyl-infusion, midazolam- } \\
\text { infusion, enflurane (non- } \\
\text { continuous) }\end{array}$ & No & Yes \\
\hline 46 & Fentanyl & L orazepam & Fentanyl-infusion, enflurane & No & Yes \\
\hline 47 & Fentanyl & D iazepam & $\begin{array}{l}\text { Fentanyl (bolus dosing), } \\
\text { diazepam (bolus dosing), } \\
\text { isoflurane (non-continuous) }\end{array}$ & No & Yes \\
\hline 48 & Fentanyl & Thiopental & Isoflurane & Yes & N ot recorded \\
\hline
\end{tabular}




\begin{tabular}{|c|c|c|c|c|c|c|c|c|c|}
\hline Patient & NM B & Airway & Pain & Auditory & Visual & Tactile & $\begin{array}{l}\text { Tried to } \\
\text { move }\end{array}$ & $\begin{array}{l}\text { Able to } \\
\text { move }\end{array}$ & $\begin{array}{c}\text { Immediate } \\
\text { understanding }\end{array}$ \\
\hline 38 & Pancuronium & ETT & Yes & No & No & Yes & No & Yes & Yes \\
\hline 39 & Pancuronium & ETT & Yes & Yes & No & Yes & & & No \\
\hline 40 & Pancuronium & ETT & No & No & No & No & & & Yes \\
\hline 41 & Pancuronium & ETT & No & No & Yes & No & & & Yes \\
\hline 42 & Pancuronium & ETT & No & No & No & No & & & Yes \\
\hline 43 & Pancuronium & ETT & No & Yes & No & No & & & No \\
\hline 44 & Atracurium & ETT & No & No & Yes & & & & Yes \\
\hline 45 & Pancuronium & ETT & Yes & Yes & No & Yes & & Yes & Yes \\
\hline 46 & Pancuronium & ETT & No & Yes & No & No & & & Yes \\
\hline 47 & Pancuronium & ETT & No & Yes & No & No & Yes & No & No \\
\hline 48 & $\begin{array}{l}\text { Succinylcholine, } \\
\text { pancuronium }\end{array}$ & EBT & Yes & Yes & No & Yes & Yes & No & Yes \\
\hline
\end{tabular}


D etails of recollection and after-effects

\begin{tabular}{cll} 
Patient & $\begin{array}{l}\text { Immediate Duration of } \\
\text { anxiety } \\
\text { awareness as } \\
\text { estimated by the } \\
\text { patient }\end{array}$ & $\begin{array}{l}\text { Awareness as the After effects } \\
\text { most unpleasant } \\
\text { experience } \\
\text { during operation }\end{array}$ \\
\hline
\end{tabular}

\begin{tabular}{llll}
\hline 38 & No & Seconds & No
\end{tabular}




\section{Patient Comments}

38 Feeling of pulling drains out of chest suggests this to be post-operative recollection from the ICU

39 Possible post-operative recollection from the ICU

40

41 Possible post-operative recollection from the ICU

42

43 Possible post-operative recollection from the ICU

44 Possible post-operative recollection from the ICU

45 Possible post-operative recollection from the ICU

46 Reoperation anesthesia: diazepam, fentanyl and non-continuous isoflurane. Recollections possibly from the time between the operations.

47

48 
Patient

\begin{tabular}{|c|c|c|c|c|c|c|c|}
\hline Patient & Study & $\begin{array}{l}\text { Year of } \\
\text { anesthesia }\end{array}$ & $\begin{array}{c}\text { Age } \\
\text { (years) }\end{array}$ & Sex & $\begin{array}{l}\text { Weight } \\
\text { (kg) }\end{array}$ & $\begin{array}{l}\text { H eight } \\
(\mathrm{cm})\end{array}$ & Surgery \\
\hline 49 & 4,5 & 1989 & 27 & $M$ & 70 & 180 & Appendectomy \\
\hline 50 & 4,5 & 1990 & 41 & $\mathrm{~F}$ & 65 & 163 & Explorative laparotomy \\
\hline 51 & 4,5 & 1992 & 36 & $\mathrm{~F}$ & 80 & 173 & Laparoscopic sterilization \\
\hline 52 & 4 & 1992 & 37 & $\mathrm{~F}$ & 97 & 169 & Tonsillectomy \\
\hline 53 & 4 & 1994 & 25 & $\mathrm{~F}$ & 55 & 169 & Laparoscopic cholecystectomy \\
\hline 54 & 4 & 1992 & 47 & $\mathrm{~F}$ & & & $\begin{array}{l}\text { M astectomy with axillary lymph node } \\
\text { dissection }\end{array}$ \\
\hline 55 & 4 & 1995 & 26 & $\mathrm{~F}$ & 64 & 162,5 & $\begin{array}{l}\text { Laparoscopic cholecystectomy later converted } \\
\text { to laparotomy }\end{array}$ \\
\hline
\end{tabular}

$\begin{array}{lllllll}56 & 4 & 1996 & 56 & \mathrm{~F} & 80 & 163\end{array}$

$\begin{array}{llllllll}57 & 4 & 1994 & 38 & M & 81 & 176 & \text { Thyreoidectomy }\end{array}$

$\begin{array}{llllllll}58 & 4 & 1994 & 33 & \mathrm{~F} & 61 & 162 & \text { Thyroid resection }\end{array}$

$\begin{array}{llllllll}59 & 4 & 1991 & 68 & \mathrm{~F} & 67 & 168 & \text { Cholecystectomy }\end{array}$ 
Anesthetic details

Patient Recalled experience
Awareness Duration of Premedication group anesthesia

(min)

49 Fell asleep, then felt that something was pushed in to his

3

$127 \quad$ Opioid mouth and throat. Heard somebody saying: "it is gone". Interpreted this meaning that he will die. Felt skin incision in his abdomen, tried to move but was not able.

50 D uring the course of the operation she gradually started to feel agonizing pain. She tried to scream or move, but was able to move her eyes only. D elusions mixed with pain, and she thought that her family is tearing her abdomen.

51 Stated that she was awake during the operation, and with terrible pain and fear of death. She also stated that her doctors deny the possibility of awareness. The patient had seen a general practitioner few days after the operation because of inability to sleep and preoccupation with death. According to the general practitioner's notes, the patient had regained consciousness during the operation and had been unable to move

52 Felt pain, and operation in her mouth. H eard discussions where a doctor suspected that the patient is not adequately anesthetized, while another doctor replied that: yes, she is.

53 Felt something put her mouth, heard discussions, felt the entry of laparoscopic instruments.

54 Woke in the middle of the operation, unable to move, shortness of breath, unable to breathe, then fell asleep again.

55 Woke early after induction, was unable to move but felt the intubation tube. Felt four sticking wounds done on her abdomen and after that excruciating pain. $\mathrm{H}$ eard the operator say: "there is no other solution but to open the abdomen". Felt somebody dry tears on her cheeks and say "is she asleep at all". Saw silver colored instruments and a brownish lump taken out of her abdomen.

56 Excruciating pain, inability to move.

57 Fell asleep, then heard discussions: a male voice speaking about the teeth, also women voices but cannot recall the discussions. Then felt something pushed in his throat, this felt unpleasant but not painful. Tried to move but was unable to.

58 Felt onion taste in her mouth, then something was pushed in her mouth and throat. Tried to move but was unable.

59 Fell asleep, then heard discussions that she cannot recall, then felt excruciating pain in the abdomen, felt the manipulation of abdominal organs.

90 Benzodiazepine

57 Benzodiazepine and opioid

100 Benzodiazepine

123 Benzodiazepine

2

3
$124 \quad$ Opioid

$78 \quad$ Antihistamine 
Anesthetic details

\begin{tabular}{|c|c|c|c|c|c|}
\hline Patient & Co-induction & Induction & M aintenance & $\mathrm{N} 20$ & $\begin{array}{l}\text { ETAGC } \\
\text { monitoring }\end{array}$ \\
\hline 49 & Fentanyl & Thiopental & Enflurane (part time) & Yes & N ot recorded \\
\hline 50 & Fentanyl & Propofol & Propofol (bolus dosing) & Yes & No \\
\hline 51 & Alfentanil & Propofol & Isoflurane & No & $\mathrm{N}$ ot recorded \\
\hline 52 & Fentanyl & Thiopental & None & Yes & No \\
\hline 53 & Fentanyl & Thiopental & Propofol-infusion, enflurane & No & N ot recorded \\
\hline 54 & Fentanyl & Thiopental & Enflurane & Yes & $\mathrm{N}$ ot recorded \\
\hline 55 & Fentanyl & Thiopental & Enflurane & Yes & Not recorded \\
\hline 56 & Fentanyl & Thiopental & Enflurane & $\begin{array}{l}\mathrm{N} \text { ot } \\
\text { recorded }\end{array}$ & $\mathrm{N}$ ot recorded \\
\hline 57 & Fentanyl & Thiopental & Enflurane & Yes & Not recorded \\
\hline 58 & Fentanyl & Thiopental & Enflurane & Yes & Not recorded \\
\hline 59 & $\begin{array}{l}\text { D roperidol, } \\
\text { fentanyl }\end{array}$ & Thiopental & Enflurane & Yes & Not recorded \\
\hline
\end{tabular}




\begin{tabular}{|c|c|c|c|c|c|c|c|c|c|}
\hline Patient & NMB & Airway & Pain & Auditory & Visual & Tactile & $\begin{array}{l}\text { Tried to } \\
\text { move }\end{array}$ & $\begin{array}{l}\text { Able to } \\
\text { move }\end{array}$ & $\begin{array}{c}\text { Immediate } \\
\text { understanding }\end{array}$ \\
\hline 49 & $\begin{array}{l}\text { Succinylcholine, } \\
\text { vecuronium }\end{array}$ & ETT & Yes & Yes & No & Yes & Yes & No & Yes \\
\hline 50 & $\begin{array}{l}\text { Succinylcholine, } \\
\text { vecuronium }\end{array}$ & ETT & Yes & No & No & Yes & Yes & No & Yes \\
\hline 51 & Atracurium & ETT & Yes & & & & Yes & No & Yes \\
\hline 52 & Vecuronium & ETT & Yes & Yes & No & Yes & Yes & No & Yes \\
\hline 53 & Vecuronium & ETT & Yes & Yes & No & Yes & & & Yes \\
\hline 54 & Vecuronium & ETT & & & & Yes & Yes & No & Yes \\
\hline 55 & Vecuronium & ETT & Yes & Yes & Yes & Yes & Yes & No & Yes \\
\hline 56 & Vecuronium & ETT & Yes & No & No & Yes & Yes & No & Yes \\
\hline 57 & Vecuronium & ETT & No & Yes & No & Yes & Yes & No & Yes \\
\hline 58 & Vecuronium & ETT & No & no & no & Yes & Yes & No & Yes \\
\hline 59 & $\begin{array}{l}\text { Succinylcholine, } \\
\text { pancuronium }\end{array}$ & ETT & Yes & Yes & No & Yes & & & Yes \\
\hline
\end{tabular}


D etails of recollection and after-effects

\begin{tabular}{|c|c|c|c|}
\hline Patient & $\begin{array}{l}\text { Immediate } \\
\text { anxiety }\end{array}$ & $\begin{array}{l}\text { D uration of } \\
\text { awareness as } \\
\text { estimated by the } \\
\text { patient }\end{array}$ & $\begin{array}{l}\text { Awareness as the After effects } \\
\text { most unpleasant } \\
\text { experience } \\
\text { during operation }\end{array}$ \\
\hline
\end{tabular}

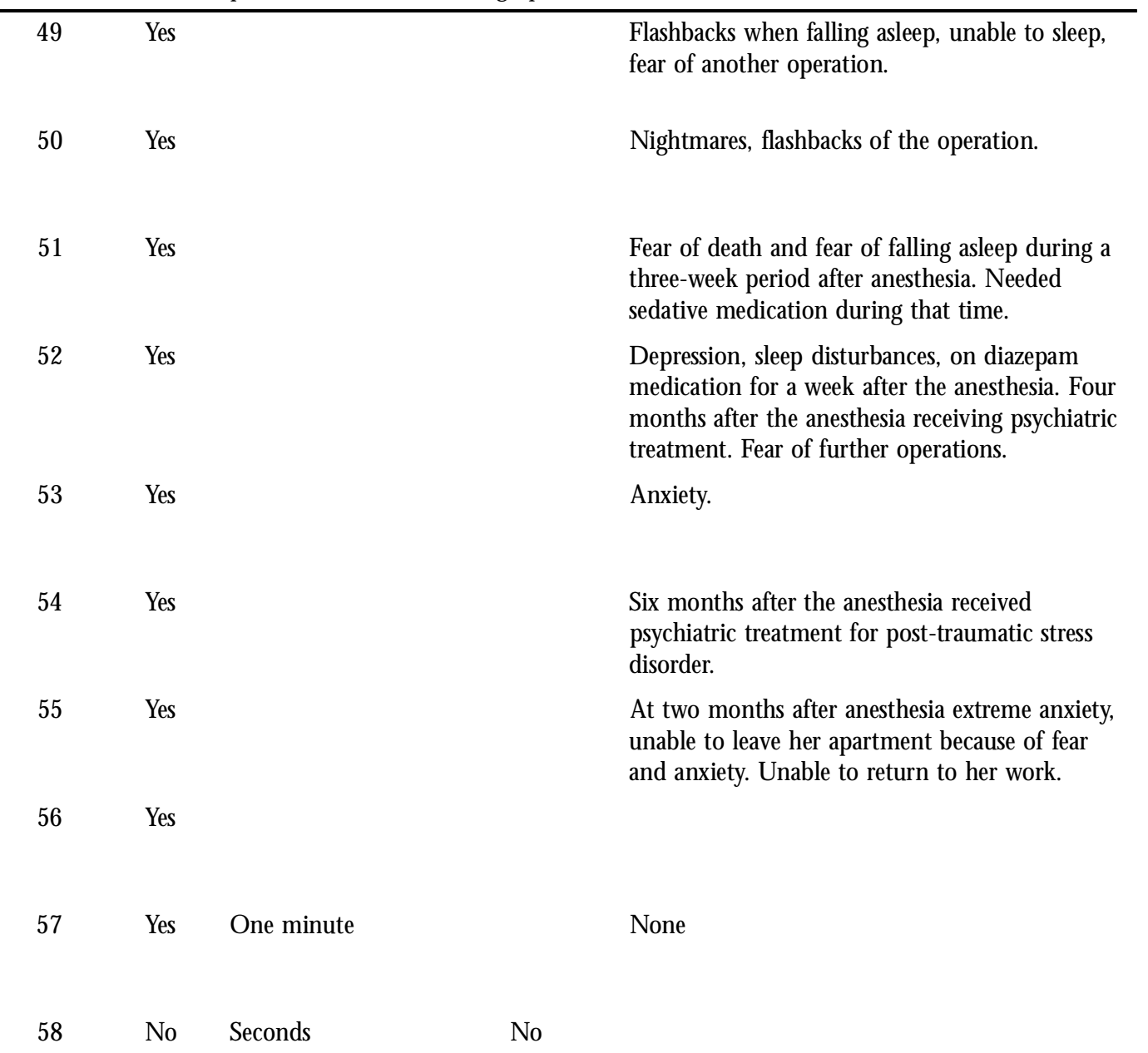


Patient Comments

49

50

51

52

53

54

55

56

57

58

59 
Patient

\begin{tabular}{|c|c|c|c|c|c|c|c|}
\hline Patient & Study & $\begin{array}{c}\text { Year of } \\
\text { anesthesia }\end{array}$ & $\begin{array}{c}\text { Age } \\
\text { (years) }\end{array}$ & Sex & $\begin{array}{l}\text { Weight } \\
(\mathrm{kg})\end{array}$ & $\begin{array}{l}\text { Height } \\
(\mathrm{cm})\end{array}$ & Surgery \\
\hline 60 & 4 & 1987 & 41 & $\mathrm{~F}$ & 56 & 164 & Insertion of breast implant \\
\hline 61 & 4 & 1976 & 25 & $\mathrm{~F}$ & 55 & 171,5 & Bronchography \\
\hline 62 & 4 & 1996 & 22 & $\mathrm{~F}$ & 70 & 173 & O ophorectomy \\
\hline 63 & 4 & 1995 & 23 & $\mathrm{~F}$ & 28,5 & & Revision of gluteal ulcer \\
\hline 64 & 4 & 1997 & 40 & $\mathrm{~F}$ & 70 & 173 & Sterilization \\
\hline 65 & 4 & 1994 & 70 & $\mathrm{~F}$ & 80 & 172 & Excision of coecal adenoma \\
\hline 66 & 4 & 1976 & 35 & $\mathrm{~F}$ & 86 & 165 & Caesarean section, sterilization \\
\hline 67 & 4 & 1993 & 40 & $\mathrm{~F}$ & 64 & 168 & Laparoscopic cholecystectomy \\
\hline 68 & 4 & 1993 & 38 & $\mathrm{~F}$ & 60 & 160 & Salpingo-oophorectomy \\
\hline 69 & 4 & 1991 & 24 & $\mathrm{~F}$ & 69 & 169 & Laparotomy for endometriosis \\
\hline 70 & 4 & 1979 & 41 & $\mathrm{~F}$ & 80 & 163 & Extirpation of intervertebral disc prolapse. \\
\hline
\end{tabular}


Anesthetic details

Patient Recalled experience
Awareness Duration of Premedication group anesthesia

(min)

60 Woke in the middle of the operation, heard discussions,

3

152 Opioid

heard the anesthesiologist comment her rhythm disturbances. Felt that something is in her mouth and throat. Thought that she is dying, unable to move, extreme anxiety.

61 Awareness during two bronchographies two days apart. Fell asleep, then woke and saw a long catheter being pushed in her mouth. Herd discussions (on the second occasion a group of medical students trained intubation)

62 Pain and manipulation in the abdomen.

2

63 Woke in the middle of the operation, saw people dressed in white around her, felt the endotracheal tube in her mouth, was unable to move, no pain.

64 Felt the scrubbing and positioning during the preparation of operation, heard discussions the content of which she doesn't recall..

65 Feels that did not fall asleep at all but felt intubation tube being pushed in her mouth. Tried to move and signal awareness but was unable. Then felt skin incision, deeper opening of the abdominal wall, manipulation of abdominal organs. Worst pain when the intestines were pushed back to abdominal cavity. Recalls discussions, recalls that someone opened her eye twice.

66 Recalls having thought: "why you are putting that tube into my mouth", noises, shortness of breath.

67 Heard noises, saw lights, felt the scrubbing, tried to signal awareness but could not.

68 Discussions, pain and manipulation in the abdomen, inability to move or breathe.

2

15 Opioid

3

2

2

3

2 of dying.

70 Shooting pain in the back 3-4 times, between episodes of pain was in a light sleep. Tried to move but could not. Felt something in her mouth.
$94 \quad$ None

3

3

$\sqrt{2}$

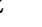

$99 \quad$ None

$30 \quad$ None

$84 \quad$ Opioid

$46 \quad$ None

$135 \quad$ None

80 Benzodiazepine

38 Benzodiazepine

3

112 Opioid 
Anesthetic details

\begin{tabular}{|c|c|c|c|c|c|}
\hline Patient & Co-induction & Induction & M aintenance & N 20 & $\begin{array}{l}\text { ETAGC } \\
\text { monitoring }\end{array}$ \\
\hline 60 & Fentanyl & Thiopental & Enflurane & Yes & Not recorded \\
\hline 61 & None & Thiopental & None & No & No \\
\hline 62 & Remifentanil & Propofol & $\begin{array}{l}\text { Propofol-infusion, remifentanil- } \\
\text { infusion }\end{array}$ & No & No \\
\hline 63 & Fentanyl & Thiopental & $\begin{array}{l}\text { Thiopental (bolus dosing), } \\
\text { isoflurane (non-continuous) }\end{array}$ & No & $\mathrm{N}$ ot recorded \\
\hline 64 & Fentanyl & Propofol & $\begin{array}{l}\text { Propofol (bolus dosing), } \\
\text { isoflurane }\end{array}$ & No & $\mathrm{N}$ ot recorded \\
\hline 65 & Fentanyl & Thiopental & Enflurane & No & $\mathrm{N}$ ot recorded \\
\hline 66 & M eperidine & Thiopental & Thiopental (bolus dosing) & Yes & No \\
\hline 67 & Alfentanil & Propofol & Propofol-infusion, isoflurane & No & $\mathrm{N}$ ot recorded \\
\hline 68 & Fentanyl & Propofol & Enflurane & Yes & $\mathrm{N}$ ot recorded \\
\hline 69 & Fentanyl & Propofol & Propofol-infusion & Yes & No \\
\hline 70 & M eperidine & Thiopental & None & Yes & No \\
\hline
\end{tabular}




\begin{tabular}{|c|c|c|c|c|c|c|c|c|c|}
\hline Patient & NMB & Airway & Pain & Auditory & Visual & Tactile & $\begin{array}{l}\text { Tried to } \\
\text { move }\end{array}$ & $\begin{array}{l}\text { Able to } \\
\text { move }\end{array}$ & $\begin{array}{l}\text { Immediate } \\
\text { understanding }\end{array}$ \\
\hline 60 & Vecuronium & ETT & No & Yes & No & Yes & Yes & No & Yes \\
\hline 61 & Succinylcholine & M ask & No & Yes & Yes & Yes & Yes & Yes & Yes \\
\hline 62 & Atracurium & ETT & Yes & No & No & Yes & & & \\
\hline 63 & Atracurium & ETT & No & Yes & Yes & Yes & Yes & No & Yes \\
\hline 64 & Atracurium & ETT & No & Yes & No & Yes & Yes & No & Yes \\
\hline 65 & Vecuronium & ETT & Yes & Yes & Yes & Yes & Yes & No & Yes \\
\hline 66 & Succinylcholine & ETT & No & Yes & No & Yes & Yes & No & Yes \\
\hline 67 & Vecuronium & ETT & No & Yes & Yes & Yes & Yes & No & Yes \\
\hline 68 & Pancuronium & ETT & Yes & Yes & No & Yes & Yes & No & Yes \\
\hline 69 & $\begin{array}{l}\text { Succinylcholine, } \\
\text { vecuronium }\end{array}$ & ETT & No & Yes & No & Yes & Yes & No & Yes \\
\hline 70 & Allopherine & ETT & Yes & No & No & Yes & Yes & No & Yes \\
\hline
\end{tabular}


D etails of recollection and after-effects

\begin{tabular}{clll} 
Patient & $\begin{array}{c}\text { Immediate Duration of } \\
\text { anxiety } \\
\text { awareness as } \\
\text { estimated by the } \\
\text { patient }\end{array}$ & $\begin{array}{l}\text { Awareness as the After effects } \\
\text { most unpleasant } \\
\text { experience } \\
\text { during operation }\end{array}$ \\
\hline 60 & Yes & M inutes & $\begin{array}{l}\text { Considers the experience as the worst one in her } \\
\text { life. N ine years after the operation fears all } \\
\text { further operations and suffers from nightmares } \\
\text { and sleep disturbances }\end{array}$ \\
61 & Yes & $\begin{array}{l}\text { Eighteen years after anesthesia wakes sometimes } \\
\text { from a nightmare that she is in the middle of } \\
\text { the operation. The incidence of nightmares has } \\
\text { diminished over the years. }\end{array}$
\end{tabular}

62

63 Yes Several minutes

Three years after the anesthesia nightmares of the operation sometimes wake her from sleep.

$64 \quad$ No Less than 5

minutes

65 Yes Very long

66 Yes Not long

67 Yes $1-2$ minutes

Told of her experience immediately in the recovery room. Discussions with the anesthesiologist, nurses, and a clinical psychologist were immediately organized.

According to the psychologist, the debriefing was effective. Four years after the experience, the patient does not suffer form obvious aftereffects.

In a subsequent cholecystectomy was very frightened of anesthesia.

No

68 Yes Several minutes

Frightened of subsequent operations.

69 Yes N ot long

70 Yes N ot long, but

Bad nightmares and sleep disturbances for over recurred 3-4 ten years. $\mathrm{N}$ ot able to return to work. 
Patient Comments

60

61

62

63

64

65

66

67

68

69

70 